\title{
Oligopoly Banking, Risky Investment, and Monetary Policy*
}

\author{
Lukas Altermatt ${ }^{\dagger}$ \\ University of Essex
}

\author{
Zijian Wang $\ddagger$ \\ Wilfrid Laurier University
}

July 2021

\begin{abstract}
Oligopolistic competition in the banking sector and risk in the real economy are important characteristics of developed economies, but have so far mostly been abstracted from in monetary economics. We build a dynamic general equilibrium model of monetary policy transmission that incorporates both of these features and document that including them leads to important insights in our understanding of the transmission mechanism. Various equilibrium cases can occur, and policies have differing effects in these cases. We calibrate the model to the U.S. economy in 2016-2019 in order to study how changes in the degree of banking competition or the policy rate would have affected equilibrium outcomes. We find that doubling banking competition would have increased welfare by $1.02 \%$, but at the cost of increasing the probability of bank default from $0.02 \%$ to $0.44 \%$. We further find that the policy rate was set optimally to minimize the probability of bank default, but that a decrease in the policy rate by $1 \mathrm{pp}$ would have increased welfare by $0.40 \%$. We also show that bank profits are increasing in the policy rate, in particular when interest rates are low. Thus, a $1 \mathrm{pp}$ reduction in the policy rate would have reduced profits per bank by $35.5 \%$ in our calibrated economy. Finally, we document that monetary policy passthrough is incomplete under imperfect competition in the banking sector, as a change in the policy rate by $1 \mathrm{pp}$ leads to a change of only $0.92 \mathrm{pp}$ in the loan rate, while pass-through to the deposit rate is nearly complete for rate increases, but almost zero for rate reductions due to the zero-lower bound.
\end{abstract}

Keywords: Oligopoly competition; Risky investment; Financial intermediation; Monetary policy

JEL Codes: D34; G32; G21; E52

\footnotetext{
${ }^{*}$ We thank Mohammed Aït Lahcen, Aleksander Berentsen, Hugo van Buggenum, Lucas Herrenbrueck, Cyril Monnet, Romina Ruprecht, Stephen Williamson, and seminar participants at various conferences for helpful discussions and comments.

${ }^{\dagger}$ lu.altermatt@gmail.com

‡zijianwang@wlu.ca
} 


\section{Introduction}

After the financial crisis of 2007-2009, economists have started to take the role of the financial system in the transmission of monetary policy seriously, as they recognized that the actions of banks and other institutions have important effects on how central banks can influence the real economy. However, most studies in monetary economics assume a perfectly competitive banking sector, and many abstract from risk in the real economy. As we document in Section 2, the banking sector in developed economies including the U.S. is clearly characterized by imperfect competition. In our opinion, modelling the banking sector accordingly is highly relevant to understand the transmission of monetary policy to the real economy. On the one hand, we need to understand how the presence of imperfect competition in the banking sector affects, and potentially limits, the transmission of monetary policy, for example through incomplete pass-through from policy rates to loan and deposit rates. On the other hand, only in a model with imperfect competition

in the banking sector (and risk in the real economy) can we study how monetary policy affects bank profits and the probability of bank default - with especially the latter being at the center of attention for policymakers after the financial crisis. In this paper, we build on existing research to create a model of monetary policy transmission that includes oligopolistic competition in the banking sector, and both idiosyncratic and aggregate risk in the real economy. We then calibrate the model to the U.S. economy in 2016-2019. Based on the calibration, we discuss how changes in the degree of competition and in the policy rate would have affected macroeconomic outcomes during that period.

Our model shows that taking the banking system's role in monetary policy transmission and the competitive structure in the banking sector seriously is pertinent to understand how central banks can affect the real economy. We document that the economy can be in various equilibrium cases depending on parameters, and that this matters for the transmission of monetary policy: for example, banks react differently to policy changes when the deposit rate is at the zero-lower bound compared to when it is not, or when the reserve requirement does or does not bind. We derive comparative statics regarding the number of banks, the supply of bonds, the interest on reserves, the reserve and the capital requirement in all equilibrium cases, and document how some of these can go in opposite directions or have no effects depending on which equilibrium case the economy is in. These results show that we need to calibrate the model in order to understand how monetary policy affects outcomes in a particular economy and during a particular time. To this end, we calibrate our model to the U.S. economy in 2016-2019 by matching several moments from the data, and study several counterfactuals in the calibrated economy. We find that doubling banking competition during that time period would have increased expected welfare by $1.02 \%$, but also increased the probability of bank default from $0.02 \%$ to $0.44 \%$, while halving the degree of competition would have reduced welfare by $1.52 \%$ and the probability of bank default by $0.018 \mathrm{pp}$. We also find that the Fed set the policy rate optimally to minimize the probability of bank default, since changes in the policy rate in either direction would have increased the probability of bank 
default. Policy was not set optimally in terms of welfare, however, as a decrease in the policy rate by $1 \mathrm{pp}$ would have led to an increase in aggregate welfare by $0.40 \%$. Further, we find that bank profits are increasing in the policy rate, and particularly so when the deposit rate is equal to zero. Since the deposit rate was very close to zero in the U.S. during our calibration period, a decrease in the policy rate by 1 pp would have lowered profit per bank by $35.5 \%$, while an increase by $1 \mathrm{pp}$ would have led to only a moderate increase in profits by $1.23 \%$. Finally, we document that monetary policy pass-through is incomplete under imperfect competition: In our calibrated economy, an increase in the policy rate by $1 \mathrm{pp}$ increases loan rates by only $0.92 \%$, and deposit rates by $0.99 \%$. Due to the zero-lower bound, a decrease in the policy rate by $1 \mathrm{pp}$ leads to a decrease of only $0.06 \mathrm{pp}$ in deposit rates, while the loan rate decreases by $0.92 \mathrm{pp}$. If the degree of banking competition is halved, pass-through to loan rates reduces further to $0.89 \mathrm{pp}$, while pass-through to deposit rates vanishes completely as lower banking competition keeps the deposit rate at the zero-lower bound even after a 1 pp increase in the policy rate.

Model and calibration summary. Our model is based on the Lagos and Wright (2005) framework, and includes banks that perform liquidity transformation as in Altermatt (2019) or Keister and Sanches (2019). We introduce competition à la Cournot in the banking sector and a risk-return trade-off for entrepreneurs as in Martinez-Miera and Repullo (2010). Each period is divided into a DM and a CM, and the economy is populated by three types of agents: households, banks, and entrepreneurs. In the DM, households meet with each other and there are gains from trade, but due to anonymity and limited commitment, households need liquid assets to complete trades. Following Williamson (2012), we assume that some meetings are unmonitored and only cash is accepted as payment, while others are monitored and bank deposits are accepted in addition to cash. In the CM, entrepreneurs are the unique agents that have investment opportunities. If an entrepreneur invests, she faces a risk-return trade-off: she can choose a project with a high success rate but a low payoff, or one with low success rate but a high payoff. The quality of the project is heterogeneous across entrepreneurs. Specifically, an entrepreneur with a better project either receives a higher return given the success rate, or has a higher success rate given the project return. There is also aggregate risk, which affects the default probability of all entrepreneurs.

Because entrepreneurs have no funds of their own, they need to borrow from other agents. We assume banks are the unique agents that can enforce loans made to entrepreneurs. Banks can fund their lending either by sweat equity or by issuing deposits. We assume that there is a fixed number of banks, and banks compete à la Cournot for loans and deposits, meaning that they have market power over the interest rates on loans and deposits, and they make profits in equilibrium. Besides lending to entrepreneurs, banks can also purchase government bonds or hold reserves. Banks are subject to reserve and capital requirements set by the government. After the DM has taken place, entrepreneurs with successful investment projects repay their loans and consume the remaining profits, and banks repay their depositors, consume their remaining profits, and are then replaced by a new set of banks. While banks can fully protect themselves against the idiosyncratic risk choices of entrepreneurs through diversification, the aggregate shock introduces the possibility of 
bank default. If banks default, i.e. if the value of their assets is less than their outstanding deposits, their remaining assets are distributed to depositors by the government.

We find that the equilibrium can be divided in three different cases, depending on parameters. In Case I, banks are indifferent about raising additional equity, as the marginal cost of deposits equals the marginal cost of equity. Thus, the capital requirement is non-binding. Case I occurs when the demand for deposits by households is low relative to the demand for loans by entrepreneurs and the supply of government bonds. In Case II, the deposit rate is above the zero-lower bound, but the marginal cost of raising deposits lies strictly below the marginal cost of raising equity. Thus, banks prefer funding themselves with deposits over equity, so the capital requirement binds. Finally, Case III is characterized by the deposit rate being at the zero-lower bound. This case occurs when the demand for deposits by households is large relative to the demand for loans by entrepreneurs and the supply of government bonds. ${ }^{1}$ In both Cases II and III, the reserve requirement may or may not bind, while it is always binding in case I.

As already mentioned above, the effects of changes in variables such as the number of banks, the interest rate on reserves, or the reserve requirement differ across these equilibrium cases, and sometimes they are ambiguous even within an equilibrium case, particularly in terms of their effect on the probability of bank default. We therefore calibrate the model to U.S. data from 20162019. To calibrate the model, we first directly set the discount factor, the inflation rate, the share of monitored meetings, the interest on reserves, the reserve and the capital requirement to match the data. We then follow Rocheteau et al. (2018) by matching the semi-elasticity of money demand in the model to the data. To do so, we use data from 1959-2007 since we need longer time series to calibrate money demand. We then jointly calibrate the number of banks, the supply of bonds, two parameters regarding the risk-return trade-off faced by entrepreneurs, and the share of entrepreneurs relative to households, by matching the expected return on loans, the expected deposit rate, the reserve-to-loan ratio, the loan default probability, and the loans-to-GDP ratio from the data. Finally, we assume a truncated normal distribution for the aggregate shock to the default probability of entrepreneurs, set the mean to one and calibrate the standard deviation such that the expected probability of bank default matches the ratio of bank failure cost to total transnational deposits. Even though our model is highly non-linear, we are able to match all parameters very precisely.

Existing literature. The New Monetarist literature based on Lagos and Wright (2005) provides an excellent framework to study the transmission of monetary policy to the real economy. Within this literature, the first paper to take the role of banks into account is Berentsen et al. (2007). In this paper, perfectly competitive banks intermediate liquid assets from agents that do not want to consume during the DM to agents that want to consume. Another early paper including banks in this literature is He et al. (2008), where there is a risk of cash being stolen, and thus agents might prefer to deposit their money at a bank and use bank liabilities to make payments instead.

\footnotetext{
${ }^{1}$ Naturally, Case II is an intermediate case between Cases I and III in terms of the demand for deposits by households relative to the demand for loans by entrepreneurs and the supply of government bonds.
} 
In Williamson (2012), agents can use interest-bearing bonds to pay in some DM meetings, whereas they can only use fiat money in others. This creates a role for banks as they are able to insure agents against this uncertainty. The bank holds a portfolio of bonds and fiat money, and allows agents that need fiat money to withdraw it. In Gu et al. (2013), banks arise endogenously if limited commitment issues between agents make credit arrangements infeasible. Gu et al. (2019) show, using a variety of different models, that banking is inherently unstable. Imhof et al. (2018) analyse how liquidity requirements affect risk-taking by banks and the quantity of deposits created. Altermatt (2019) studies how monetary policy is transmitted to the real economy in a model where perfectly competitive banks perform liquidity creation by investing in illiquid assets such as loans to entrepreneurs and bonds and issue liquid assets. Keister and Sanches (2019) study how the introduction of central bank digital currencies affects outcomes in a model where banks perform a similar role. Chiu et al. (2019) extend this model by giving banks market power on the liabilities' side, and show that the introduction of central bank digital currencies can be welfare improving if it reduces banks' market power. Dong et al. (2017) was the first paper to study oligopolistic banking competition in this literature, but in their model, banks do not create liquid assets and extend loans to entrepreneurs as in our paper. Instead, they intermediate funds as in Berentsen et al. (2007). Head et al. (2021) also incorporate imperfect banking competition into the framework from Berentsen et al. (2007) by modelling the banking sector in the vein of Burdett and Judd (1983). Ait Lahcen and Gomis-Porqueras (2021) model banks as in Berentsen et al. (2007) and add an idiosyncratic cost of accessing the bank to study endogenous financial inclusion. Andolfatto et al. (2019) integrate banks a la Diamond (1997) in a New Monetarist framework and show that nominal deposit contracts combined with a central bank acting as a lender of last resort allow for efficient liquidity insurance and a panic-free banking system.

In the broader literature on macroeconomics, Gertler and Karadi (2011) is an important paper on the transmission of monetary policy through the financial system. In this paper, an agency problem between banks and their depositors leads to endogenous constraints on the banks' leverage ratios. Curdia and Woodford (2009) is another paper that integrates a banking sector into a quantitative macroeconomic model. In Gertler et al. (2012), banks can choose to finance themselves through equity or short term debt, so bank risk exposure arises endogenously. The authors use the model to assess quantitatively how perceptions of fundamental risk and of government credit policy in a crisis affect the vulnerability of the financial system ex ante. Meanwhile, Gertler and Kiyotaki (2015) studies bank runs in an economy with liquidity mismatch. Bianchi and Bigio (2017) develop a tractable model of banks' liquidity management and the credit channel of monetary policy. In their model, banks are heterogeneous, but perfectly competitive, and they bargain on the interbank market over reserves.

While imperfect banking competition has largely been abstracted from macroeconomic models on monetary policy transmission, it has been studied in microeconomic models of banking. Keeley (1990) is an early example of a theoretical framework on the relationship of banking competition and financial stability. The paper argues that a reduction in charter value and monopoly rents for 
banks leads to an increase in bank defaults due to an agency problem. However, Allen and Gale (2004b) show that with incomplete markets, the efficiency gains from increased competition in the banking sector outweigh the losses resulting from a financial crisis, so even though eliminating bank defaults is possible, they occur in the constrained-efficient equilibrium. In Allen and Gale (2004a), the authors point out that it is not obvious that an increase in banking competition leads to less financial stability, and study a number of frameworks where this is not the case. Similarly, Boyd and De Nicolo (2005) argue that lower competition on loan markets increases lending rates, which then leads borrowers to take on riskier investments. In turn, this increases the risk of both borrower and bank defaults. Due to these countervailing forces, Martinez-Miera and Repullo (2010) argue that the relationship between competition and bank failure is U-shaped. Instead of reducing competition, another way to limit the agency problem is to enforce capital requirements on banks. While Marshall and Prescott (2001) show that capital requirements can indeed limit the agency problem, Hellmann et al. (2000) argue that such capital requirements can lead to Pareto-inefficient outcomes, as they also reduce the banks' franchise value and thus incentivize banks to take on more risk. Repullo (2004) shows that risk-based capital requirements can be used to effectively control risk-shifting incentives. Kashyap et al. (2020) study optimal banking regulation in the presence of credit and run-risk, and show that banks rely more on deposit funding than is optimal without regulation, while bank lending can be higher or lower than a planner would want. While we focus on symmetric equilibria with equally-sized banks, Corbae and D'Erasmo (2021) study how regulatory policies affect bank failure rates as well as lending and interest rates in a model with an endogenous size distribution of banks.

Outline. The rest of the paper is organized as follows: Section 2 documents data facts on competition in the banking sector. Section 3 describes the model. Section 4 discusses the equilibrium, and Section 5 analyses the comparative statics of some key variables. Section 6 describes the calibration strategy and discusses the calibrated economy. Section 7 discusses the counterfactuals. Finally, Section 8 concludes the paper.

\section{Data Facts on Banking Competition}

In many countries, the majority of the assets in the banking sector are controlled by a few large banks. Figure 1 plots the percentages of all bank assets owned by top 5 banks of selected countries in 2017. The figure shows that the concentration in the banking industry ranges from $46 \%$ (U.S.) to $97 \%$ (Finland). When looking at the top 10 banks, this number increases even further, in particular for the U.S., where the asset share of the top 5 banks is somewhat moderate. The degree of concentration at a few large banks is not a recent phenomenon either, and it is also not limited to developed economies: Figure 2 shows the degree of concentration for countries with different income levels at different points in time, and documents that it has been stable across both dimensions. 


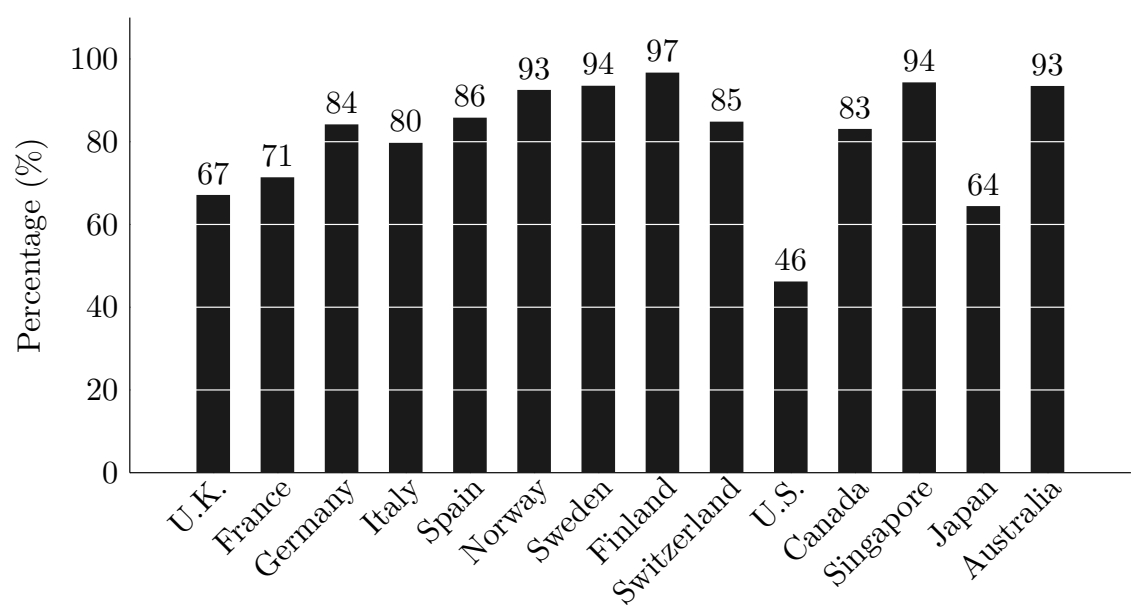

Source: World Bank Global Financial Development Database.

Figure 1: Percentages of Bank Assets Held by Top 5 Banks in 2017.

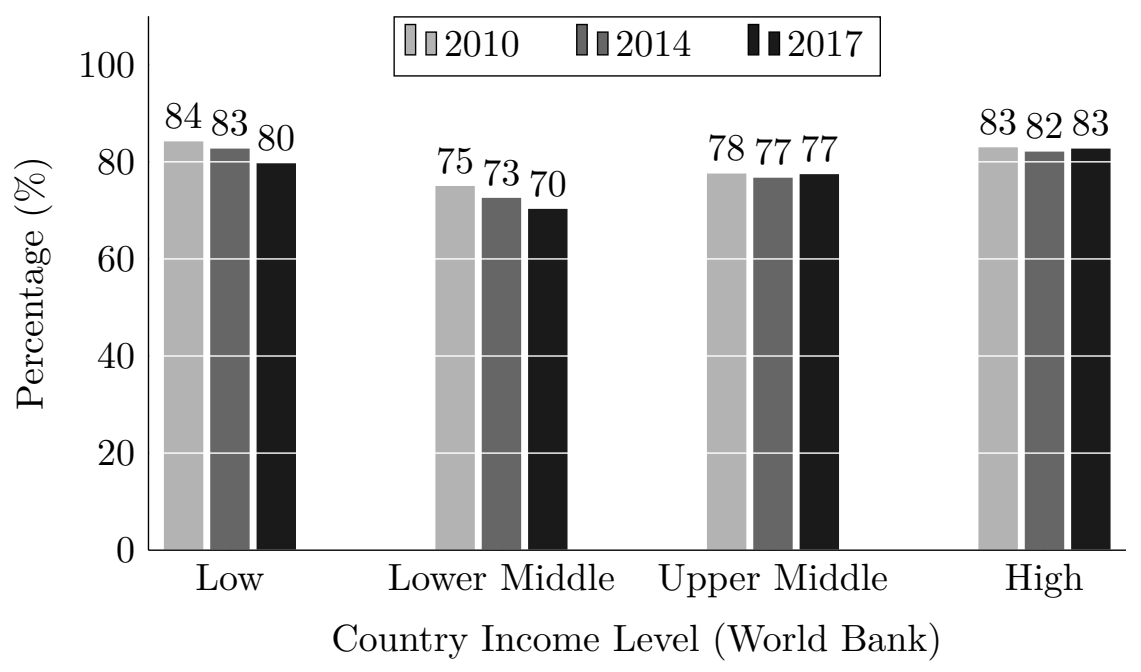

Source: World Bank Global Financial Development Database.

Figure 2: Average Percentages of Bank Assets Held by Top 5 Banks.

While the documented concentration of assets among a few large banks hints towards market power of banks, it is no perfect evidence by itself. Perhaps the threat of entry by new contestants is enough to ensure that banks behave in competitive manner, while economies of scale could explain why concentration of assets is so high. However, there is both anecdotal and quantitative evidence that this is not the case, at least for the U.S. Figure 3 shows the interest rate on excess reserves and the average deposit rate earned on checking deposits worth less than $\$ 100,000$ from January 2010 until December 2019. Since reserves at the central bank are a perfectly safe asset for banks, the difference between the interest rates on reserves and deposits is a risk-free profit margin for banks. Conversely, this profit opportunity should attract new entrants that offer deposits at a higher rate than existing banks, thereby forcing them to also increase the interest paid on their deposits. In fact, this is exactly what TNB U.S.A Inc. was planning to do, but the Federal Reserve has refused 
to open a reserve account for TNB, thereby basically denying them entry into the banking market. ${ }^{2}$

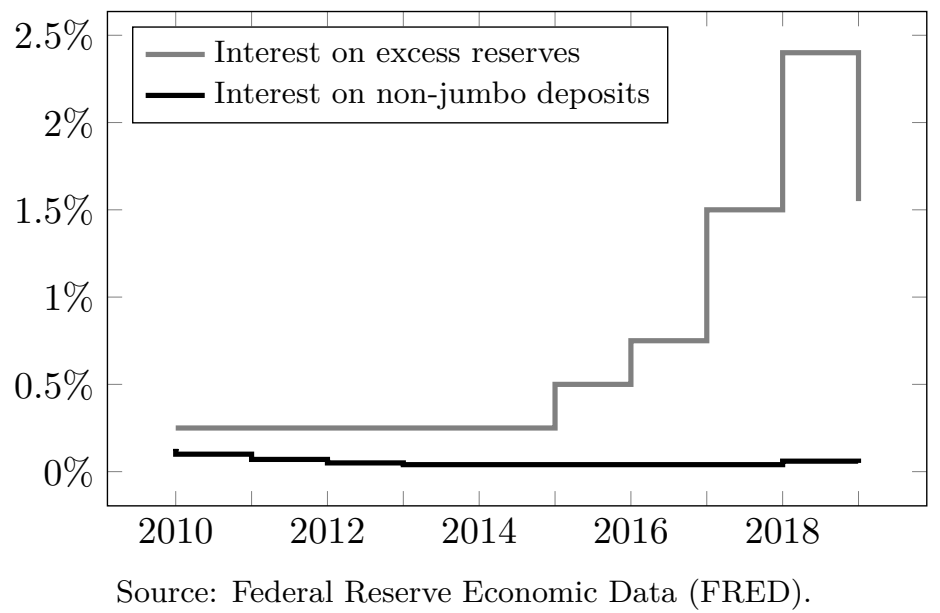

Figure 3: Interest on excess reserves and interest on non-jumbo deposits for the U.S.

Given these observations, we conclude that the banking market in developed economies, and in particular in the U.S., is characterized by imperfect competition, and that there is an opportunity for existing players in the market to earn oligopoly rents.

\section{The Model}

\subsection{Physical Environment}

Time is discrete and continues forever. Every period is divided into two subperiods: the DM (the decentralized market) and the CM (the centralized market). There is a measure two of infinitelylived households, divided equally into buyers and sellers. In the DM, buyers consume a DM good that can only be produced by sellers. In the CM, sellers consume a CM good that can be produced by all agents. The CM good also serves as the numéraire. Both DM and CM goods are perishable and cannot be stored across periods. A buyer's instantaneous utility is given by

$$
u\left(q_{t}\right)-l_{t}
$$

where $q_{t} \geq 0$ is the consumption of the DM good and $l_{t}$ is the labor supplied in the CM. We assume $u^{\prime}()>0,. u^{\prime \prime}()<$.0 , and $-q u^{\prime \prime}(q) / u^{\prime}(q)<1 .^{3}$ A seller's instantaneous utility is given by

$$
x_{t}-h_{t},
$$

\footnotetext{
${ }^{2}$ For more on this, see e.g. https://www.bloomberg.com/opinion/articles/2019-03-08/the-fed-versus-the\narrow-bank.

${ }^{3}$ The assumption $-q u^{\prime \prime}(q) / u^{\prime}(q)<1$ ensures that demand for deposits is increasing in the deposit interest rate, which is generally observed in the data. The assumption is standard in papers on monetary policy and banking; see e.g., Williamson (2012).
} 
where $x_{t}$ is the consumption of the CM good and $h_{t}$ is the labor supplied in the DM. We assume that by using one unit of labor, sellers can produce one unit of the DM good, and all agents can produce one unit of the CM good. All households share the same discount factor $\beta$. We assume there is no discounting between subperiods.

Each period starts with the DM. At the beginning of the DM, a buyer is matched with a seller with probability one, and buyers make take-it-or-leave it offers to sellers. ${ }^{4}$ Because buyers and sellers are anonymous in the DM, credit arrangements are not possible and a medium of exchange is necessary. Following Williamson (2012), we assume that a fraction $1-\eta$ of the meetings are unmonitored, which means buyers can only use cash as payment. The remaining meetings are monitored, which means buyers can pay with either cash or bank deposits. Differing from Williamson (2012), we assume that buyers learn the type of meeting they will be in during the next $\mathrm{DM}$ at the beginning of the previous CM, so there is no uncertainty regarding payments.

In addition to households, there is also measure $S$ of entrepreneurs who only live for one period. Each entrepreneur is born in the CM of period $t$ and is endowed with a project that can produce $\mathrm{CM}$ goods in the $\mathrm{CM}$ of period $t+1$. Each project requires one unit of capital investment, which can be converted from one unit of the CM good. Before the production begins, each entrepreneur must choose a production technology. The production technology is represented by $R \in\left(0, R^{i}\right]$ where $R^{i}$ is specific to entrepreneur $i$. The output given $R^{i}$, the entrepreneur's choice of $R$, and an aggregate shock $s$, is

$$
y\left(R, R^{i}, s\right)=\left\{\begin{array}{l}
0 \text { with probability } p\left(R, R^{i}, s\right), \\
R \text { with probability } 1-p\left(R, R^{i}, s\right) .
\end{array}\right.
$$

In words, expression (3.3) says that if an entrepreneur chooses $R$, the production will yield $R$ with probability $1-p\left(R, R^{i}, s\right)$ and 0 otherwise. We assume that $p\left(R, R^{i}, s\right)$ is increasing in $R$ and $s$ and is decreasing in $R^{i}$. Conditional on $s$, the realization of $y\left(R, R^{i}, s\right)$ is independent across all entrepreneurs. Note that $R^{i}$ can be interpreted as an entrepreneur's innate ability. An entrepreneur with a larger $R^{i}$ can choose a technology with higher potential yield and is more likely to succeed for any given $R$ and $s$. We assume $R^{i}$ is determined when an entrepreneur is born and follows a distribution on $[0, \bar{R}]$ characterized by the $\operatorname{CDF} F(\cdot)$ and $\operatorname{PDF} f(\cdot)$. The aggregate shock $s$ follows a distribution on $[\underline{s}, \bar{s}]$ characterized by the $\operatorname{CDF} G(\cdot)$. Finally, after production, capital fully depreciates. Entrepreneurs only consume in the second CM of their lives, and they derive linear utility from consuming the CM good.

The economy also contains $N$ banks that are born in the CM of period $t$ and dissolve in the $\mathrm{CM}$ of period $t+1$. Unlike buyers, banks can commit to their liabilities, and therefore bank deposits

\footnotetext{
${ }^{4}$ Lagos and Wright (2005) explore the role of different bargaining powers, and Rocheteau and Wright (2005) explore the role of different trading protocols in similar models. We assume take-it-or-leave it offers in order not to complicate the model further, but our results are robust to other specifications, and the findings from the two papers mentioned regarding how different setups in the DM affect outcomes generally apply here as well.
} 
are accepted as payment in the DM. Because entrepreneurs are not endowed with any CM good and they cannot work in the CM, they must borrow from other agents in the economy in order to invest. We assume banks can costlessly verify entrepreneurs' output in the CM while the cost for households is infinite. ${ }^{5}$ Hence, entrepreneurs can only borrow from banks. We assume banks can work in the CM using the same technology as buyers, and working generates linear disutility. This can be interpreted as giving banks the option to raise sweat equity. Alternatively, banks can fund their lending by issuing deposits. Banks receive linear utility from consuming during the second $\mathrm{CM}$ of their existence, and they discount at rate $\beta$ between periods. Banks compete à la Cournot in both the loan market and the deposit market. Deposits can be transferred to other agents in the DM, and in the next CM they can be redeemed (with interest) for the consumption good.

The economic activities in the $\mathrm{CM}$ are as follows. At the beginning of the CM, entrepreneurs born in the last period settle their debt with banks and consume. Then banks settle their debt with households and consume. We assume that both entrepreneurs and banks are subject to limited liability. That is, they can default on their liabilities if their net worth is negative. If an entrepreneur declares bankruptcy, a bank can seize the entrepreneur's assets. If a bank defaults on its deposit liabilities, a government will seize the bank's assets and distribute them to its creditors. Finally, after old generations of entrepreneurs and banks consume, they are replaced with a new set of entrepreneurs and banks.

The government in the model economy controls the supply of fiat money and issues a oneperiod nominal bond. Let $M_{t}^{H}$ and $M_{t}^{B}$ denote the amount of money held by households and banks (i.e., reserves) in period $t$, respectively. We assume the total money supply grows at net rate $\mu$, i.e., $M_{t+1}^{H}+M_{t+1}^{B}=(1+\mu)\left(M_{t}^{H}+M_{t}^{B}\right)$. We also assume that the government pays interest on reserves held by banks. Denote the nominal interest on reserves as $i^{R}$. Each unit of government bonds pays $1+i_{t}^{B}$ units of money in the CM of period $t$. Let $B_{t}$ denote the government bonds outstanding in period $t$. We assume government bonds cannot be used as payment in the DM. ${ }^{6}$ The government also collects a lump-sum tax $\tau_{t}$ from households. The government's budget constraint is

$$
\phi_{t}\left(M_{t}^{H}+M_{t}^{B}+B_{t}\right)+\tau_{t}=\phi_{t}\left(M_{t-1}^{H}+\left(1+i_{t}^{R}\right) M_{t-1}^{B}+\left(1+i_{t}^{B}\right) B_{t-1}\right)
$$

where $\phi_{t}$ is the price of money in terms of CM good. We define $r_{t}^{B}=\frac{\phi_{t}\left(1+i_{t}^{B}\right)}{\phi_{t-1}}$ to be the gross real interest rate on government bonds.

\subsection{Household's Problems in the DM and CM}

In what follows, we restrict our attention to stationary equilibria, which implies $\frac{\phi_{t}}{\phi_{t+1}}=1+\mu$ and $r^{B}=\frac{1+i^{B}}{1+\mu}$. Now, let $a$ denote the amount of real assets a buyer has at the beginning of the DM.

\footnotetext{
${ }^{5}$ Alternatively, one may assume costly state verification à la Diamond (1984), and Williamson (1986). However, since we mainly focus on the oligopolistic banking competition, we assume the cost of verification for banks is zero.

${ }^{6}$ For example, government bonds may not be recognizable by sellers in the DM.
} 
As is standard in models following Lagos and Wright (2005), the households' value function in the $\mathrm{CM}$ is linear in their real wealth at the end of the DM. Hence, buyers solve

$$
\max _{q} u(q)-q \quad \text { s.t. } q \leq a .
$$

Let $q(a)$ denote the buyer's consumption in the DM. Then $q=\min \left\{a, q^{*}\right\}$, where $u^{\prime}\left(q^{*}\right)=1$.

Next, we turn to the CM. Let $r^{D}$ denote the expected gross real deposit rate. Note that in a stationary equilibrium, the return on fiat money is equal to $1 /(1+\mu)$. Let $z$ and $d$ denote the amount of real fiat money balances and bank deposits a monitored buyer chooses to carry. Monitored buyers in the CM solve

$$
\begin{aligned}
& \quad \max _{z, d, q^{d}}-\frac{z}{\beta}-\frac{d}{\beta}+u\left(q^{d}\right)+\frac{z}{1+\mu}+r^{D} d-q^{d} \\
& \text { s.t. } q^{d}=\min \left\{\frac{z}{1+\mu}+r^{D} d, q^{*}\right\} .
\end{aligned}
$$

Monitored buyers will carry fiat money if and only if $1 /(1+\mu) \geq r^{D}$. Monitored buyers will exhaust their money and deposits in the DM (i.e. $\left.q^{d}=z /(1+\mu)+r^{D} d\right)$ unless $\max \left\{1 /(1+\mu), r^{D}\right\} \geq 1 / \beta .{ }^{7}$ Note that because government bonds cannot be used as payment in the DM, buyers will hold bonds if and only if $r^{B} \geq 1 / \beta$. Similarly, sellers will hold money, bank deposits and government bonds if and only if $1 /(1+\mu) \geq 1 / \beta, r^{D} \geq 1 / \beta$ and $r^{B} \geq 1 / \beta$, respectively. Unmonitored buyers solve

$$
\begin{aligned}
& \max _{\tilde{z}, q^{m}}-\frac{\tilde{z}}{\beta}+u\left(q^{m}\right)+\frac{\tilde{z}}{1+\mu}-q^{m} \\
\text { s.t. } & q^{m}=\min \left\{\frac{\tilde{z}}{1+\mu}, q^{*}\right\} .
\end{aligned}
$$

Similar to monitored buyers, unmonitored buyers will hold bonds if and only if $r^{B} \geq 1 / \beta$. Since they cannot use deposits in the DM, they will also only hold deposits if $r^{D} \geq 1 / \beta$. Finally, they will exhaust their money holdings unless $1 /(1+\mu) \geq 1 / \beta$. We denote the total demand for government bonds from households as $b^{H}$.

\subsection{Entrepreneur's Problem in the CM}

Let $r^{L}$ denote the gross real lending rate. First, entrepreneurs choose the production technology by maximising their expected value from producing, given the loan rate and their technology:

$$
v\left(r^{L}, R^{i}\right)=\max _{R} \mathbb{E}\left\{\left[1-p\left(R, R^{i}, s\right)\right]\left(R-r^{L}\right)\right\},
$$

\footnotetext{
${ }^{7}$ In other words, monitored buyers carry fiat money only if the nominal rate on deposits is negative, and they exhaust their liquid assets in the DM unless the economy is at the Friedman rule $(1+\mu=\beta)$, or the real deposit rate fully compensates for discounting $\left(r^{D}=1 / \beta\right)$.
} 
where the expectation is taken over $s$. In words, (3.10) says that with probability $1-p\left(R, R^{i}, s\right)$, the entrepreneur succeeds, and her surplus after repaying the loan is $R-r^{L}$. It is clear that as long as $r^{L}>0$, entrepreneurs default if and only if their projects fail. Now, define

$$
p\left(R, R^{i}\right)=\mathbb{E}\left[p\left(R, R^{i}, s\right)\right]
$$

and let $R^{*}\left(r^{L}, R^{i}\right)$ denote the solution. Then

$$
1-p\left(R^{*}\left(r^{L}, R^{i}\right), R^{i}\right)-p_{R}\left(R^{*}\left(r^{L}, R^{i}\right), R^{i}\right)\left(R^{*}\left(r^{L}, R^{i}\right)-r^{L}\right) \geq 0
$$

with equality when $R^{*}\left(r^{L}, R^{i}\right) \in\left(0, R^{i}\right)$. Note that entrepreneurs will never choose $R=0$. Now, suppose $p_{R R}(\cdot) \geq 0$. Then, there exists a unique solution as long as $R^{i} \geq r^{L}$, and $R^{*}\left(r^{L}, r^{L}\right)=r^{L}$. Furthermore, under this assumption, $R^{*}\left(r^{L}, R^{i}\right)$ is increasing in $r^{L}$ and $R^{i}$. Finally, let

$$
v\left(r^{L}, R^{i}\right)=\left[1-p\left(R^{*}\left(r^{L}, R^{i}\right), R^{i}\right)\right]\left(R^{*}\left(r^{L}, R^{i}\right)-r^{L}\right) .
$$

It is clear that $v\left(r^{L}, R^{i}\right)$ is decreasing in $r^{L}$. Hence, entrepreneurs are willing to invest in projects (i.e., $v\left(r^{L}, R^{i}\right) \geq 0$ ) if and only if $R^{i} \geq r^{L}$.

\subsection{Bank's Problem in the CM}

Since only entrepreneurs with $R^{i} \geq r^{L}$ borrow from banks, the demand for loans is decreasing in $r^{L}$ and is given by

$$
L\left(r^{L}\right)=S\left[1-F\left(r^{L}\right)\right]
$$

Total demand for deposits $D\left(r^{D}\right)$ is increasing in $r^{D}$ and given by

$$
D\left(r^{D}\right)=\left\{\begin{array}{l}
0, \text { if } r^{D}<\frac{1}{1+\mu} \\
\eta\left(u^{\prime}\right)^{-1}\left(\frac{1}{\beta r^{D}}\right) / r^{D}, \text { if } \frac{1}{1+\mu} \leq r^{D}<1 / \beta \\
\geq \beta \eta q^{*}, \text { if } r^{D} \geq 1 / \beta .
\end{array}\right.
$$

Conditional on $s$, the expected probability of default on loans is

$$
P\left(r^{L}, s\right)=\frac{1}{1-F\left(r^{L}\right)} \int_{r^{L}}^{\bar{R}} p\left(R^{*}\left(r^{L}, R^{i}\right), R^{i}, s\right) f\left(R^{i}\right) \mathrm{d} R^{i} .
$$

Note that with the aggregate shock, banks may default in equilibrium. Specifically, let $l_{j}$ and $d_{j}$ denote the quantities of loans and deposits originated from bank $j$. Let $z_{j}$ and $b_{j}$ denote the quantities of reserves and government bonds held by bank $j$. Recall that $i^{R}$ is the nominal interest rate on reserves. Let $\tilde{r}^{D}$ denote the deposit rate a bank pays if it does not default. Under limited 
liability, banks default if and only if

$$
l_{j} r^{L}\left[1-P\left(r^{L}, s\right)\right]+\frac{z_{j}\left(1+i^{R}\right)}{1+\mu}+b_{j} r^{B}<d_{j} \tilde{r}^{D}
$$

i.e., if the return on their assets is less than the redemption value of deposits. It is important to note that $r^{D}$ represents the expected deposit rate. Because banks may default, $\tilde{r}^{D}$ will be larger than $r^{D}$. Specifically,

$$
d_{j} r^{D}=\mathbb{E}\left[\min \left\{l_{j} r^{L}\left[1-P\left(r^{L}, s\right)\right]+\frac{z_{j}\left(1+i^{R}\right)}{1+\mu}+b_{j} r^{B}, d_{j} \tilde{r}^{D}\right\}\right],
$$

where the expectation is taken over $s$. Banks' expected payoff in the CM is equal to

$$
\mathbb{E}\left[\max \left\{l_{j} r^{L}\left[1-P\left(r^{L}, s\right)\right]+\frac{z_{j}\left(1+i^{R}\right)}{1+\mu}+b_{j} r^{B}-d_{j} \tilde{r}^{D}, 0\right\}\right] .
$$

Note that if we add up (3.18) and (3.19), we get

$$
\begin{aligned}
& d_{j} r^{D}+\mathbb{E}\left[\max \left\{l_{j} r^{L}\left[1-P\left(r^{L}, s\right)\right]+\frac{z_{j}\left(1+i^{R}\right)}{1+\mu}+b_{j} r^{B}-d_{j} \tilde{r}^{D}, 0\right\}\right] \\
= & \mathbb{E}\left[l_{j} r^{L}\left[1-P\left(r^{L}, s\right)\right]+\frac{z_{j}\left(1+i^{R}\right)}{1+\mu}+b_{j} r^{B}\right]=l_{j} r^{L}\left[1-P\left(r^{L}\right)\right]+\frac{z_{j}\left(1+i^{R}\right)}{1+\mu}+b_{j} r^{B},
\end{aligned}
$$

where $P\left(r^{L}\right)=\mathbb{E}\left[P\left(r^{L}, s\right)\right]$. Now, let $e_{j}$ the amount of equity raised by bank $j$. Let $r^{L}(L)$ and $r^{D}(D)$ be the inverse demand functions for loans and deposits. Bank $j$ solves

$$
\begin{aligned}
& \max _{d_{j} \geq 0, e_{j} \geq 0, z_{j} \geq 0, b_{j} \geq 0} \Pi_{j}=-e_{j}+\beta\left[l_{j} r^{L}(L)\left[1-P\left(r^{L}(L)\right)\right]+\frac{z_{j}\left(1+i^{R}\right)}{1+\mu}+b_{j} r^{B}-d_{j} r^{D}(D)\right], \\
& \text { s.t. } l_{j}=d_{j}+e_{j}-z_{j}-b_{j} \\
& \qquad e_{j} \geq \gamma l_{j} \\
& \quad z_{j} \geq \delta d_{j},
\end{aligned}
$$

with $L=l_{j}+\sum_{j^{\prime} \neq j} l_{j^{\prime}}$ and $D=d_{j}+\sum_{j^{\prime} \neq j} d_{j^{\prime}}$. Constraints (3.22) and (3.23) represent capital and reserve requirements on banks, respectively. Bank $j$ takes the other banks' choices as given when choosing $l_{j}$ and $d_{j}$. We focus our attention on symmetric solutions where $l_{j}$ and $d_{j}$ are the same for all $j$. Now, define $H(L)=r^{L}(L)\left[1-P\left(r^{L}(L)\right)\right]$, the expected return per unit of loan. Let $\zeta$ and $\kappa$ be the Lagrangian multipliers for constraints (3.22) and (3.23), respectively. The first order conditions w.r.t. $z_{j}, b_{j}, d_{j}$, and $e_{j}$ are given by the following.

$$
l_{j} H^{\prime}(L)+H(L)=\frac{1+i^{R}}{1+\mu}+\zeta \gamma+\kappa
$$




$$
\begin{aligned}
& l_{j} H^{\prime}(L)+H(L)=r^{B}+\zeta \gamma \\
& l_{j} H^{\prime}(L)+H(L)=r^{D}(D)+d_{j} r^{D^{\prime}}(D)+\zeta \gamma+\kappa \delta ; \\
& l_{j} H^{\prime}(L)+H(L)=\frac{1}{\beta}-\zeta(1-\gamma) .
\end{aligned}
$$

It is also useful to derive the probability of bank defaults using (3.17). Let $\hat{s}$ solve

$$
D r^{D}(D)=\int_{\hat{s}}^{\bar{s}} L H(L, s) \mathrm{d} G(s)+G(\hat{s}) L H(L, \hat{s})+\frac{z^{B}\left(1+i^{R}\right)}{1+\mu}+b^{B} r^{B}
$$

where $z^{B}$ and $b^{B}$ are the total reserves and government bonds held by banks, respectively. Note that the right-hand side of (3.28) is decreasing in $\hat{s}$. Hence, $\hat{s}$ is unique, and the probability of bank default in equilibrium is $\Psi=1-G(\hat{s})$. Note that in a symmetric equilibrium, either all banks fail or no banks fail.

\section{Equilibrium}

We restrict our attention to stationary equilibria. Recall the quantity of government bonds held by a household is $b^{H}$, and the total supply of government bonds is $b$. Below we define the equilibrium.

Definition 4.1 A stationary and symmetric equilibrium consists of the quantity of bank loans L, the quantity of deposits $D$, the quantity of equity raised $E$, the quantity of reserves held by banks $z^{B}$, the quantity of government bonds held by banks $b^{B}$, the quantity of government bonds held by households $b^{H}$, a loan rate $r^{L}$, a deposit rate $r^{D}$ and a government bond rate $r^{B}$ such that

(1) $L, D, E, z^{B}$, and $b^{B}$ solve the first order conditions (3.24) - (3.27) with $d_{j}=D / N, e_{j}=E / N$, $l_{j}=L / N, z_{j}=z^{B} / N$, and $b_{j}=b^{B} / N$ for all $j$;

(2) $r^{L}$ is given by (3.14) and $r^{D}$ is given by (3.15);

(3) $r^{B}$ clears the bond market: $2 b^{H}+b^{B}=b$.

The next proposition shows the existence and uniqueness of a symmetric equilibrium.

Proposition 4.1 Assume that $H^{\prime}(L)<0$ and $H^{\prime \prime}(L)<0$ for all $L \in[0, S]$, and that $r^{D^{\prime}}(D)>0$ and $r^{D \prime \prime}(D) \geq 0$ for all $D \geq 0$. Then, there exists a unique symmetric equilibrium.

Proof: see Appendix B.1.

Since the equilibrium conditions are characterized by a number of inequalities that may or may not hold in equilibrium, we find it convenient to distinguish different equilibrium cases that can occur. In the following, we will discuss these cases separately. 


\subsection{Case I}

Suppose that $r^{B}=1 / \beta$. In this case, the capital requirement (3.23) does not bind because the cost of raising equity is equal to the return from government bonds. Thus, we have

$$
\frac{L}{N} H^{\prime}(L)+H(L)=\frac{1}{\beta}
$$

As long as $\frac{1+i^{R}}{1+\mu}<\frac{1}{\beta}$, the reserve requirement (3.22) binds in this case. Hence, $D$ is given by

$$
r^{D}(D)+\frac{D}{N} r^{D^{\prime}}(D)=\frac{1-\delta}{\beta}+\frac{\delta\left(1+i^{R}\right)}{1+\mu}
$$

Then, we have $z^{B}=\delta D$ and $E \in[\gamma L, \infty)$. Finally, we have $b^{B}=E+D-L-z^{B}$. Such an equilibrium exists if the above conditions hold for $r^{D}(D) \geq \frac{1}{1+\mu}$ and $b^{B}<b$.

Case I is characterized by high returns on assets and high costs of liabilities. This implies that this case occurs if the supply of high-return assets is abundant relative to the demand for loans. Thus, banks are willing to pay high interest rates on deposits in order to fund the investment opportunities, and they opt to raise some sweat equity in order to avoid increasing the marginal cost of deposits by too much.

\subsection{Case II}

Suppose now that $r^{B}<1 / \beta$. In this case, bonds are only held by banks. In addition, the capital requirement (3.23) binds, but the reserve requirement may or may not bind.

First, suppose the reserve requirement binds. Then, we have $D=((1-\gamma) L+b) /(1-\delta)$. From (3.24) - (3.27), we can derive the following expression for $L$ :

$$
\frac{L}{N} H^{\prime}(L)+H(L)+\frac{(1-\gamma) \delta\left(1+i^{R}\right)}{(1-\delta)(1+\mu)}=\frac{1-\gamma}{1-\delta}\left[r^{D}(D)+\frac{D}{N} r^{D^{\prime}}(D)\right]+\frac{\gamma}{\beta}
$$

Note that $L$ is given by this expression only if $r^{D}(D) \geq \frac{1}{1+\mu}$ and $r^{B} \geq \frac{1+i^{R}}{1+\mu}$, where

$$
r^{B}=\frac{1}{1-\gamma}\left[\frac{L}{N} H^{\prime}(L)+H(L)\right]-\frac{\gamma}{(1-\gamma) \beta} .
$$

We denote this scenario as Case IIA. To understand (4.4), first note that it can be rewritten as

$$
\frac{L}{N} H^{\prime}(L)+H(L)=(1-\gamma) r^{B}+\frac{\gamma}{\beta}
$$

The left-hand side is the marginal benefit of issuing one more unit of loans, while the right-hand side is the opportunity cost. Specifically, instead of issuing one more unit of loans, the bank could 
have saved $\gamma$ units of labour in the CM (because a proportion $\gamma$ of the loans must be funded through equity) and invest in $1-\gamma$ units of government bonds.

If the amount of $L$ that satisfies (4.3) is such that that the right-hand side of (4.4) is smaller than $\frac{1+i^{R}}{1+\mu}$, then the reserve requirement no longer binds and banks may hold excess reserves in equilibrium. In this case, we have

$$
r^{D}(D)+\frac{D}{N} r^{D^{\prime}}(D)=\frac{1+i^{R}}{1+\mu},
$$

and

$$
\frac{1}{1-\gamma}\left[\frac{L}{N} H^{\prime}(L)+H(L)\right]=\frac{1+i^{R}}{1+\mu}+\frac{\gamma}{(1-\gamma) \beta} .
$$

The bond rate is now given by $r^{B}=\frac{1+i^{R}}{1+\mu}$. Note that $D$ and $L$ are given by the above two expressions only if $r^{D}(D) \geq \frac{1}{1+\mu}$. We denote this scenario as Case IIB.

Case II is characterized by both the bond rate and the deposit rate being away from their upper and lower bounds, respectively. Thus, the marginal cost of deposits has to equal the marginal return on loans in this case. In case IIA, the bond interest rate can be interpreted as the policy rate by which the monetary authority can affect equilibrium outcomes (the monetary authority can change $r^{B}$ through open-market operations, which we will discuss in the next section), while in case IIB, the interest rate on reserves can be interpreted as the policy rate, as the monetary authority can affect equilibrium outcomes by varying $i^{R}$.

\subsection{Case III}

Case III is characterized by $r^{D}(D)=\frac{1}{1+\mu}$. In equilibrium, $r^{D}(D)<\frac{1}{1+\mu}$ is not possible because buyers will hold case instead. Therefore, $r^{D}(D)$ is bounded below by $\frac{1}{1+\mu}$, i.e., the zero lower bound. For $r^{D}(D)=\frac{1}{1+\mu}$, fiat money and deposits are perfect substitutes for monitored buyers, which implies that the demand for deposits does not have a unique solution. However, in such case, $D$ is bounded above by

$$
D^{\prime}=\eta\left(u^{\prime}\right)^{-1}\left(\frac{1+\mu}{\beta}\right)(1+\mu)
$$

If $D=D^{\prime}$, the marginal cost of increasing the amount of deposits is given by $r^{D}(D)+\frac{D}{N} r^{D^{\prime}}(D)$, but for any $D<D^{\prime}$, the marginal cost of increasing $\mathrm{D}$ is given by $r^{D}(D)=\frac{1}{1+\mu}$, as varying the amount of deposits does not affect the deposit interest rate. Since $\frac{D}{N} r^{D^{\prime}}(D)$ is strictly positive, this leads to a jump in the marginal cost of deposits at $D^{\prime}$. Therefore, (3.24) - (3.27) become

$$
l_{j} H^{\prime}(L)+H(L)=\frac{1+i^{R}}{1+\mu}+\zeta \gamma+\kappa
$$




$$
\begin{aligned}
& l_{j} H^{\prime}(L)+H(L)=r^{B}+\zeta \gamma \\
& l_{j} H^{\prime}(L)+H(L) \geq \frac{1}{1+\mu}+\zeta \gamma+\kappa \delta ; \\
& l_{j} H^{\prime}(L)+H(L)=\frac{1}{\beta}-\zeta(1-\gamma) .
\end{aligned}
$$

In particular, the equality in (3.26) is replaced with an inequality in (4.11).

To solve the equilibrium in this case, first suppose that the inequality in (4.11) is strict. Then $D=D^{\prime}$. If the reserve requirement binds, we have $(1-\gamma) L=(1-\delta) D^{\prime}-b$, and

$$
r^{B}=\frac{1}{1-\gamma}\left[\frac{L}{N} H^{\prime}(L)+H(L)\right]-\frac{\gamma}{(1-\gamma) \beta} .
$$

Such an equilibrium exists only if $r^{B}>\frac{1+i^{R}}{1+\mu}$. We denote this scenario as Case IIIA. If the reserve requirement does not bind, we have

$$
\frac{1}{1-\gamma}\left[\frac{L}{N} H^{\prime}(L)+H(L)\right]=\frac{1+i^{R}}{1+\mu}+\frac{\gamma}{(1-\gamma) \beta} .
$$

Such an equilibrium exists only if $i^{R}>0$. We denote this scenario as Case IIIB. Finally, assume the equality in (4.11) holds. Note that the only way for both (4.9) and (4.11) to hold in this scenario is that $i^{R}=0$ and $\kappa=0$. Then, we have

$$
\frac{1}{1-\gamma}\left[\frac{L}{N} H^{\prime}(L)+H(L)\right]=\frac{1}{1+\mu}+\frac{\gamma}{(1-\gamma) \beta} .
$$

We also classify this scenario as Case IIIB.

Case III is characterized by low returns on assets and low costs of liabilities. This implies that such case occurs when good investment opportunities are scarce relative to the demand for deposits. Thus, banks are willing to lend to entrepreneurs at low interest rates, since the funding they receive from depositors is abundant. Similar to Case II, Case III is separated into A and B versions, where $r^{B}$ should be interpreted as the policy rate in Case IIIA and $i^{R}$ should be interpreted as the policy rate in Case IIIB.

\section{Comparative Statics}

Before discussing the calibration of the model, we first want to present the comparative statics of five key variables. As will become clear in this section, these comparative statics vary quite a bit across the different equilibrium cases. In our opinion, this underlines the importance of developing a serious model that is able to identify various corner solutions that exist before analyzing the effects of various policies empirically. The five variables we analyze here are: the number of banks 
$N$, the supply of government bonds $b$, the interest on reserves $i^{R}$, the reserve requirement $\delta$, and the capital requirement $\gamma$. Except for $N$, these variables can be directly set by the government, and $N$ might be influenced indirectly through policy. We focus on the effects of policy changes on aggregate loan supply $L$, aggregate deposit demand $D$, interest rates, profits per bank $\Pi$ given by

$$
\Pi=-\frac{E}{N}+\beta\left[\frac{L}{N} r^{L}(L)\left[1-P\left(r^{L}(L)\right)\right]+\frac{z^{B}}{N} \frac{1+i^{R}}{1+\mu}+\frac{b^{B}}{N} r^{B}-\frac{D}{N} r^{D}(D)\right],
$$

and bank default probability $\Psi=1-G(\hat{s})$, where $\hat{s}$ is given by (see Section 3.4 )

$$
D r^{D}(D)=\int_{\hat{s}}^{\bar{s}} L H(L, s) \mathrm{d} G(s)+G(\hat{s}) L H(L, \hat{s})+\frac{z^{B}\left(1+i^{R}\right)}{1+\mu}+b^{B} r^{B} .
$$

Note that the deposit rate $r^{D}$ is always increasing in $D$ and the loan rate $r^{L}$ is always decreasing in $L$, so we focus on government bond rate $r^{B}$ when discussing interest rate changes in the economy. Also, recall that in Case I, banks are indifferent between raising more equity and purchasing more government bonds $\left(b^{B}\right)$. As a result, bank default probability is not well-defined. Hence, we focus on Case IIA, IIB, IIIA, and IIIB when discussing bank default probability.

\subsection{Increasing the Number of Banks $N$}

First, we analyze how the number of banks affects equilibrium outcomes.

Proposition 5.1 Consider an increase in $N$.

(1) L will increase in all cases except for Case IIIA.

(2) D will increase in all cases except for Case IIIA and IIIB.

(3) $r^{B}$ remains unchanged in Case I, IIB, and IIIB. In Case IIA, $r^{B}$ may increase or decrease. In Case IIIA, $r^{B}$ will increase.

(4) $\Pi$ will decrease in Case I, IIB, and IIIB. In Case IIA, $\Pi$ will decrease if $r^{B}$ decreases. In Case IIIA, П will decrease if in equilibrium $\frac{2 N+1}{N+1} \frac{L}{N} H^{\prime}(L)+H(L)-\frac{\gamma}{\beta}>0$.

(5) $\Psi$ will decrease in Case IIIA. The effect is ambiguous in Case IIA, IIB, and IIIB. However, if $L H^{\prime}(L)+H(L)<0$, then $\Psi$ will increase in Cases IIA, IIB, and IIIB.

Proof: see Appendix B.2.

\begin{tabular}{l|lllll}
\hline \hline & I & IIA & IIB & IIIA & IIIB \\
\hline \hline$L$ & + & + & + & 0 & + \\
$D$ & + & + & + & 0 & 0 \\
$r^{B}$ & 0 & $?$ & 0 & + & 0 \\
$\Pi$ & - & $?$ & - & $?$ & - \\
$\Psi$ & & $?$ & $?$ & - & $?$ \\
\hline \hline
\end{tabular}

Table 1: Comparative statics for $N$ across the different equilibrium regimes. 
When there are more banks, each bank has less impact on the loan rate and the deposit rate. This gives banks a higher incentive to issue more loans and bank deposits, so both loans and deposits increase with $N$ in most cases. However, in Case IIIA, both $L$ and $D$ are given by corner solutions, and hence they are not affected by a small increase in $N$. In Case IIIB, only $D$ is given by a corner solution, and hence $L$ will increase if $N$ is larger.

How government bond rate reacts to an increase in $N$ depends on the equilibrium cases. First, in Cases I, IIB, and IIIB, $r^{B}$ is fixed to exogenous variables $\left(\frac{1}{\beta}\right.$ in case I and $\frac{1+i^{R}}{1+\mu}$ in Cases IIB and IIIB), and therefore is unaffected by changes in $N$. In Case IIA, $r^{B}$ is determined by the marginal return on loans (see expression (4.4)), which may increase or decrease following an increase in $N$. This is because while $L$ is larger (and hence the expected return on loans $H(L)$ is smaller), the impact of a marginal increase in $L$ on the loan rate, $\left|\frac{L}{N} H^{\prime}(L)\right|$, may also be smaller. In Case IIIA, $r^{B}$ is also determined by the marginal return on loans. However, since $L$ does not change, $r^{B}$ will be unambiguously larger. Intuitively, competition between banks lowers the the impact of a marginal increase in $L$ on the loan rate, $\left|\frac{L}{N} H^{\prime}(L)\right|$, which makes issuing loans more attractive compared to investing in government bonds. As a result, the government bond rate must increase.

In general, bank profit decreases when there is more competition. However, as we have shown, $r^{B}$ may increase, which can increase bank profit. If $r^{B}$ decreases in Case IIA, bank profit will decrease as well. In Case IIIA, the condition $\frac{2 N+1}{N+1} \frac{L}{N} H^{\prime}(L)+H(L)-\frac{\gamma}{\beta}>0$ guarantees that the increase in $r^{B}$ is sufficiently small so that bank profit will still decrease. Note that these conditions are sufficient but not necessary for bank profit to decrease.

Finally, as shown by (5.2), the default probability depends on the banking industry's total deposit liabilities (i.e., $D r^{D}(D)$ ), total return from loans for any given $s$ (i.e., $L H(L, s)$ ), total

return from reserves (i.e., $\left.\frac{z^{B}\left(1+i^{R}\right)}{1+\mu}\right)$, and total return from government bonds (i.e., $\left.b^{B} r^{B}\right)$. The bank default probability decreases in Case IIIA because a higher return from government bonds (i.e., $b^{B} r^{B}$ ) provides a larger cushion against a negative shock. However, in Case IIA and IIB, $D$ and $L$ will also change following an increase in $N$. An increase in $D$ tends to increase default probability, because it increases bank's liabilities. An increase in $L$ has ambiguous effects, because it may increase or decrease the total return from loans. If $L H^{\prime}(L)+H(L)<0$, however, the total return from loans will decrease following an increase in $L$. In such case, bank default probability will increase.

\subsection{Increasing the Quantity of Government Bonds $b$}

Next, we analyze how the quantity of government bonds in the economy affects equilibrium outcomes. The quantity of bonds can be varied through open-market operations. For example, an increase in $b$ can result from an open-market sale of government bonds by the central bank.

Proposition 5.2 Consider an increase in $b$.

(1) L will decrease in Cases IIA and IIIA and remain unchanged in the other cases. 
(2) D will increase in Case IIA and remain unchanged in the other cases.

(3) $r^{B}$ will increase in Cases IIA and IIIA and remain unchanged in the other cases.

(4) $\Pi$ will increase in Cases IIA and IIIA and remain unchanged in the other cases.

(5) $\Psi$ will remain unchanged in Cases IIB and IIIB. The effect is ambiguous in Cases IIA and IIIA. However, $\Psi$ will decrease in Case IIIA if $L H^{\prime}(L)+H(L)<0$.

Proof: see Appendix B.2.

\begin{tabular}{l|lllll}
\hline \hline & I & IIA & IIB & IIIA & IIIB \\
\hline \hline$L$ & 0 & - & 0 & - & 0 \\
$D$ & 0 & + & 0 & 0 & 0 \\
$r^{B}$ & 0 & + & 0 & + & 0 \\
$\Pi$ & 0 & + & 0 & + & 0 \\
$\Psi$ & & $?$ & 0 & $?$ & 0 \\
\hline \hline
\end{tabular}

Table 2: Comparative statics for $b$ across the different equilibrium regimes.

In Case I, increasing $b$ has no effect because banks are indifferent between holding one more unit of government bonds or not. In Cases IIB and IIIB, increasing $b$ also has no effect because banks will simply substitute government bonds for reserves. In Cases IIA and IIIA, however, increasing $b$ will crowd out bank loans. In Case IIA, this will also lead to bank issuing more deposits. In Case IIIA, because the equilibrium is in a corner solution for deposits, $D$ will remain unchanged. In these two cases, the government bond rate also increases to incentivize banks to hold the additional bonds. This also means that banks receive a higher return from government bonds, which leads to higher profit for banks.

Bank default probability, however, may increase or decrease in Case IIA and IIIA. Firstly, a higher $r^{b}$ and a larger supply of government bonds tend to decrease default probability. However, a smaller $L$ may increase or decrease the total return from loans, and a larger $D$ will increase banks' liabilities. Consequently, the overall effect of increasing $b$ on bank default is ambiguous in Case IIA. However, if $L H^{\prime}(L)+H(L)<0$, a smaller $L$ will increase the return from loans. Since $D$ does not change in Case IIIA, this means that the default probability will decrease.

\subsection{Increasing the Interest on Reserves $i^{R}$}

In this subsection, we analyse the effect of increasing $i^{R}$.

Proposition 5.3 Consider an increase in $i^{R}$.

(1) L will increase in Cases IIA, decrease in Cases IIB and IIIB, and remain unchanged in the other cases.

(2) D will increase in Cases I, IIA, and IIB, and remain unchanged in the other cases.

(3) $r^{B}$ will decrease in Cases IIA, increase in Cases IIB and IIIB, and remain unchanged in the other cases.

(4) П will increase in all cases except Case IIA, in which the effect is ambiguous. 
(5) $\Psi$ will decrease in Case IIIA. In all the other cases, the effect is ambiguous. However, $\Psi$ will also decrease in Case IIIB if $L H^{\prime}(L)+H(L)<0$.

Proof: see Appendix B.2.

\begin{tabular}{l|lllll}
\hline \hline & I & IIA & IIB & IIIA & IIIB \\
\hline \hline$L$ & 0 & + & - & 0 & - \\
$D$ & + & + & + & 0 & 0 \\
$r^{B}$ & 0 & - & + & 0 & + \\
$\Pi$ & + & $?$ & + & + & + \\
$\Psi$ & & $?$ & $?$ & - & $?$ \\
\hline \hline
\end{tabular}

Table 3: Comparative statics for $i^{R}$ across the different equilibrium regimes.

In Case IIA, the reserve requirement binds. For banks, funding more loans with more deposits is costly because it means banks will have to hold more low-return reserves. Hence, for banks, a higher $i^{R}$ lowers the cost of issuing bank deposits. Consequently, banks issue more deposits and use them to fund additional loans. In Case IIB and IIIB, however, the reserve requirement does not bind. This implies that banks are indifferent on the margin between making an additional loan or holding reserves. When $i^{R}$ increases, reserves become more attractive than loans, so banks reduce $L$. The changes in $r^{B}$ then follow directly from the changes in $L$ because government bonds and loans are substitutes for banks. When loans become more attractive to banks in Case IIA, $r^{B}$ decreases. When loans become less attractive to banks in Case IIB and IIIB, $r^{B}$ increases. Finally, $L$ is unchanged in Case I because loan return is pinned by $r^{B}$, which is equal to $1 / \beta$ and is unaffected by the change in $i^{R}$. In Case IIIA, $L$ and $D$ are unchanged because the equilibrium is characterized by a corner solution.

In general, bank profit is increasing in $i^{R}$. However, because banks take the government bond rate as given, they do not take into account the effect of their competition on the government bond rate. In Case IIA, it is possible that the decrease in $r^{B}$ lowers bank profit. In all the other cases, $r^{B}$ either increases or remains unchanged. Consequently, bank profit is increasing in $i^{R}$.

Finally, the effect on bank default probability is in general ambiguous. While a higher $i^{R}$ can lead to a larger holding of safe assets, it may also change $L$, which can either increase or decrease the total return from loans. In Cases IIA and IIB, a higher $i^{R}$ also increases bank's total deposit liabilities, which tend to increase bank default probability. However, in Case IIIA, because $L$ and $D$ remain unchanged, a higher $i^{R}$ only has the effect of increasing bank's income from holding reserves. Hence, bank default probability will unambiguously decrease. Finally, in Case IIIB, if $L H^{\prime}(L)+H(L)<0$, then because $L$ will decrease, the total return from loans will increase. Since $D$ remains unchanged, bank default probability will decrease.

\subsection{Increasing the Reserve Requirement $\delta$}

The next proposition summarizes the effects of increasing the reserve requirement. 
Proposition 5.4 Consider an increase in $\delta$.

(1) L will decrease in Cases IIA and IIIA, and remain unchanged in the other cases.

(2) $D$ will decrease in Case I, and remain unchanged in Cases IIB, IIIB, and IIIA. In Case IIA, the effect is ambiguous.

(3) $r^{B}$ will increase in Cases IIA and IIIA, and remain unchanged in the other cases.

(4) $\Pi$ will decrease in Case I, and remain unchanged in Cases IIB and IIIB. In Cases IIA and IIIA, the effect is ambiguous.

(5) $\Psi$ remains unchanged in Case IIB and IIIB. The effect is ambiguous in Cases IIA and IIIA. However, $\Psi$ will decrease in Case IIIA if $L H^{\prime}(L)+H(L)<0$.

Proof: see Appendix B.2.

\begin{tabular}{l|lllll}
\hline \hline & I & IIA & IIB & IIIA & IIIB \\
\hline \hline$L$ & 0 & - & 0 & - & 0 \\
$D$ & - & $?$ & 0 & 0 & 0 \\
$r^{B}$ & 0 & + & 0 & + & 0 \\
$\Pi$ & - & $?$ & 0 & $?$ & 0 \\
$\Psi$ & & $?$ & 0 & $?$ & 0 \\
\hline \hline
\end{tabular}

Table 4: Comparative statics for $\delta$ across the different equilibrium regimes.

In Cases IIB and IIIB, the reserve requirement does not bind. Hence, increasing the reserve requirement has no effect on the equilibrium. In Case IIA, the reserve requirement binds, and increasing the reserve requirement will make it more costly for banks to fund investment with deposits. Hence, $L$ decreases and $r^{B}$ increases. However, to comply with the new reserve requirement, banks also need to hold more reserves, which can be achieved through issuing more deposits. Consequently, in this case, the effect on $D$ is ambiguous.

In Case I, a higher reserve requirement increases the cost of issuing deposits, which also happens in Cases IIA and IIIA. However, in the latter two cases, $r^{B}$ will also increase, which will increase the income of banks. The mechanism is similar to when the government increases $i^{R}$ : because banks take the government bond rate as given, they do not take the effect of their competition on the government bond rate into account. In this case, the lower demand for government bonds benefits banks. Consequently, the overall effect of increasing the reserve requirement on bank profit is ambiguous in cases IIA and IIIA.

Finally, in Cases IIA and IIIA, while increasing the reserve requirement makes banks hold more safe assets, it also forces banks to lower $L$, which may increase or decrease the total return from loans. As a result, increasing the reserve requirement has an ambiguous effect on bank default probability. However, in Case IIIB, if $L H^{\prime}(L)+H(L)<0$, then because $L$ will decrease, the total return from loans will increase. Since $D$ remains unchanged, bank default probability will decrease.

\subsection{Increasing the Capital Requirement $\gamma$}

Finally, we study the effect of increasing the capital requirement. 
Proposition 5.5 Consider an increase in $\gamma$.

(1) L will increase in Case IIIA, decrease in Cases IIB and IIIB, and remain unchanged in Case I. If $u(q)=\frac{q^{1-\sigma}-1}{1-\sigma}$, then as long as $\frac{1+(\epsilon-1) \sigma}{(1+\mu)(1-\sigma)}>\frac{1}{\beta}$ where $\epsilon=1-b /[(1-\delta) D]$, L will also increase in Case IIA.

(2) D will decrease in Case IIA, and remain unchanged in the other cases;

(3) $r^{B}$ will decrease in Case IIIA and remain unchanged in Cases I, IIB, and IIIB. If $u(q)=\frac{q^{1-\sigma}-1}{1-\sigma}$ and $\frac{1+(\epsilon-1) \sigma}{(1+\mu)(1-\sigma)}>\frac{1}{\beta}$, then $r^{B}$ will decrease in Case IIA.

(4) $\Pi$ will remain unchanged in Case I and decrease in the other cases.

(5) The effect on $\Psi$ is in general ambiguous. However, suppose that $L H^{\prime}(L)+H(L)<0$ in Cases IIB, IIIA, and IIIB. Then $\Psi$ will decrease in Cases IIB and IIIB but increase in Case IIIA.

Proof: see Appendix B.2.

\begin{tabular}{l|lllll}
\hline \hline & I & IIA & IIB & IIIA & IIIB \\
\hline \hline$L$ & 0 & $?$ & - & + & - \\
$D$ & 0 & - & 0 & 0 & 0 \\
$r^{B}$ & 0 & $?$ & 0 & - & 0 \\
$\Pi$ & 0 & - & - & - & - \\
$\Psi$ & & $?$ & $?$ & $?$ & $?$ \\
\hline \hline
\end{tabular}

Table 5: Comparative statics for $\gamma$ across the different equilibrium regimes.

First, the capital requirement is nonbinding in Case I since banks are indifferent about raising more equity and investing it in bonds, so changing $\gamma$ does not affect equilibrium outcomes. In the other cases, an increase in $\gamma$ implies that issuing loans becomes more expensive, since banks need to hold more equity. One may think that this will make banks decrease the amount of loans they make, but this is not true in every case. In Case IIA, banks would like to reduce loans, but at the same time, raising more equity means banks have more funds to invest, and since loans still pay a higher marginal return than reserves and banks already hold all bonds, loans are the best investment option. Thus, $L$ may actually increase as a reaction to the increase in $\gamma$. On the liabilities side, the forced increase in equity leads to a reduction in deposits. Case IIIA is similar, but with the difference being that $D$ is pinned down and thus does not change. Since banks do not reduce deposits, their only option is to invest in the new equity in $L$. Finally, note that $r^{B}$ reacts accordingly in these cases: In Case IIA, it increases if $L$ goes down, and decreases if $L$ increases, while it unambiguously decreases in Case IIIA. In Cases IIB and IIIB, the reserve requirement is slack, and therefore banks prefer to invest in more reserves if they are forced to raise more equity. Thus, $L$ decreases in these cases, while $D$ and $r^{B}$ are unaffected.

Bank profit will decrease except in Case I, where the capital requirement does not bind. This is because compared to deposits, equity is more costly for banks to raise. In Cases IIA and IIIA, bank profit will further decrease due to the decrease in $r^{B}$.

Finally, the effect of $\gamma$ on bank default probability is in general ambiguous. In Cases IIB and IIIB, a higher $\gamma$ will increase bank's holdings of safe assets, but it will also lower $L$, which 
may increase or decrease the total return from loans. In Cases IIA and IIIA, the increase in $L$ (and also the decrease in $D$ in Case IIA) tends to decrease bank default probability. The overall effect is nevertheless ambiguous because the decrease in $r^{B}$ will lower bank profit. However, if $L H^{\prime}(L)+H(L)<0$, then because $L$ decreases in Cases IIB and IIIB, the total return from loans will increase. Since $D$ remains unchanged in these cases, bank default probability will decrease. In contrast, because $L$ increases in Case IIIA, the total return from loans will decrease if $L H^{\prime}(L)+$ $H(L)<0$. This means that bank default probability will increase.

\section{Calibration}

To quantify our results, we calibrate the model to the U.S. economy during 2016-2019. We choose this time period since the Federal Reserve started actively using the interest rate on (excess) reserves as a policy tool in 2016, and continued doing so until the onset of the COVID-19 pandemic in 2020. All of our calibration targets are matched to moments from this time period, except for money demand, for which we need a longer time series and we thus calibrate separately, using data from 1984-2007.

We set a period to be equal to one year and make the following assumptions on buyers' utility function $u(q)$ and the success probabilities of entrepreneurs' projects $p\left(R, R^{i}, s\right)$ :

$$
\begin{aligned}
& u(q)=\frac{q^{1-\sigma}-1}{1-\sigma}, \\
& p\left(R, R^{i}, s\right)=s\left(\frac{R}{R^{i}}\right)^{\alpha}, \\
& \mathbb{E}\left[p\left(R, R^{i}, s\right)\right]=p\left(R, R^{i}\right)=\left(\frac{R}{R^{i}}\right)^{\alpha} .
\end{aligned}
$$

We also assume that entrepreneur's ability $R^{i}$ follows a uniform distribution on $[0, \bar{R}]$, while the aggregate shock $s$ follows a truncated normal distribution. The realization of $s$ is independent of whether an individual entrepreneur's project is successful or not.

There are 16 parameters to calibrate: inflation rate $(\mu)$, proportion of monitored meetings in the $\operatorname{DM}(\eta)$, nominal interest rate on reserves $\left(i^{R}\right)$, reserve requirement $(\delta)$, capital requirement $(\gamma)$, discount factor $(\beta)$, buyer's preference $(\sigma)$, the number of banks $(N)$, upper bound of the distribution of entrepreneur's ability $(\bar{R})$, government bond supply $(b)$, the measure of entrepreneurs $(S)$, parameter $\alpha$ in $p\left(R, R^{i}\right)$, and four parameters that describe the distribution of the aggregate shock.

We pick the first 5 parameters directly to match the data. We obtain all data from Federal Reserve Economic Data (FRED) except for the proportion of non-cash transactions, which is from the 2016 Survey of Consumer Payment Choice. ${ }^{8}$ We also pick $\beta$ directly to be consistent with

\footnotetext{
${ }^{8}$ The value reported in the data is the number of transactions made with cash relative to the number of transactions
} 
literature.

\begin{tabular}{llll}
\hline Parameter & Notation & Value & Calibration target \\
\hline \hline Inflation rate & $\mu$ & $1.82 \%$ & Average inflation (CPI): 2016-19 \\
Prop. of monitored DM meetings & $\eta$ & 0.85 & Prop. of non-cash transactions (2016) \\
Nominal interest rate on reserves & $i^{R}$ & $1.40 \%$ & Average IOER: 2016-19 \\
Reserve requirement & $\delta$ & $8.83 \%$ & Average reserve requirement: 2016-19 \\
Capital requirement & $\gamma$ & $6 \%$ & Basel III capital requirement (2016) \\
Discount factor & $\beta$ & 0.98 & Standard in the literature \\
\hline
\end{tabular}

Table 6: Externally calibrated parameters.

Next, we follow Rocheteau et al. (2018) and calibrate $\sigma$ by matching the semi-elasticity of money demand in the model to the data. The semi-elasticity of money demand in our model is given by

$$
\frac{\partial \log \left(q^{m}\right)}{\partial \iota}=-\frac{1}{\sigma \iota}
$$

where $\iota=(1+\mu) / \beta$ and $q^{m}$ is the output in unmonitored meetings (see Section 3.2). We calculate empirical money demand semi-elasticity using the currency-to-nominal GDP ratio from FRED and Moody's AAA corporate bond yield from FRED. We set the period for calibration to 1959-2007. ${ }^{9}$ The following figure shows the money demand data between 1959 and 2007. Our estimated semielasticity of money demand is -3.94 , which corresponds to $\sigma=0.24 .^{10}$

The third step is to jointly calibrate $N, \bar{R}, b, \alpha$, and $S$ so that the expected return on loans $r^{L}\left(1-P\left(r^{L}\right)\right.$ ) (see Section 3.4), expected deposit rate $r^{D}$, reserve-to-loan ratio $z^{B} / L$, loan default probability $P\left(r^{L}\right)$, and loans-to-GDP ratio match their counterparts in the data, i.e., average return on loans, average deposit rate, average reserves-to-loan ratio, average loan default probability, and average commercial and industrial loans-to-GDP ratio. ${ }^{11}$ The following table summarizes the calibration results. We obtain all data from FRED except for loan rates, which are derived from Call reports data collected by Drechsler et al. (2017). ${ }^{12}$ To calculate the average return on loans, we divide total interest income on loans by total quantity of loans. We exclude the lowest $10 \%$ of

without cash, which directly matches the parameter in our model.

${ }^{9}$ We do not include data from 2008 and onwards since the demand for currency increased during and after the financial crisis, likely for non-transactional reasons, such as store-of-value or flight-to-safety motives. Since our model does not include such reasons to hold currency, we find it best to exclude post-crisis data. Chiu et al. (2019) argue that one should use pre-crisis data to estimate money demand elasticity.

${ }^{10}$ This approach relies on the underlying assumption that the money demand semi-elasticity for transactional use has not fundamentally changed between 1959-2007 and 2016-2019. To confirm this, we use a different method to calibrate $\sigma$ as a robustness check. Specifically, we calculate the elasticity $M /(P Y)$ in the model for 2016-2019, where $M / P$ is the demand for real balances and bank deposits, and $Y$ is real GDP. Then, we match model elasticity to data. We obtain a similar value of $\sigma=0.31$.

${ }^{11}$ Note that we do not target the supply of government bonds directly. The reason is that banks hold a lot more assets in reality than we allow for in the model. Thus, government bonds should be interpreted as encompassing a large array of safe assets that are traded on financial markets.

${ }^{12}$ We do not use deposit rate data from this source since it includes commercial deposits, while other variables in our calibration (e.g. the proportion of non-cash transactions $\eta$ ) are for households only. 


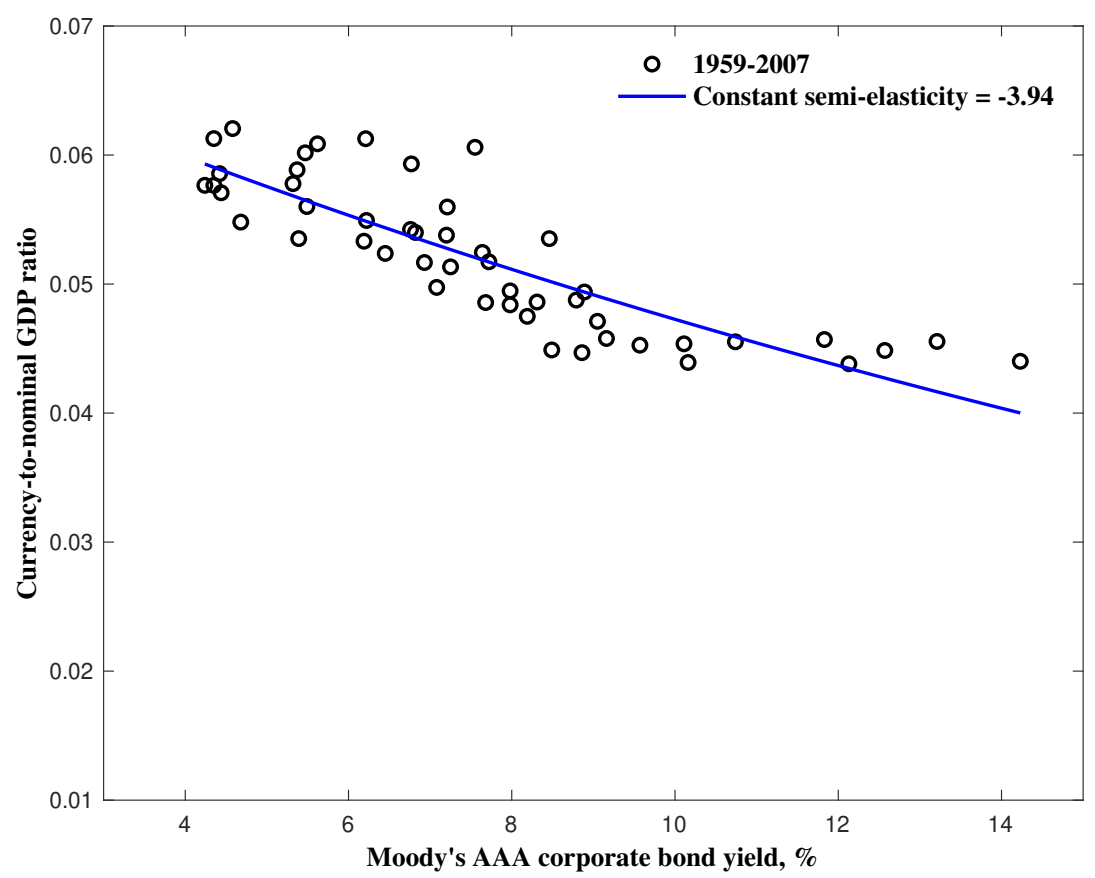

Figure 4: Money demand

the sample as they are likely from safe loans, and then we calculate the weighted average across all banks.

\begin{tabular}{llll}
\hline Parameter & Notation & Value & Calibration target \\
\hline \hline Number of banks & $N$ & 23 & Avg. return on loans and Avg. deposit rate: 2016-19 \\
Upper bound of ability dist. & $\bar{R}$ & 1.95 & Avg. return on loans and Avg. deposit rate: 2016-19 \\
Government bond supply & $b$ & 0.42 & Avg. reserves-to-loan ratio: 2016-19 \\
Parameter in $p\left(R, R^{i}\right)$ & $\alpha$ & 574.22 & Avg. loan default rate: 2016-19 \\
Measure of entrepreneurs & $S$ & 0.51 & Avg. comm. \& ind. loans-to-GDP ratio: 2016-19 \\
\hline
\end{tabular}

Table 7: Internally calibrated parameters.

The final step is to calibrate the four parameters that describe the truncated normal distribution of the aggregate shock: $\hat{\mu}, \hat{\sigma}$, the lower bound $\hat{a}$, and the upper bound $\hat{b}$. Note that $\hat{\mu}$ and $\hat{\sigma}$ are the mean and variance of the corresponding normal distribution. We fix $\hat{a}$ to 0 and $\hat{b}$ to 50 . Since we assume $\mathbb{E}\left[p\left(R, R^{i}, s\right)\right]=p\left(R, R^{i}\right)$, the mean of $s$ must be 1 . Hence, for any given $\hat{\sigma}, \hat{\mu}$ is given by

$$
1=\hat{\mu}+\frac{\phi\left(\frac{\hat{a}-\hat{\mu}}{\hat{\sigma}}\right)-\phi\left(\frac{\hat{b}-\hat{\mu}}{\hat{\sigma}}\right)}{\Phi\left(\frac{\hat{b}-\hat{\mu}}{\hat{\sigma}}\right)-\Phi\left(\frac{\hat{a}-\hat{\mu}}{\hat{\sigma}}\right)},
$$

where $\phi($.$) and \Phi($.$) are the PDF and CDF of standard normal distribution, respectively. We use$ the ratio between bank failure cost to the Federal Deposit Insurance Corporation (FDIC) and total 
transnational deposits as a proxy for bank default probability in data. The average of this ratio between 2016 and 2019 is $0.02 \%$. We then calibrate $\hat{\sigma}$ so that the default probability given by (3.28) matches the data. We obtain $\hat{\sigma}=3.08$ and $\hat{\mu}=0.25$.

\subsection{Model Fit and Calibration Results}

The model fit is summarized in Table 8. Even though our model is highly nonlinear, all targets are matched very closely.

\begin{tabular}{lll}
\hline Target & Data & Model \\
\hline \hline Average nominal return on loans: 2016-19 & $5.47 \%$ & $5.44 \%$ \\
Average nominal deposit rate: 2016-19 & $0.05 \%$ & $0.06 \%$ \\
Average reserves-to-loan ratio: 2016-19 & $12.65 \%$ & $12.65 \%$ \\
Average loan default rate: 2016-19 & $1.26 \%$ & $1.26 \%$ \\
Average commercial and industry loans-to-GDP ratio: 2016-19 & $10.80 \%$ & $10.80 \%$ \\
Average bank default probability: 2016-19 & $0.02 \%$ & $0.02 \%$ \\
\hline
\end{tabular}

Table 8: Model Fit

According to our calibration, the U.S. economy was in equilibrium Case IIB during 20162019 - a scenario where banks hold excess reserves, while the nominal interest rate on deposits is positive. This makes a lot of sense, as banks were indeed holding excess reserves during that period and the Federal Reserve was conducting monetary policy via the interest rate on excess reserves. The average nominal deposit rate was also positive during our calibration period, even though only barely so. As a result, our calibrated economy is also very close to the transition point into equilibrium Case IIIB, which we will discuss in depth in the next section. Furthermore, there were 23 banks in the U.S. economy according to our calibration. This result should not be taken literally - instead, our model implies that the banking sector behaved as if there were 23 banks with equal size and market power, while in reality banks differ in size.

\section{Counterfactual Analysis}

In this section, we analyse how changes in the degree of banking competition, in the policy rate, and in the reserve requirement would have affected the U.S. economy during 2016-2019. As we have discussed in Section 5, the theoretical effects of changes in these variables differ across equilibrium cases. The analysis in this section allows us to not only pin down the direction of the effects the policy changes have on other variables but also quantify them. We also study how the effectiveness of monetary policy is affected by the degree of banking competition in the economy, by comparing how changes in monetary policy affect outcomes in the baseline versus a counterfactual world with 
a different degree of banking competition. ${ }^{13}$

In addition to the equilibrium outcomes discussed in Section 4, we also study the effects of policies on expected aggregate welfare $W$, which is simply an equal-weighted sum of all agents' expected utility:

$$
\begin{aligned}
W= & (1-\eta)\left[u\left(q^{m}\right)-q^{m}\right]+\eta\left[u\left(q^{d}\right)-q^{d}\right] \\
& +\beta S \mathbb{E}\left[\int_{r^{L}}^{\bar{R}} R^{*}\left(r^{L}, R^{i}\right)\left[1-p\left(R^{*}\left(r^{L}, R^{i}\right), R^{i}, s\right)\right] f\left(R^{i}\right) \mathrm{d} R^{i}\right]-L .
\end{aligned}
$$

First, $(1-\eta)\left[u\left(q^{m}\right)-q^{m}\right]+\eta\left[u\left(q^{d}\right)-q^{d}\right]$ is the total surplus from trade in the DM. Second, note that $R^{*}\left(r^{L}, R^{i}\right)$ is given by $(3.12)$, and $\beta S \mathbb{E}\left[\int_{r^{L}}^{\bar{R}} R^{*}\left(r^{L}, R^{i}\right)\left[1-p\left(R^{*}\left(r^{L}, R^{i}\right), R^{i}, s\right)\right] f\left(R^{i}\right) \mathrm{d} R^{i}\right]$ is the discounted expected output by entrepreneurs, where the expectation is taken over $s$, the aggregate shock, and $S$ is the measure of entrepreneurs. Recall that all agents derive linear utility from consuming the CM good, and buyers and bankers derive linear disutility from producing the CM good. Hence, the production of CM good by agents other than entrepreneurs does not appear in the welfare definition.

\subsection{Banking Competition}

\begin{tabular}{lrr}
\hline & $\frac{1}{2} N=12$ & $2 N=46$ \\
\hline \hline$W$ & $-1.52 \%$ & $+1.02 \%$ \\
$L$ & $-3.67 \%$ & $+2.12 \%$ \\
$D$ & $-0.19 \%$ & $+2.18 \%$ \\
$i^{L}$ & $+3.37 \mathrm{pp}$ & $-1.95 \mathrm{pp}$ \\
$i^{D}$ & $-0.0574 \mathrm{pp}$ & $+0.67 \mathrm{pp}$ \\
$\Pi$ & $+167.12 \%$ & $-74.1 \%$ \\
$\Psi$ & $-0.0184 \mathrm{pp}$ & $+0.42 \mathrm{pp}$ \\
Case & IIIB & IIB \\
\hline
\end{tabular}

Table 9: The effect of changes in $N$ on equilibrium outcomes.

Table 9 reports the changes in macroeconomic outcomes relative to our baseline calibration with banking competition being twice and half as high as it effectively was, respectively. ${ }^{14}$ Doubling $N$ keeps the economy in equilibrium Case IIB, while halving the number of banks moves the economy into Case IIIB. More banking competition is good for welfare but bad for banks: doubling the competition among banks increases welfare by $1.02 \%$, but reduces profit per bank by $74.1 \%$. Note that profit per bank would have only reduced by $50 \%$ (since $N$ is doubled) had each bank

\footnotetext{
${ }^{13}$ We focus on a few policies and mostly on discrete changes in order to highlight what we find most interesting. For more thorough analyses, see Appendix A for how changes in $N, i^{R}, b, \delta$, and $\gamma$ affect all equilibrium outcomes in our calibrated economy.

${ }^{14}$ Since $N=23$ in our calibration and the number of banks needs to be an integer, $2 N=46$ while $\frac{1}{2} N=12$.
} 
simply reduced their assets and liabilities by $50 \%$ while keeping the relative composition of their balance sheet unchanged. A decrease larger than 50\% means that not only does each bank receive less profit, but the entire banking industry receives less profit as well. This is because the more banks there are, the less banks internalize the effects of their actions on equilibrium interest rates. This implies that the wedge between deposit and loan rates and thus profit margins for banks are reduced. In turn, the smaller wedge between these rates also explains the increase in welfare that comes with higher $N$ : on the one hand, higher deposit rates make holding liquidity less costly for buyers, thereby increasing their DM consumption. On the other hand, lower loan rates increase $\mathrm{CM}$ investment. Note that the deposit rate only decreases marginally when banking competition is further reduced relative to the benchmark. The reason for this is that deposit rates are close to zero already, and once they are at zero they cannot be reduced further. Even though this dampens the negative effects from reducing banking competition on welfare, the welfare loss from halving banking competition relative to the benchmark is larger than the welfare gain from doubling the number of banks. This goes to show that welfare reacts particularly strongly to changes in the number of banks when $N$ is low.

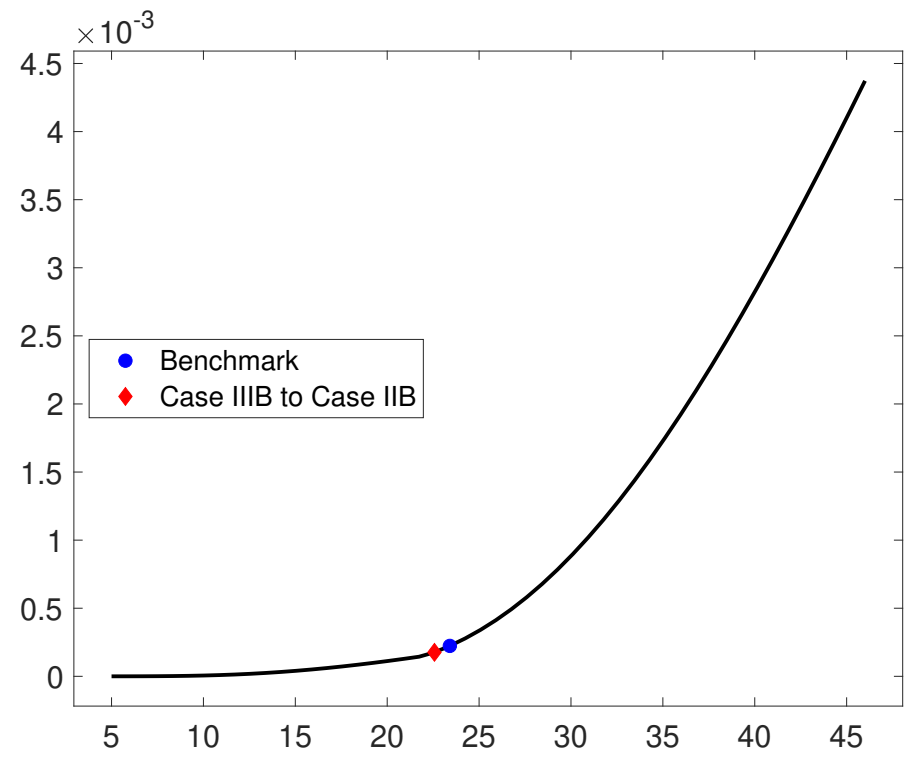

Figure 5: Effects of $N$ on Bank Default Probability.

In our theoretical analysis, we note that the effect of changes in $N$ on the bank default probability $\Psi$ is ambiguous in cases IIB and IIIB. Our quantitative analysis shows that $\Psi$ is increasing in $N$, so while stronger banking competition is good for welfare, it also increases the risk of bank failure, and it does so in a non-trivial way: Since the probability of bank failure is only about $0.02 \%$ according to our calibration, the increase by $0.42 \mathrm{pp}$ in $\Psi$ that follows from doubling $N$ implies that bank failure becomes more than 20 times more likely with fiercer banking competition. Figure 5 shows how the probability of bank default varies with $N$. 


\subsection{Changes in the Policy Rate}

Next, we study how varying the policy rate affects equilibrium outcomes.

\begin{tabular}{lrr}
\hline & $i^{R}-1 p p$ & $i^{R}+1 p p$ \\
\hline \hline$W$ & $+0.40 \%$ & $-0.21 \%$ \\
$L$ & $+1.00 \%$ & $-1.00 \%$ \\
$D$ & $-0.19 \%$ & $+3.23 \%$ \\
$i^{L}$ & $-0.92 \mathrm{pp}$ & $+0.92 \mathrm{pp}$ \\
$i^{D}$ & $-0.0574 \mathrm{pp}$ & $+0.99 \mathrm{pp}$ \\
$\Pi$ & $-35.53 \%$ & $+1.23 \%$ \\
$\Psi$ & $+0.20 \mathrm{pp}$ & $+0.0012 \mathrm{pp}$ \\
Case & IIIB & IIB \\
\hline
\end{tabular}

Table 10: The effect of changes in $i^{R}$ on equilibrium outcomes.

Table 10 shows how an increase or a decrease in the nominal interest rate on reserves $i^{R}$ by 1 pp affects the calibrated economy. ${ }^{15}$ Recall that we calibrate the model to an interest rate on reserves of $1.4 \%$, so the counterfactuals presented here correspond to economies with $i^{R}=0.4 \%$ and $i^{R}=2.4 \%$, respectively. The first main takeaway is the welfare effects of changes in interest on reserves. In general, increases in the deposit rate are good for welfare since they allow for more trades in the DM, while lower loan rates are good for welfare since they increase investment and lower risk-taking of entrepreneurs. Thus, the welfare effect of changes in the policy rate is in general ambiguous. However, in equilibrium Case IIIB, changes in the policy rate affect only the loan rate, since the deposit rate is equal to zero and does not react to marginal changes in the policy rate. Since our calibrated economy is very close to equilibrium Case IIIB, it is no surprise that a decrease in the policy rate is good for welfare, as the positive effects from lowering the loan rate dominate the small negative effect from further lowering the deposit rate to zero. Interestingly, an increase in the policy rate lowers welfare in our calibration, which shows that the negative effects from reducing loans dominate the positive effects from increasing deposits.

Another important takeaway from Table 10 is that interest-rate pass-through is incomplete under imperfect competition. The loan rate changes by only $0.92 \mathrm{pp}$ following a $1 \mathrm{pp}$ change in the policy rate in either direction. Pass-through to the deposit rate is almost complete with 0.99pp following an increase in the policy rate, but for decreases in the policy rate, the deposit rate barely changes as it is close to the zero-lower bound already in the baseline calibration. We investigate in more detail how interest rate pass-through is affected by $N$ in the next section.

The third main takeaway from Table 10 is the strong reduction in profits per bank to a decrease

\footnotetext{
${ }^{15}$ Since monetary policy in the U.S. was mainly conducted through the interest rate on excess reserves during our calibration time period, we focus on $i^{R}$ as the policy rate here. However, as long as the reserve requirement is nonbinding, (i.e., the economy is in cases IIIB or IIB), $i^{R}=i^{b}$ and both can be interpreted as the policy rate in our model economy. An increase in the policy rate could also be implemented through open-market operations, which leads to similar results, as we discuss in Appendix A.
} 
in the policy rate. While we have already shown theoretically that an increase in the policy rate increases profits per bank in Cases IIB and IIIB, the quantitative analysis here shows that this effect is particularly strong in equilibrium Case IIIB. This is because while in general, the higher policy rate increases both the return on the banks' assets and the cost of their liabilities, the latter effect is nonexistent in Case IIIB as the deposit rate is stuck at zero. This can also be seen from Figure 6 , which shows that $\Pi$ is strongly increasing in the policy rate as long as the economy is in Case IIIB, while the increase becomes much more gradual once the economy is in Case IIB. ${ }^{16}$ Another way to think about this is that banks with market power would like to set a constant wedge between the loan rate and the deposit rate, but due to the zero lower bound, they cannot set the lower bound of this wedge (the deposit rate) arbitrarily low. This reduces their profit margin. In this sense, setting interest rates close to zero is a way for the central bank to reduce banks' market power.

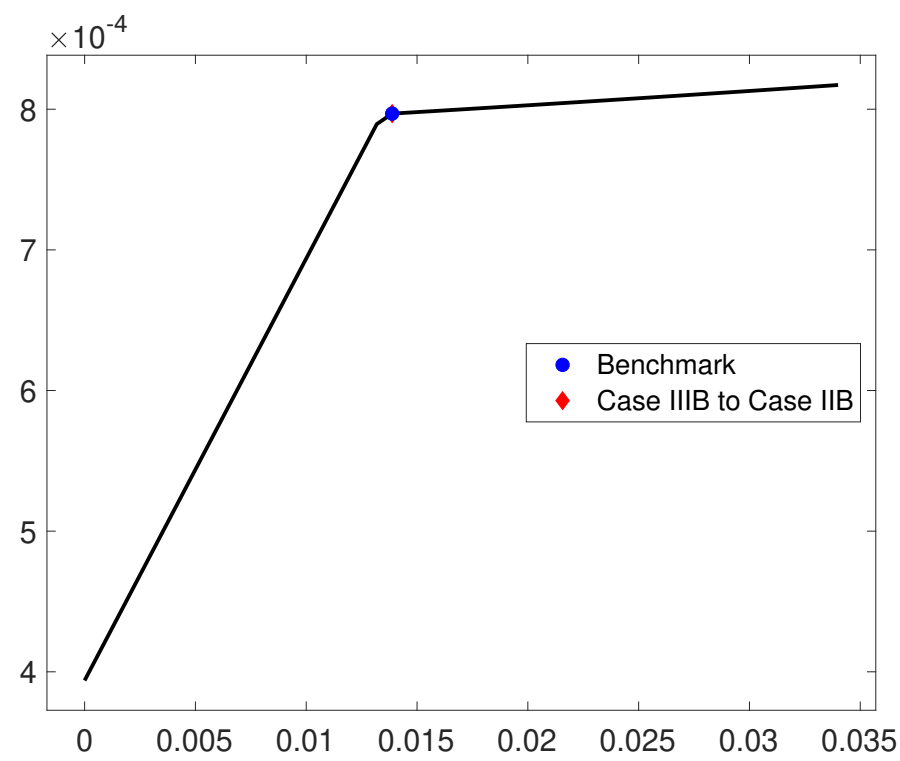

Figure 6: Effects of $i^{R}$ on Bank Profit.

The final result we want to highlight is the effect of policy rate changes on the bank default probability $\Psi$, which are generally ambiguous in the model. It turns out that the Fed has set monetary policy pretty effectively in terms of minimizing the risk of bank default during 2016-2019, since changes in the policy rate in either direction would have led to increases in the probability of bank default. Figure 7 shows how $\Psi$ changes with the policy rate and in particular how lower policy rates drastically increase the probability of bank default once the economy is in Case IIIB.

\footnotetext{
${ }^{16}$ The Figure also shows that the economy is precisely at the transition point between Case IIIB and IIB in our benchmark, so the effects from a decrease in the policy rate reported in Table 10 play out almost entirely in Case IIIB, while those from an increase in the policy rate play out in Case IIB.
} 


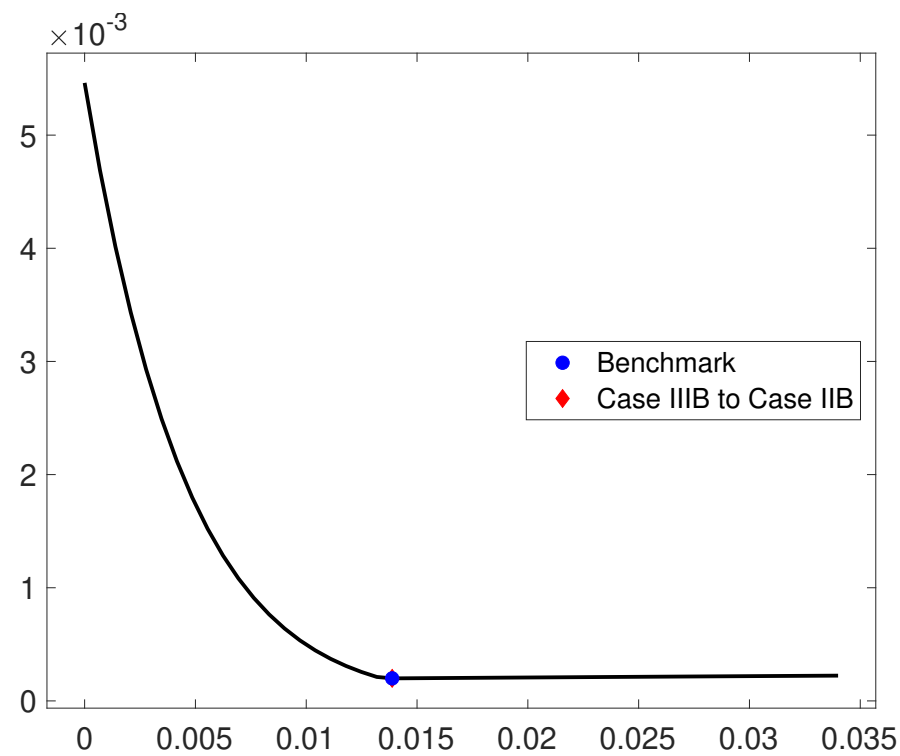

Figure 7: Effects of $i^{R}$ on Bank Default Probability.

\subsection{Effectiveness of Monetary Policy with Different $N$}

After discussing how changes in the degree of banking competition and changes in monetary policy affect the calibrated economy, we assess how the two interact by repeating the exercise in the previous section with $\frac{1}{2} N \approx 12, N=23$ (baseline), and $2 N=46$. The purpose is to compare how the effectiveness of monetary policy changes when $N$ varies. Table 11 reports effects of an increase in $i^{R}$ while Table 12 reports effects of a decrease in $i^{R}$. In both tables, the results in the $N$ column are the changes relative to our baseline calibration, which we already reported in Table 10. The results in the $\frac{1}{2} N(2 N)$ column are the changes relative to an economy with $\frac{1}{2} N(2 N)$ but with the baseline interest on reserves (i.e., $1.4 \%$ ).

\begin{tabular}{lrrr}
\hline & \multicolumn{1}{c}{$\frac{1}{2} N$} & $N$ & $2 N$ \\
\hline \hline$W$ & $-0.40 \%$ & $-0.21 \%$ & $-0.25 \%$ \\
$L$ & $-1.00 \%$ & $-1.00 \%$ & $-1.00 \%$ \\
$D$ & unchanged & $+3.23 \%$ & $+3.23 \%$ \\
$i^{L}$ & $+0.89 \mathrm{pp}$ & $+0.92 \mathrm{pp}$ & $+0.94 \mathrm{pp}$ \\
$i^{D}$ & unchanged & $+0.99 \mathrm{pp}$ & $+0.99 \mathrm{pp}$ \\
$\Pi$ & $+26.48 \%$ & $+1.23 \%$ & $+1.21 \%$ \\
$\Psi$ & $-0.0014 \mathrm{pp}$ & $+0.0012 \mathrm{pp}$ & $+0.0316 \mathrm{pp}$ \\
Case transition & IIIB unchanged & IIB unchanged & IIB unchanged \\
\hline
\end{tabular}

Table 11: The effects of an increase in $i^{R}$ by 1 pp with different $N$. 


\begin{tabular}{lrrr}
\hline & $\frac{1}{2} N$ & $N$ & $2 N$ \\
\hline \hline$W$ & $+0.40 \%$ & $+0.40 \%$ & $+0.26 \%$ \\
$L$ & $+1.00 \%$ & $+1.00 \%$ & $+1.00 \%$ \\
$D$ & unchanged & $-0.19 \%$ & $-2.31 \%$ \\
$i^{L}$ & $-0.89 \mathrm{pp}$ & $-0.92 \mathrm{pp}$ & $-0.94 \mathrm{pp}$ \\
$i^{D}$ & unchanged & $-0.0574 \mathrm{pp}$ & $-0.72 \mathrm{pp}$ \\
$\Pi$ & $-26.46 \%$ & $-35.53 \%$ & $-20.77 \%$ \\
$\Psi$ & $+0.023 \mathrm{pp}$ & $+0.20 \mathrm{pp}$ & $+0.32 \mathrm{pp}$ \\
Case transition & IIIB unchanged & IIB to IIIB & IIB to IIIB \\
\hline
\end{tabular}

Table 12: The effects of a decrease in $i^{R}$ by 1 pp with different $N$.

From Tables 11 and 12, we can see how the pass-through to loan rates increases with $N$, which implies that the monetary authority gains stronger control over investment with higher banking competition. ${ }^{17}$ For the deposit rate, the analysis is complicated by the zero-lower bound. However, Table 11 shows that pass-through to deposit rates is already pretty complete in the baseline economy, and that a further increase in the number of banks does not increase it. On the other hand, fewer banks drive the economy closer to the zero-lower bound. Specifically, with $\frac{1}{2} N=12$ banks, even a $1 \mathrm{pp}$ increase in the policy rate is not enough to lift the deposit rate above zero, and interest rate cuts do (next to) nothing with $\frac{1}{2} N$ or $N$ banks, because the deposit rate is at zero or very close to zero. Thus, lower banking competition indirectly reduces pass-through to deposit rates, thereby reducing the central bank's control over inside money creation by bringing deposit rates closer to the zero-lower bound.

The effect of monetary policy on welfare appears to be non-monotone in $N$, which is due to two opposing effects. As discussed in the previous section, the effect of policy rate changes on welfare is particularly strong in equilibrium Case IIIB, because monetary policy only affects loan rates in this case. Since a lower $N$ makes it more likely that the economy is in Case IIIB, this effect leads to stronger welfare effects of monetary policy when $N$ is low. However, the increased pass-through with higher $N$ leads to larger reactions in the economy to policy changes and thus stronger welfare effects of monetary policy when $N$ is higher.

For profits per bank, the prior analysis has shown that they react much more strongly to interest rate changes in equilibrium Case IIIB than IIB. Since a lower number of banks makes it more likely that the economy is in Case IIIB, lower $N$ tends to make profits per bank more reactive to monetary policy.

Finally, for the probability of bank default, the analysis is further complicated by the fact that the probability of bank default changes non-monotonically with $i^{R}$. Perhaps most interesting in this regard is the effect of changes in the policy rate in the economy with $2 N$. We already know

\footnotetext{
${ }^{17}$ Interestingly, the relative change in loans made is the same in all three regimes, but note that the absolute change is larger with higher $N$, as higher $N$ increases loans made in the economy and thus the same relative change has to correspond to a larger absolute change.
} 
from Table 9 that doubling the degree of competition in the banking sector significantly increases the probability of bank default. Tables 11 and 12 now show that this increase cannot be undone by simultaneously changing the policy rate - instead, changing the policy rate in either direction leads to further increases in the probability of bank default. In particular, lowering the policy rate by $1 \mathrm{pp}$ with $2 N$ increases the probability of bank default to almost $0.8 \%$, compared to only $0.02 \%$ in our calibrated economy.

We can also measure the effectiveness of monetary policy by varying government bond supply or by targeting the level of excess reserves. To study the former, we increase the bond supply by $10 \%$, which corresponds to an open-market sale of assets by the central bank. We again repeat the exercise with $N, \frac{1}{2} N$, and $2 N$. Table 13 reports the results. ${ }^{18}$

\begin{tabular}{lrrr}
\hline & $\frac{1}{2} N$ & $N$ & $2 N$ \\
\hline \hline$i^{b}$ & $+1.40 \mathrm{pp}$ & $+0.55 \mathrm{pp}$ & $+0.098 \mathrm{pp}$ \\
$W$ & $-0.54 \%$ & $-0.12 \%$ & $-0.0239 \%$ \\
$L$ & $-1.41 \%$ & $-0.55 \%$ & $-0.098 \%$ \\
$D$ & $+0.34 \%$ & $+1.62 \%$ & $+0.29 \%$ \\
$i^{L}$ & $+1.25 \mathrm{pp}$ & $+0.51 \mathrm{pp}$ & $+0.092 \mathrm{pp}$ \\
$i^{D}$ & $+0.11 \mathrm{pp}$ & $+0.50 \mathrm{pp}$ & $+0.089 \mathrm{pp}$ \\
$\Pi$ & $+31.06 \%$ & $+0.56 \%$ & $+0.10 \%$ \\
$\Psi$ & $-0.0015 \mathrm{pp}$ & $+0.00087 \mathrm{pp}$ & $+0.0033 \mathrm{pp}$ \\
Case transition & IIIB to IIA & IIB to IIA & IIB to IIA \\
\hline
\end{tabular}

Table 13: The effects of an increase in $b$ by $10 \%$ with different $N$.

First, note that in all three scenarios, the economy transitions from a case where the reserve requirement does not bind to a case where it binds. This is necessary for open-market operations to have real effects, as we have shown in our theoretical analysis. Second, note that the effects of increasing $b$ on the bond interest rate vastly differ across the three economies. With $2 N$ banks, the bond interest rate increases by less than $0.1 \mathrm{pp}$, while it increases by $1.4 \mathrm{pp}$ with $\frac{1}{2} N$ banks. The effect on loans and loan rates also tends to be stronger with lower $N$. On the other hand, the effect on deposits shows no clear pattern as $N$ changes.

When the competition in the banking sector is high, banks also compete fiercely over available assets, so they are willing to hold the additional bonds even if they offer only a slightly higher return than the assets the banks already hold do. If banking competition is low, banks are more reluctant to change their balance sheet composition, and thus must be induced by much higher rates to hold the additional bonds. A similar story is going on with loans: With low banking competition and the high increase in the bond interest rate, banks reduce loans by a lot, which benefits them in two ways: First, they can get rid of the most risky loans as the loan rate increases and replace them with safe government bonds instead. Second, they earn more on their remaining loans as the loan

\footnotetext{
${ }^{18}$ We focus on open-market sales here because an open-market purchase of assets has no effect in equilibrium Case IIIB.
} 
rate goes up. With high banking competition, banks do not take the marginal effect on the loan rate into account in the same extent, and thus are much less willing to reduce loans made.

In principle, banks are also more willing to raise additional liabilities in order to finance the purchase of the additional bonds when banking competition is fierce, whereas they are much more wary of doing so when there is less competition, as raising more deposits increases the deposit rate and thus also the cost of liabilities for banks. However, in equilibrium Cases IIB and IIIB, the first margin banks adjust as a reaction to the increase in bonds are their excess reserve holdings, as bonds and reserves are perfect substitutes whenever the reserve requirement does not bind. Since banks hold more excess reserves when banking competition is stronger, the amount of deposits made by banks starts reacting to the increase in bonds at a later point, which explains why the increase in deposits is smallest under $2 N .^{19}$

\subsection{Changes in the Reserve Requirement}

Before concluding the paper, we highlight how changing the reserve requirement $\delta$ affects the probability of bank failure $\Psi$ and bank profits $\Pi$ in our calibration. As we discussed in Section 5.4, increasing the reserve requirement has ambiguous effects on these variables in equilibrium Cases IIA and IIIA. The result that increasing the reserve requirement does not always make bank default less likely may seem counter-intuitive, as the reserve requirement is a policy instrument which is typically used in order to make banks safer. Figure 8 shows how changing $\delta$ affects the probability of bank failure in our calibration and shows that increasing $\delta$ does indeed lead to a higher probability of bank default once it is set high enough to move the economy into Case IIA.

Perhaps even more surprisingly, profits per bank are also increasing in $\delta$ in our calibration, as can be seen in Figure 9. This seems counter-intuitive, since banks could always hold more reserves if that allows them to increase profits. However, forcing all banks to hold more reserves is different from banks holding more reserves voluntarily, because it has effects on other assets, namely government bonds. When banks are forced to hold more reserves, their demand for bonds decreases. Since the amount of bonds available for banks to hold is independent of their demand, this leads to an increase in the bond interest rate. Thus, $\Pi$ increases in $\delta$ because the positive externality from the higher bond rate dominates the cost of holding more reserves. ${ }^{20}$

\footnotetext{
${ }^{19}$ Note that the different results from the experiments on interest on reserves and open-market operations are not due to the policy we study, but to the way we design the experiments. I.e., we could design the experiment such that we study an open-market sale of assets that leads to a $1 \mathrm{pp}$ increase in $i^{B}$ for all $N$ we study, and then the results would be the same as in our interest on reserves experiment. To put this differently, it does not matter which policy tool the central bank uses, but just whether an interest rate or an asset quantity is targeted. We think that both results are interesting and that the interest rate target is somewhat more natural with interest on reserves, while the asset quantity target can be more naturally studied with open-market operations (understanding that when central banks use open-market operations in practice, they typically also follow an interest rate target).

${ }^{20}$ It is important to note that this analysis assumes passive monetary policy. If the monetary authority simultaneously enacts open-market operations to keep the bond interest rate constant, the positive externality will vanish.
} 


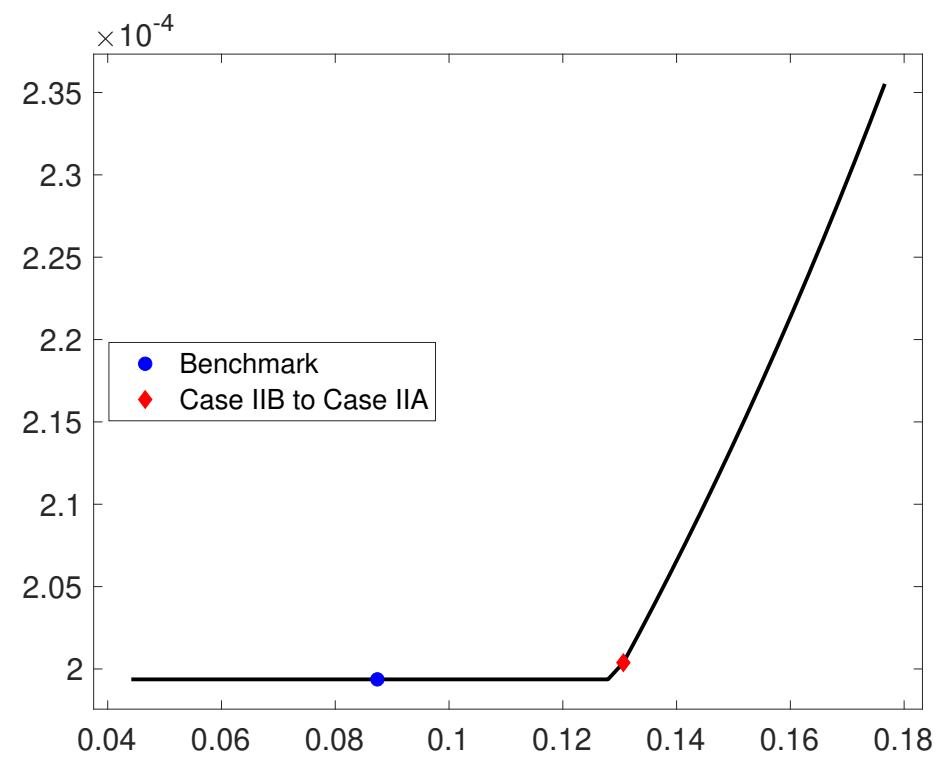

Figure 8: Effects of $\delta$ on Bank Default Probability

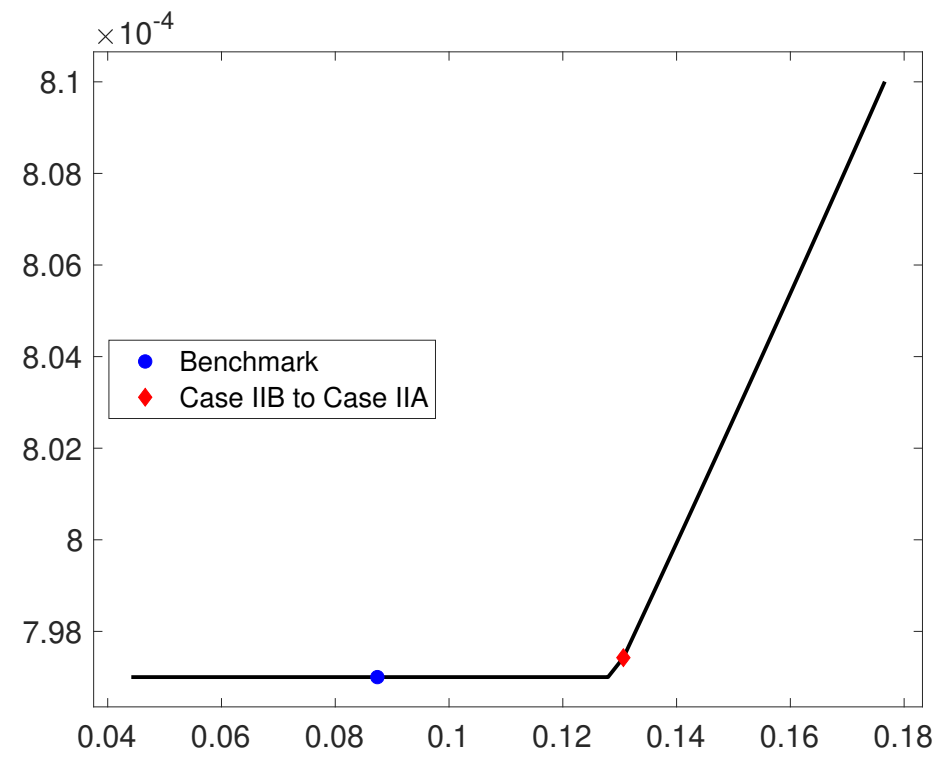

Figure 9: Effects of $\delta$ on Bank Profit

For a graphical analysis of how changes in $\delta$ and in the capital requirement $\gamma$ affect other equilibrium outcomes, see Appendix A.

\section{Conclusion}

We build a dynamic general equilibrium model with oligopolistic banking competition and risky investment to study how these features affect the transmission of monetary policy to the real economy. We show that including these characteristics of developed economies is relevant to 
understand how policymakers can affect the real economy. Our model entails three equilibrium cases: One where banks are indifferent between raising deposits and sweat equity, one where the deposit rate is strictly positive, but the marginal cost of deposits is strictly below the marginal cost of equity, and one where the nominal deposit rate is equal to zero. The latter two can be further distinguished depending on whether the reserve requirement does or does not bind. The theoretical effects of changing the number of banks in the economy, the supply of bonds, the interest rate on reserves, the reserve requirement, and the capital requirement on macroeconomic variables differ among these cases, and some of them are ambiguous even within cases. The calibration of our model to the U.S. economy during 2016-2019 shows that welfare could have been improved by either increasing competition in the banking sector or reducing the policy rate, but only at the cost of significantly increasing the probability of bank default. We also document that bank profits are increasing in the policy rate, with the effect being particularly strong close to the zero-lower bound, and that interest rate pass-through of monetary policy is incomplete under imperfect competition. 


\section{References}

Allen, F. and D. Gale (2004a). Competition and financial stability. Journal of Money, Credit and Banking 36(3), 453-480.

Allen, F. and D. Gale (2004b). Financial intermediaries and markets. Econometrica 72(4), 10231061.

Altermatt, L. (2019). Inside money, investment, and unconventional monetary policy. University of Zurich, Department of Economics Working Paper No. 247.

Andolfatto, D., A. Berentsen, and F. Martin (2019). Money, banking and financial markets. Review of Economic Studies, forthcoming.

Aït Lahcen, M. and P. Gomis-Porqueras (2021). A model of endogenous financial inclusion: Implications for inequality and monetary policy. Journal of Money, Credit and Banking.

Berentsen, A., G. Camera, and C. Waller (2007). Money, credit and banking. Journal of Economic Theory 135 (1), 171-195.

Bianchi, J. and S. Bigio (2017). Banks, liquidity management and monetary policy. NBER Working Paper 20490.

Boyd, J. H. and G. De Nicolo (2005). The theory of bank risk taking and competition revisited. The Journal of Finance 60(3), 1329-1343.

Burdett, K. and K. L. Judd (1983). Equilibrium price dispersion. Econometrica 51 (4), 955-969.

Chiu, J., S. M. Davoodalhosseini, J. H. Jiang, and Y. Zhu (2019). Central bank digital currency and banking. mimeo.

Corbae, D. and P. D'Erasmo (2021). Capital buffers in a quantitative model of banking industry dynamics. Econometrica 8.

Curdia, V. and M. Woodford (2009). Conventional and unconventional monetary policy. Federal Reserve Bank of New York Staff Report no. 404.

Diamond, D. (1997). Liquidity, banks, and markets. Journal of Political Economy 105(5), 928-956.

Diamond, D. W. (1984). Financial intermediation and delegated monitoring. The Review of Economic Studies 51(3), 393-414.

Dong, M., S. Huangfu, H. Sun, and C. Zhou (2017). A macroeconomic theory of banking oligopoly. mimeo.

Drechsler, I., A. Savov, and P. Schnabl (2017). The deposits channel of monetary policy. The Quarterly Journal of Economics 132(4), 1819-1876.

Gertler, M. and P. Karadi (2011). A model of unconventional monetary policy. Journal of Monetary Economics 58, 17-34.

Gertler, M. and N. Kiyotaki (2015). Banking, liquidity, and bank runs in an infinite horizon economy. American Economic Review 105(7), 2011-2043.

Gertler, M., N. Kiyotaki, and A. Queralto (2012). Financial crises, bank risk exposure and 
government financial policy. Journal of Monetary Economics 59, S17-S34. Supplement.

Gu, C., F. Mattesini, C. Monnet, and R. Wright (2013). Banking: A new monetarist approach. The Review of Economic Studies 80(2), 636-662.

Gu, C., C. Monnet, E. Nosal, and R. Wright (2019). On the instability of banking and financial intermediation. University of Missouri WP1901.

He, P., L. Huang, and R. Wright (2008). Money, banking, and monetary policy. Journal of Monetary Economics 55, 1013-1024.

Head, A., T. Kam, I.-M. Ng, and I. Paan (2021). Money, credit and imperfect competition among banks. mimeo.

Hellmann, T. F., K. C. Murdock, and J. E. Stiglitz (2000). Liberalization, moral hazard in banking, and prudential regulation: Are capital requirements enough? American Economic Review 90(1), $147-165$.

Imhof, S., C. Monnet, and S. Zhang (2018). The risk-taking channel of liquidity regulations and monetary policy. mimeo.

Kashyap, A., D. Tsomocos, and A. Vardoulakis (2020). Optimal bank regulation in the presence of credit and run-risk. NBER Working Paper 26689.

Keeley, M. C. (1990). Deposit insurance, risk, and market power in banking. American Economic Review, 1183-1200.

Keister, T. and D. Sanches (2019). Should central banks issue digital currency? Federal Reserve Bank of Philadelphia Working Paper 19-26.

Lagos, R. and R. Wright (2005). A unified framework for monetary theory and policy analysis. Journal of Political Economy 113(3), 463-484.

Marshall, D. and E. Prescott (2001). Bank capital regulation with and without state-contingent penalties. Carnegie-Rochester Conference Series on Public Policy 54(1), 139-184.

Martinez-Miera, D. and R. Repullo (2010). Does competition reduce the risk of bank failure? The Review of Financial Studies 23(10), 3638-3664.

Repullo, R. (2004). Capital requirements, market power, and risk-taking in banking. Journal of financial Intermediation 13(2), 156-182.

Rocheteau, G. and R. Wright (2005). Money in search equilibrium, in competitive equilibrium, and in competitive search equilibrium. Econometrica 73(1), 175-202.

Rocheteau, G., R. Wright, and C. Zhang (2018). Corporate finance and monetary policy. American Economic Review 108(4-5), 1147-86.

Williamson, S. D. (1986). Costly monitoring, financial intermediation, and equilibrium credit rationing. Journal of Monetary Economics 18(2), 159-179.

Williamson, S. D. (2012). Liquidity, monetary policy, and the financial crisis: A new monetarist approach. American Economic Review 102(6), 2570-2605. 


\section{Appendix A Additional Quantitative Results}

\begin{tabular}{|c|c|c|c|}
\hline & $\frac{1}{2} N$ & $N$ & $2 N$ \\
\hline$\overline{b^{B}}$ & $+9.25 \%(+0.039)$ & $+12.34 \%(+0.052)$ & $+14.81 \%(+0.0625)$ \\
\hline$W$ & $-0.40 \%$ & $-0.23 \%$ & $-0.27 \%$ \\
\hline$L$ & $-1.00 \%$ & $-1.00 \%$ & $-1.00 \%$ \\
\hline$D$ & unchanged & $+2.94 \%$ & $+2.94 \%$ \\
\hline$i^{L}$ & $+0.89 \mathrm{pp}$ & $+0.92 \mathrm{pp}$ & $+0.94 \mathrm{pp}$ \\
\hline$i^{D}$ & unchanged & $+0.90 \mathrm{pp}$ & $+0.91 \mathrm{pp}$ \\
\hline$\Pi$ & $+24.03 \%$ & $+1.03 \%$ & $+1.01 \%$ \\
\hline$\Psi$ & $-0.0014 \mathrm{pp}$ & $+0.0016 \mathrm{pp}$ & $+0.0345 \mathrm{pp}$ \\
\hline Case transition & IIIB to IIIA & IIB to IIA & IIB to IIA \\
\hline
\end{tabular}

Table 14: The effects of an increase in $i^{b}$ by 1 pp with different $N$.

Instead of increasing the policy rate by increasing the interest rate on reserves $i^{R}$, the monetary authority could also conduct open-market operations such that the policy rate increases by $1 \mathrm{pp}$. Table 14 shows the effect of this policy with different $N$. By comparing these results with those in Table 11, we can determine to which extent it matters whether the monetary authority uses open-market operations or the interest rate on reserves to increase the policy rate by $1 \mathrm{pp}$. For loans, loan rates, and the probability of default by entrepreneurs, it does not matter which rate is increased by $1 \mathrm{pp}$, as the economy reacts in exactly the same way. For deposits, deposit rates, bank profits, and the probability of bank default, it matters slightly, because increasing the interest rate on reserves implies $i^{R}=i^{b}$ continues to hold as the bond interest rate increases endogenously and thus banks earn this (marginal) return on all their assets. Meanwhile, increasing the bond rate through open-market operations while keeping the interest rate on reserves constant implies $i^{b}>i^{R}$, which in turn makes the reserve requirement bind, and implies that banks earn a lower marginal return on their required reserves than on their remaining assets, which lowers their profits and their willingness to issue deposits. The most interesting result from 14 however is that the size of the open-market operation that is required to engineer an increase in $i^{b}$ by $1 \mathrm{pp}$ is strongly increasing with $N$.

Figures 10-14 show how changes in $N, i^{R}, b, \delta$, and $\gamma$ affect loan rates, deposit rates, nominal bond rates, loans, deposits, aggregate welfare, the probability of bank failure, and profits per bank in our calibration. We highlighted some of these in the main text, but we also want to report the others here for completeness. 
Nominal loan rate $i^{L}$
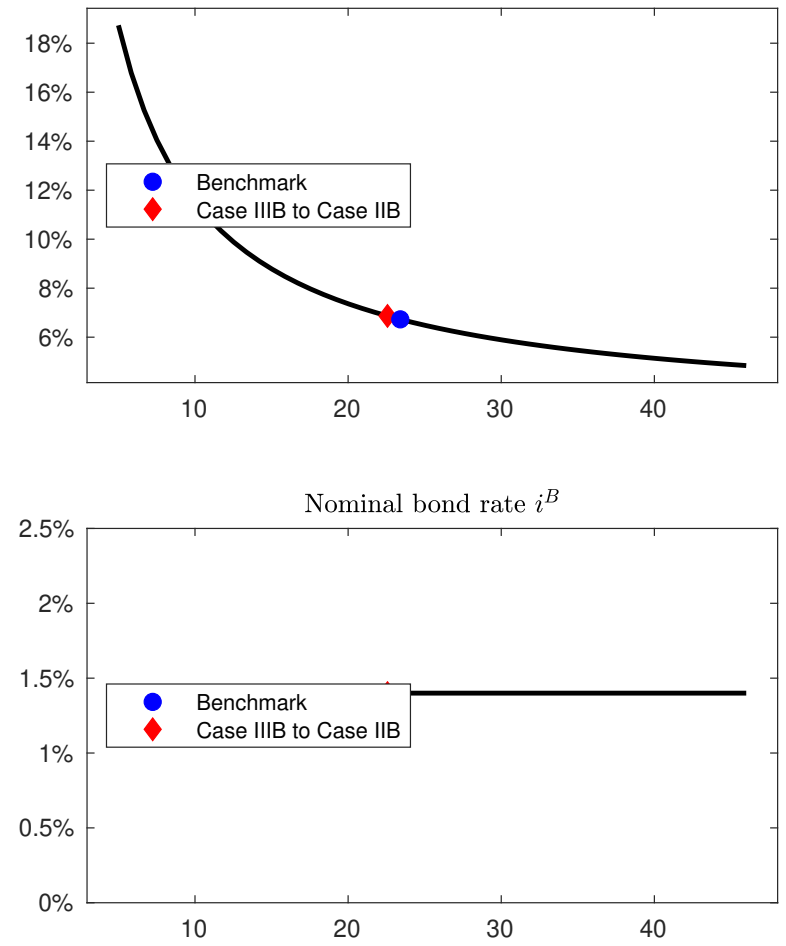

Deposits $D$
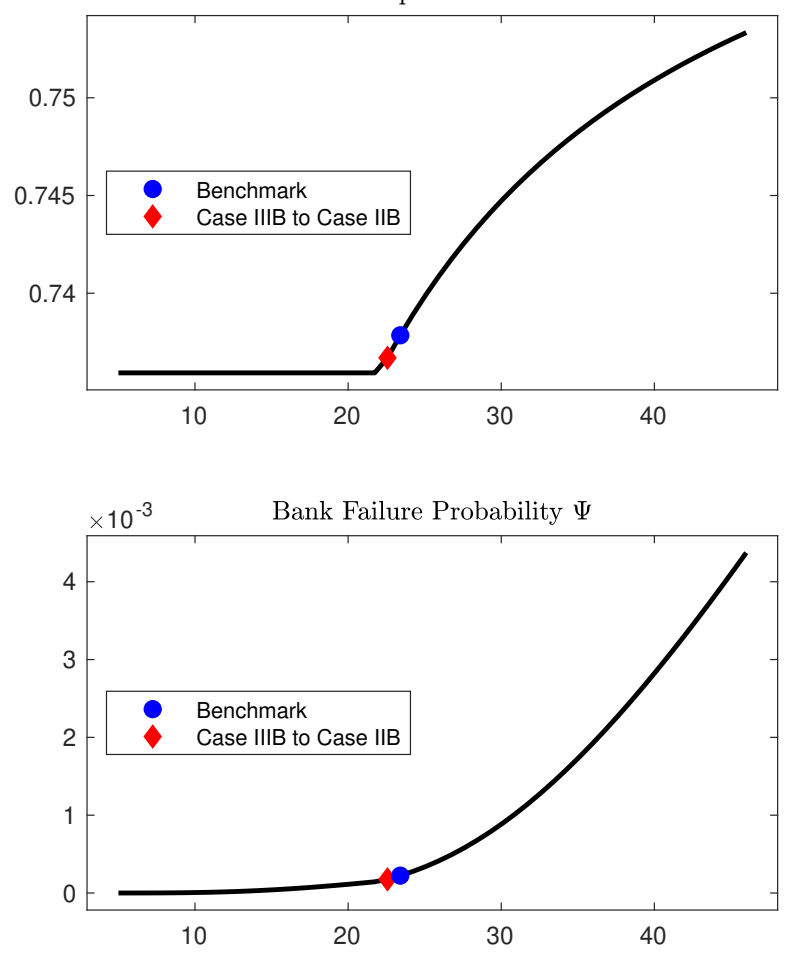

Nominal deposit rate $i^{D}$

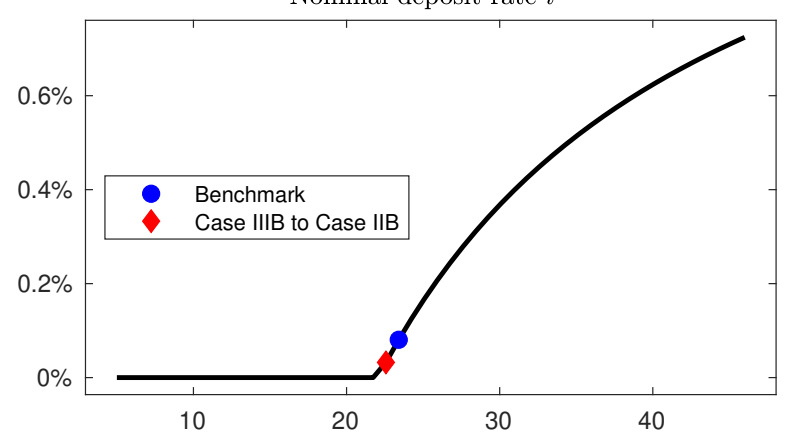

Loans $L$

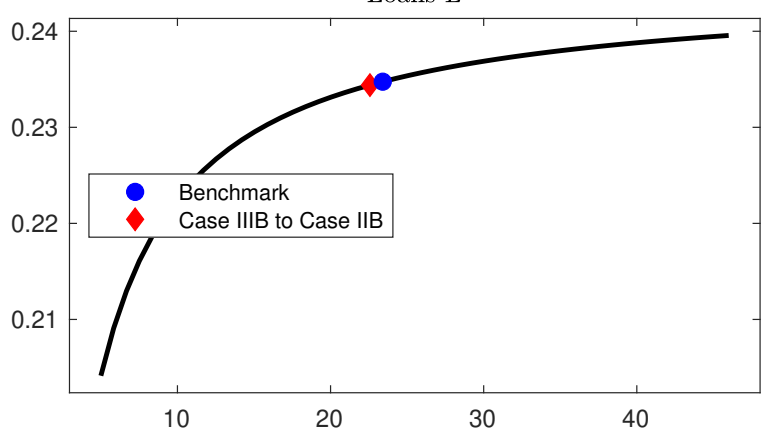

Aggregate welfare $W$

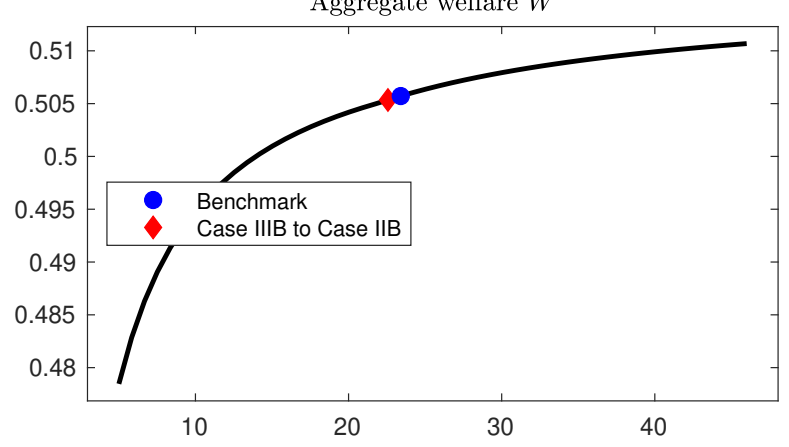

Bank Profit $\Pi$

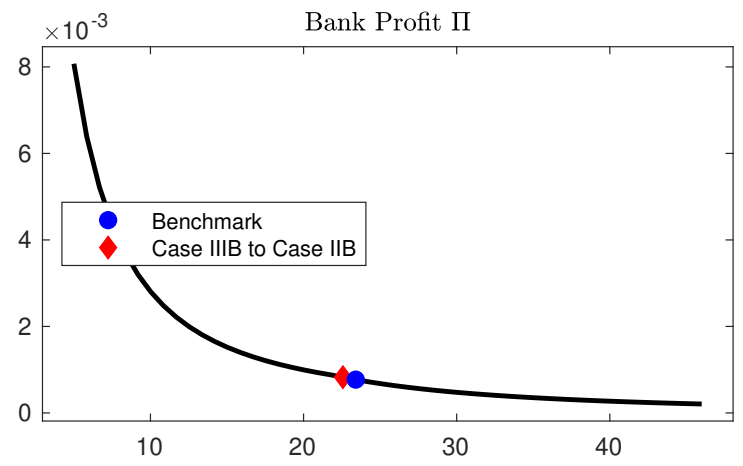

Figure 10: Effects of $N$ 

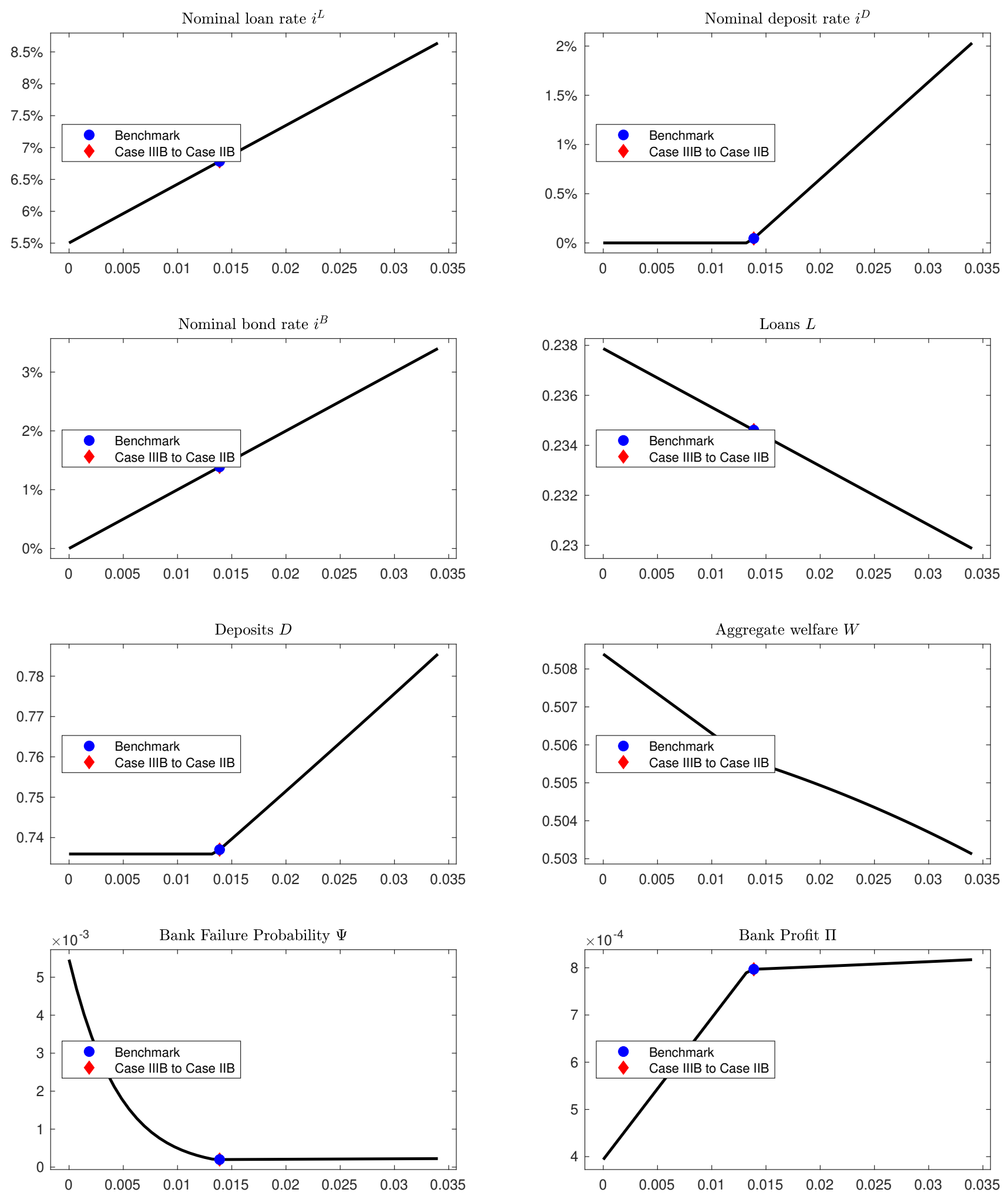

Figure 11: Effects of $i^{R}$ 

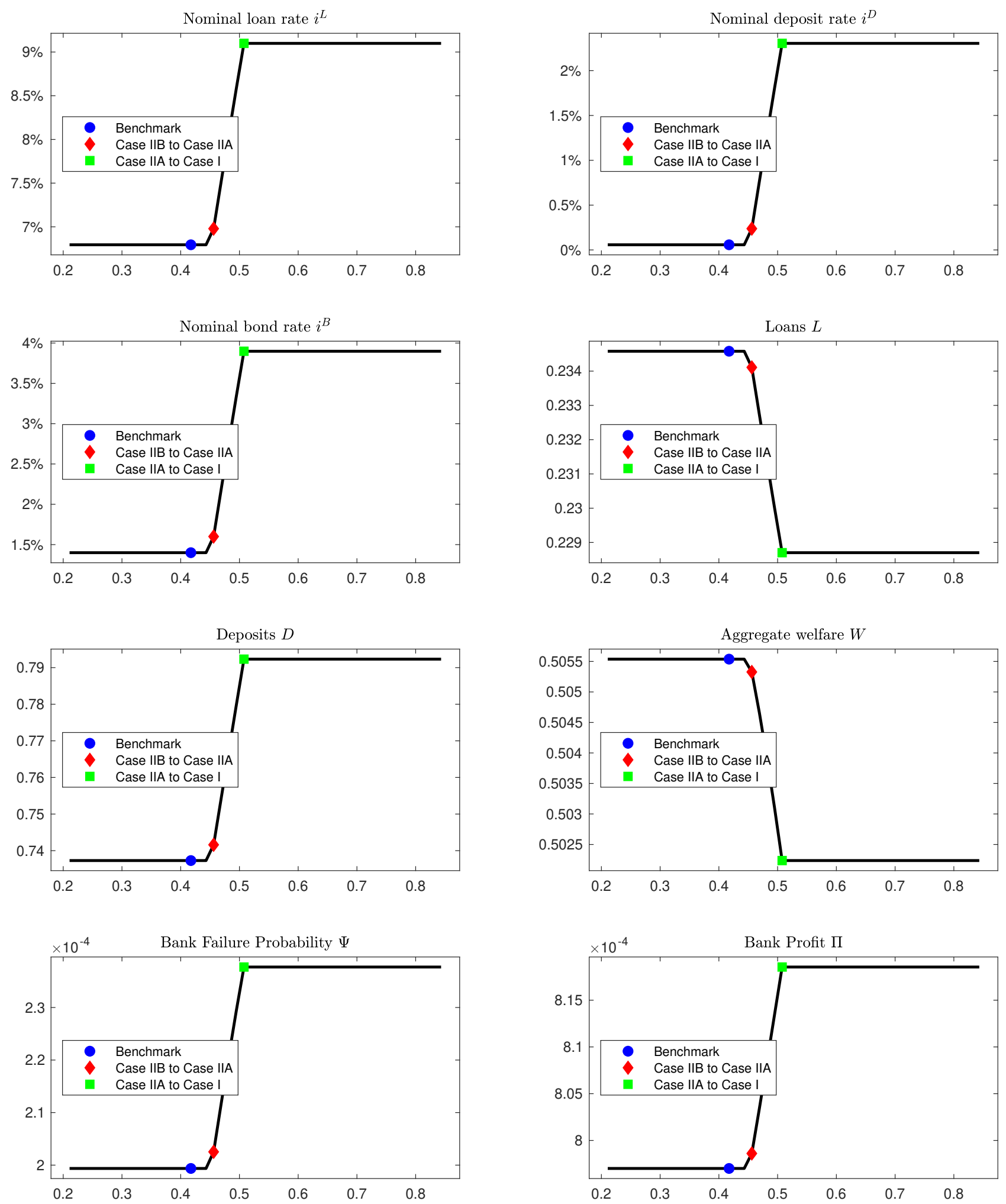

Figure 12: Effects of $b$ 

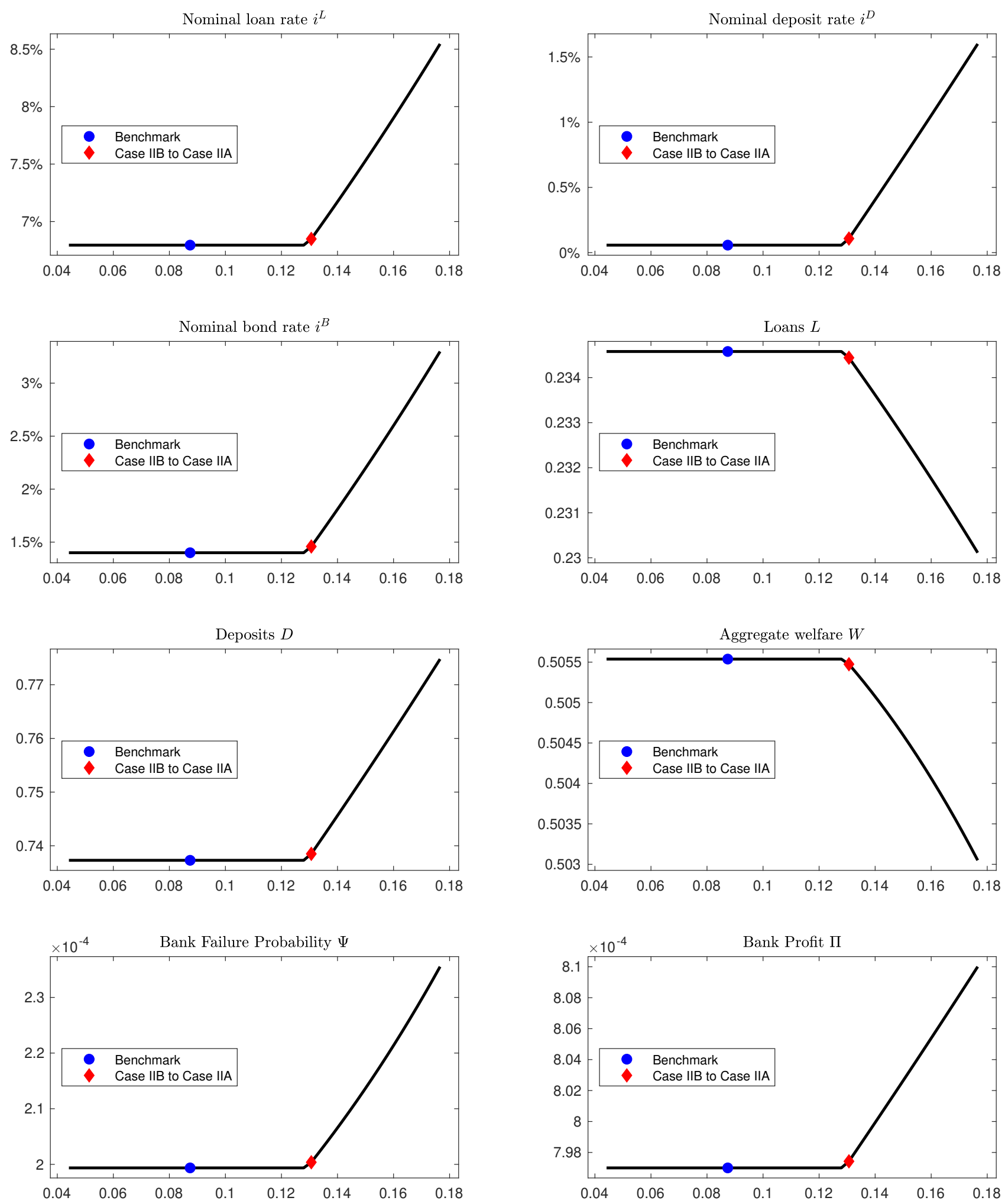

Figure 13: Effects of $\delta$ 

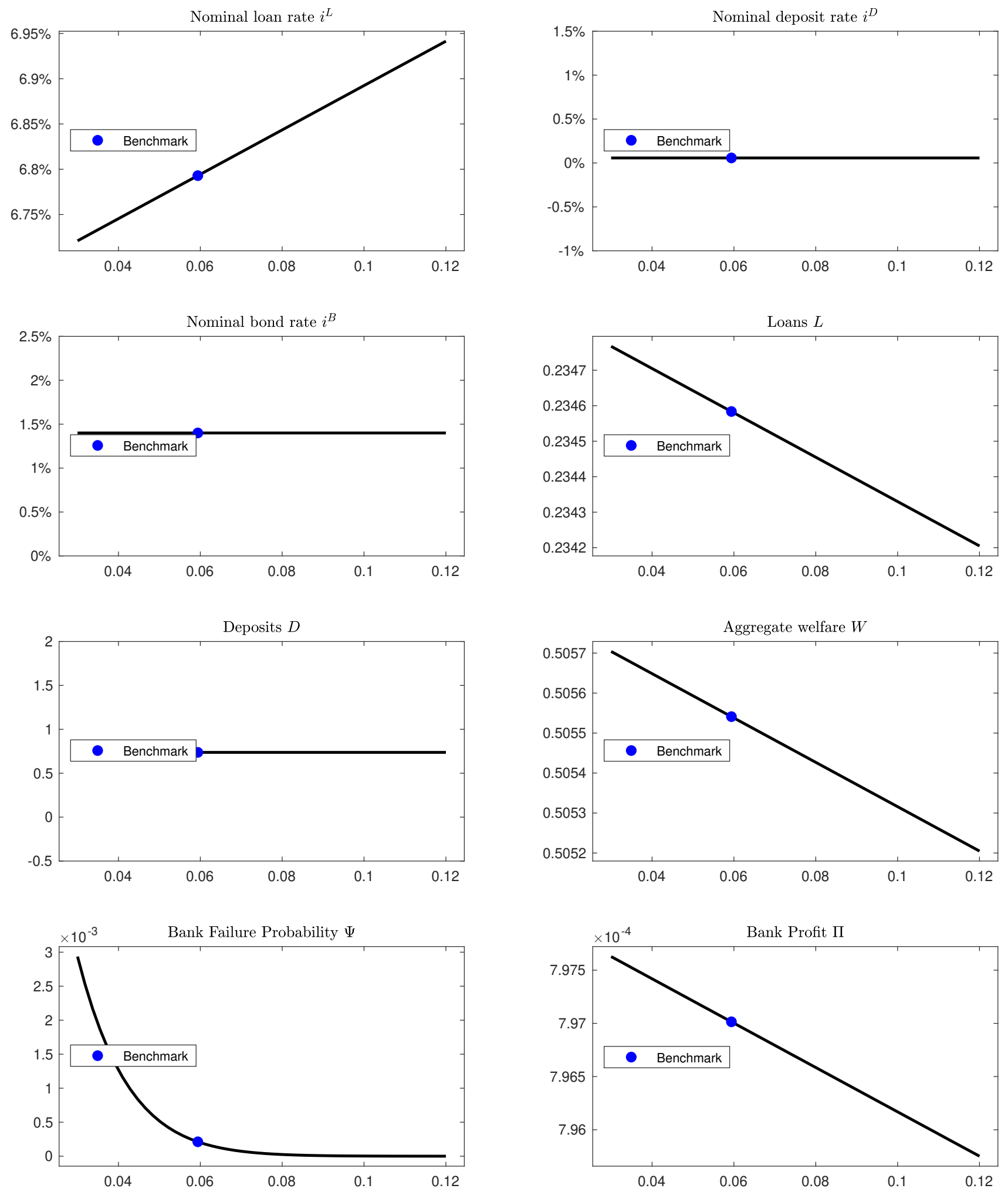

Figure 14: Effects of $\gamma$ 


\section{Appendix B Proofs}

\section{B.1 Proofs for Section 4}

Proof of Proposition 4.1: It is easy to see that if $H^{\prime}(L)<0$ and $H^{\prime \prime}(L)<0$ for all $L \in[0, S]$ and $r^{D^{\prime}}(D)>0$ and $r^{D \prime \prime}(D) \geq 0$ for all $D \geq 0$, then in all five cases (Case I, IIA, IIB, IIIA, and IIIB), there is a unique solution to bank's problem as long as such a solution exists. We need only show that for any given parameter values, there is one and only one case that can exist in equilibrium.

First, suppose the parameter values are such that Case I exists and denote the equilibrium $L$ and $D$ as $L^{I}$ and $D^{I}$. Now, consider Case IIA. If we plug in $L^{I}$ and $D=\left((1-\gamma) L^{I}+b\right) /(1-\delta)$ into (4.3), we have

$$
r^{D}(D)+\frac{D}{N} r^{D \prime}(D)>\frac{1-\delta}{\beta}+\frac{\delta\left(1+i^{R}\right)}{1+\mu},
$$

which means $L$ must be smaller to satisfy (4.3). Then, we have $\frac{L}{N} H^{\prime}(L)+H(L)>\frac{1}{\beta}$, which cannot happen in equilibrium because banks would have raised more equity and lend more to entrepreneurs. In other words, Case IIA cannot exist. Next, consider Case IIB. If it exists, because

$$
\frac{(1-\gamma)\left(1+i^{R}\right)}{1+\mu}+\frac{\gamma}{\beta}<\frac{1}{\beta} \quad \text { and } \quad \frac{1-\delta}{\beta}+\frac{\delta\left(1+i^{R}\right)}{1+\mu}>\frac{1+i^{R}}{1+\mu}
$$

we have $L^{I I B}>L^{I}$ and $D^{I I B}<D^{I}$. Since $b^{B} \leq(1-\delta) D-(1-\gamma) L, L^{I I B}>L^{I}$ and $D^{I I B}<D^{I}$ mean that banks hold fewer government bonds, a contradiction. Finally, consider Cases IIIA and IIIB. In the first case, the existence of a solution would imply that $L$ is smaller, which means $\frac{L}{N} H^{\prime}(L)+H(L)>\frac{1}{\beta}$. In the second case, the existence of a solution would imply that $b^{B}$ is smaller, a contradiction.

Second, suppose the parameter values are such that Case IIA exists. By the above arguments, Case I cannot exist. Note also that in Case IIA, we have

$$
r^{D}(D)+\frac{D}{N} r^{D^{\prime}}(D)=(1-\delta) r^{B}+\frac{\delta\left(1+i^{R}\right)}{1+\mu}>\frac{1+i^{R}}{1+\mu}
$$

and

$$
\frac{1}{1-\gamma}\left[\frac{L}{N} H^{\prime}(L)+H(L)\right]>\frac{1+i^{R}}{1+\mu}+\frac{\gamma}{(1-\gamma) \beta} .
$$

If Case IIB exists, then $D$ will be smaller but $L$ will be larger. This means $b^{B}$ must be smaller, a contradiction. Similarly, Case IIIB cannot exist. Finally, if Case IIIA exists, then because Case IIA exists by assumption, banks could have increased their profits by increasing $D$ and $L$, a contradiction.

Third, suppose the parameter values are such that Case IIB exists. By the above arguments, Case I and IIA cannot exist. If Case IIIB exists, because $r^{D}(D)=\frac{1}{1+\mu}$, it must be that

$$
r^{D}(D)+\frac{D}{N} r^{D^{\prime}}(D)<\frac{1+i^{R}}{1+\mu} .
$$

Then banks could have increased their profits by increasing $D$ and investing it into reserves, a contradiction. If Case IIIA exists, then banks could also have increased their profits by increasing $D$ and investing it into reserves.

Finally, suppose the parameter values are such that Case IIIA exists. By the above arguments, Case I, IIA, and IIB cannot exist. Note that in Case IIIA,

$$
r^{B}=\frac{1}{1-\gamma}\left[\frac{L}{N} H^{\prime}(L)+H(L)\right]-\frac{\gamma}{(1-\gamma) \beta}>\frac{1+i^{R}}{1+\mu}
$$

If Case IIIB exists, then $L$ would be larger so $b^{B}$ would have been smaller, a contradiction. This also means that if Case IIIB exists, none of the other cases can exist. Hence, if there exists an equilibrium, then it is unique. 


\section{B.2 Proofs for Section 5}

Before we prove Proposition 5.1 to 5.4, we prove the following lemma that will be useful later. Define $H(L, s)=r^{L}(L)\left[1-P\left(r^{L}(L), s\right)\right]$.

Lemma B.1 Assume there exists a random variable $Z$ such that $\left|H_{L}(L, s)\right| \leq Z$ a.s. for all $L$ and that $\mathbb{E}(Z)<\infty$. Then $H^{\prime}(L)=\mathbb{E}\left[H_{L}(L, s)\right]$, where the expectation is taken over $s$.

Proof: Note that

$$
H^{\prime}(L)=\lim _{t \rightarrow 0} \frac{H(L+t)-H(L)}{t}=\lim _{t \rightarrow 0} \mathbb{E}\left[\frac{H_{L}(L+t, s)-H_{L}(L, s)}{t}\right]=\lim _{t \rightarrow 0} \mathbb{E}\left[H_{L}(h(t), s)\right],
$$

where $h(t) \in(L, L+t)$ exists because of the Mean Value Theorem. Since $\left|H_{L}(L, s)\right| \leq Z$ a.s. for all $L$, then by the Dominated Convergence Theorem, we have

$$
H^{\prime}(L)=\lim _{t \rightarrow 0} \mathbb{E}\left[H_{L}(h(t), s)\right]=\mathbb{E}\left[H_{L}(L, s)\right]
$$

which is the desired result.

Proof of Proposition 5.1: We consider the effects of increasing $N$ to $N+1$ in all five cases.

\section{Case I}

In this case, the FOCs are

$$
\frac{L}{N+1} H^{\prime}(L)+H(L)=\frac{1}{\beta}
$$

and

$$
r^{D}(D)+\frac{D}{N+1} r^{D^{\prime}}(D)=\frac{1-\delta}{\beta}+\frac{\delta\left(1+i^{R}\right)}{1+\mu} .
$$

Because $H^{\prime}(L)<0$ and $r^{D^{\prime}}(D)>0$, the left-hand side of (B.9) will be larger, while the left-hand side of (B.10) will be smaller than before. Hence, $L$ and $D$ must increase. Since $r^{B}=1 / \beta$, it is unaffected by the increase in $N$.

Bank profit is given by

$$
-\frac{E}{N+1}+\beta\left[\frac{L}{N+1} r^{L}(L)\left[1-P\left(r^{L}(L)\right)\right]+\frac{z^{B}}{N+1} \frac{1+i^{R}}{1+\mu}+\frac{b^{B}}{N+1} \frac{1}{\beta}-\frac{D}{N+1} r^{D}(D)\right] .
$$

If bank profit is equal to or larger than before, then one bank could have deviated and increase the loans and deposits it issues when there were $N$ banks. This will give the deviating bank a strictly higher profit, a contradiction.

\section{Case IIA}

In this case, we have $D=((1-\gamma) L+b) /(1-\delta)$ and

$$
\frac{L}{N+1} H^{\prime}(L)+H(L)+\frac{(1-\gamma) \delta\left(1+i^{R}\right)}{(1-\delta)(1+\mu)}=\frac{1-\gamma}{1-\delta}\left[r^{D}(D)+\frac{D}{N+1} r^{D^{\prime}}(D)\right]+\frac{\gamma}{\beta} .
$$

If the number of banks increases to $N+1$, the left-hand side will increase while the right-hand side will decrease. Hence, $L$ must increase, which means $D$ will increase as well. Note that $r^{B}$ is given by

$$
r^{B}=\frac{1}{1-\gamma}\left[\frac{L}{N+1} H^{\prime}(L)+H(L)\right]-\frac{\gamma}{(1-\gamma) \beta},
$$

so (B.12) can be rewritten as

$$
r^{D}(D)+\frac{D}{N+1} r^{D^{\prime}}(D)=(1-\delta) r^{B}+\frac{\delta\left(1+i^{R}\right)}{1+\mu} .
$$


Since the left-hand side may increase or decrease compared to the benchmark, $r^{B}$ may decrease, increase, or remain unchanged. If $r^{B}$ decreases or remains the same, then bank profit will be lower.

Finally, consider bank default probability $1-G(\hat{s})$. Note that $\hat{s}$ is given by

$$
D r^{D}(D)=\int_{\hat{s}}^{\bar{s}} L H(L, s) \mathrm{d} G(s)+G(\hat{s}) L H(L, \hat{s})+\frac{\left(1+i^{R}\right) \delta D}{1+\mu}+b r^{B} .
$$

Take total derivative to get

$$
\begin{aligned}
& {\left[D \hat{r}^{D^{\prime}}(D)+\hat{r}^{D}(D)-\frac{\left(1+i^{R}\right) \delta}{1+\mu}\right] \mathrm{d} D-\frac{b}{1-\gamma}\left[\frac{H^{\prime}(L)}{N}+\frac{L}{N} H^{\prime \prime}(L)+H^{\prime}(L)\right] \mathrm{d} L} \\
& =G(\hat{s}) L H_{s}(L, \hat{s}) \mathrm{d} \hat{s}+\left\{\int_{\hat{s}}^{\bar{s}}\left[L H_{L}(L, s)+H(L, s)\right] \mathrm{d} G(s)+G(\hat{s})\left[L H_{L}(L, \hat{s})+H(L, \hat{s})\right]\right\} \mathrm{d} L .
\end{aligned}
$$

Note that $D \hat{r}^{D^{\prime}}(D)+\hat{r}^{D}(D)-\frac{\left(1+i^{R}\right) \delta}{1+\mu}>0$ and $\frac{H^{\prime}(L)}{N}+\frac{L}{N} H^{\prime \prime}(L)+H^{\prime}(L)<0$. In addition, by Lemma B.1 we have

$\int_{\hat{s}}^{\bar{s}}\left[L H_{L}(L, s)+H(L, s)\right] \mathrm{d} G(s)+G(\hat{s})\left[L H_{L}(L, \hat{s})+H(L, \hat{s})\right]<\mathbb{E}\left[L H^{\prime}(L, s)+H(L, s)\right]=L H^{\prime}(L)+H(L)<0$, Hence, default probability will increase.

\section{Case IIB}

In this case, the FOCs are

$$
r^{D}(D)+\frac{D}{N+1} r^{D^{\prime}}(D)=\frac{1+i^{R}}{1+\mu}
$$

and

$$
\frac{1}{1-\gamma}\left[\frac{L}{N+1} H^{\prime}(L)+H(L)\right]=\frac{1+i^{R}}{1+\mu}+\frac{\gamma}{(1-\gamma) \beta} .
$$

Similar to Case I, $L$ and $D$ must increase. Since $r^{B}=\frac{1+i^{R}}{1+\mu}$, government bond rate is unaffected by the increase in $N$.

Bank profit is given by

$$
-\frac{E}{N+1}+\beta\left[\frac{L}{N+1} r^{L}(L)\left[1-P\left(r^{L}(L)\right)\right]+\frac{z^{B}}{N+1} \frac{1+i^{R}}{1+\mu}+\frac{b}{N+1} \frac{1+i^{R}}{1+\mu}-\frac{D}{N+1} r^{D}(D)\right] .
$$

Again, similar to Case I, if bank profit is equal to or larger than before, then one bank could have deviated and increase the loans and deposits it issues when there were $N$ banks. This will give the deviating bank a strictly higher profit, a contradiction.

Finally, consider bank default probability $1-G(\hat{s})$. Note that $\hat{s}$ is given by

$$
D r^{D}(D)=\int_{\hat{s}}^{\bar{s}} L H(L, s) \mathrm{d} G(s)+G(\hat{s}) L H(L, \hat{s})+\frac{\left(1+i^{R}\right)(D-(1-\gamma) L)}{1+\mu} .
$$

Take total derivative to get

$$
\begin{aligned}
& {\left[D \hat{r}^{D^{\prime}}(D)+\hat{r}^{D}(D)-\frac{1+i^{R}}{1+\mu}\right] \mathrm{d} D+\frac{\left(1+i^{R}\right)(1-\gamma)}{1+\mu} \mathrm{d} L} \\
& =G(\hat{s}) L H_{s}(L, \hat{s}) \mathrm{d} \hat{s}+\left\{\int_{\hat{s}}^{\bar{s}}\left[L H_{L}(L, s)+H(L, s)\right] \mathrm{d} G(s)+G(\hat{s})\left[L H_{L}(L, \hat{s})+H(L, \hat{s})\right]\right\} \mathrm{d} L .
\end{aligned}
$$

Note that $D \hat{r}^{D \prime}(D)+\hat{r}^{D}(D)-\frac{1+i^{R}}{1+\mu}>0$. In addition, by Lemma B.1 we have

$\int_{\hat{s}}^{\bar{s}}\left[L H_{L}(L, s)+H(L, s)\right] \mathrm{d} G(s)+G(\hat{s})\left[L H_{L}(L, \hat{s})+H(L, \hat{s})\right]<\mathbb{E}\left[L H^{\prime}(L, s)+H(L, s)\right]=L H^{\prime}(L)+H(L)<0$,

Hence, default probability will increase. 


\section{Case IIIA}

In this case, we have $(1-\gamma) L=(1-\delta) D^{\prime}-b$, and

$$
D^{\prime}=\eta\left(u^{\prime}\right)^{-1}\left(\frac{1+\mu}{\beta}\right)(1+\mu) \text {. }
$$

Then increasing the number of banks to $N+1$ has no effect on $L$ or $D$. Since $r^{B}$ is given by

$$
r^{B}=\frac{1}{1-\gamma}\left[\frac{L}{N+1} H^{\prime}(L)+H(L)\right]-\frac{\gamma}{(1-\gamma) \beta},
$$

it will increase following the increase in $N$.

Next, consider bank profit. Note that the bond rate when there are $N$ banks is $\frac{L}{N} H^{\prime}(L)+H(L)-\frac{\gamma}{\beta}$, and bond holding per bank is $b / N$. With $N+1$ banks, bond holding per bank becomes $b /(N+1)$. Now, suppose

$$
\begin{aligned}
& \frac{N+1}{N}\left\{\frac{L}{N} H^{\prime}(L)+H(L)-\frac{\gamma}{\beta}\right\}-\left[\frac{L}{N+1} H^{\prime}(L)+H(L)-\frac{\gamma}{\beta}\right] \\
= & \frac{1}{N}\left\{\frac{2 N+1}{N+1} \frac{L}{N} H^{\prime}(L)+H(L)-\frac{\gamma}{\beta}\right\}>0 .
\end{aligned}
$$

This means that

$$
\frac{b}{N+1}\left[\frac{1}{1-\gamma}\left[\frac{L}{N+1} H^{\prime}(L)+H(L)\right]-\frac{\gamma}{(1-\gamma) \beta}\right]<\frac{b}{N+1} \frac{N+1}{N}\left\{\frac{L}{N} H^{\prime}(L)+H(L)-\frac{\gamma}{\beta}\right\}
$$

In other words, for each bank, the income from government bonds, $b^{B} r^{B}$, will decrease when there are $N+1$ banks, despite that bond rate is higher. Hence, bank profit will decrease.

Finally, consider bank default probability $1-G(\hat{s})$. Note that $\hat{s}$ is given by

$$
D r^{D}(D)=\int_{\hat{s}}^{\bar{s}} L H(L, s) \mathrm{d} G(s)+G(\hat{s}) L H(L, \hat{s})+\frac{\left(1+i^{R}\right) \delta D}{1+\mu}+b r^{B} .
$$

Since increasing $N$ has no effect on $L$ or $D$ but $r^{B}$ will increase, default probability will decrease.

\section{Case IIIB}

In this case, the FOCs are

$$
D^{\prime}=\eta\left(u^{\prime}\right)^{-1}\left(\frac{1+\mu}{\beta}\right)(1+\mu)
$$

and

$$
\frac{1}{1-\gamma}\left[\frac{L}{N+1} H^{\prime}(L)+H(L)\right]=\frac{1+i^{R}}{1+\mu}+\frac{\gamma}{(1-\gamma) \beta} .
$$

Hence, $L$ will increase while $D$ remain unchanged. This means that banks will raise more equity and lower the investment in reserves. Since $r^{B}=\frac{1+i^{R}}{1+\mu}$, government bond rate is unaffected by the increase in $N$.

Similar to Case IIB, bank profit must decrease, because otherwise one bank could have deviated and increase the loans it issues. This will give the deviating bank a strictly higher profit, a contradiction.

Finally, consider bank default probability $1-G(\hat{s})$. Note that $\hat{s}$ is given by

$$
D r^{D}(D)=\int_{\hat{s}}^{\bar{s}} L H(L, s) \mathrm{d} G(s)+G(\hat{s}) L H(L, \hat{s})+\frac{\left(1+i^{R}\right)(D-(1-\gamma) L)}{1+\mu} .
$$

Take total derivative to get

$$
\begin{aligned}
& \frac{\left(1+i^{R}\right)(1-\gamma)}{1+\mu} \mathrm{d} L \\
& =G(\hat{s}) L H_{s}(L, \hat{s}) \mathrm{d} \hat{s}+\left\{\int_{\hat{s}}^{\bar{s}}\left[L H_{L}(L, s)+H(L, s)\right] \mathrm{d} G(s)+G(\hat{s})\left[L H_{L}(L, \hat{s})+H(L, \hat{s})\right]\right\} \mathrm{d} L .
\end{aligned}
$$


Note that by Lemma B.1 we have

$\int_{\hat{s}}^{\bar{s}}\left[L H_{L}(L, s)+H(L, s)\right] \mathrm{d} G(s)+G(\hat{s})\left[L H_{L}(L, \hat{s})+H(L, \hat{s})\right]<\mathbb{E}\left[L H^{\prime}(L, s)+H(L, s)\right]=L H^{\prime}(L)+H(L)<0$,

Hence, default probability will increase.

Proof of Proposition 5.2: We consider the effects of a marginal increase in $b$ in all five cases.

\section{Case I}

In this case, because banks do not hold all government bonds, a marginal increase in $b$ has no effect on $L$ or $D$. Since $r^{B}=1 / \beta$, it is unaffected by the increase in $b$. Similarly, bank profit is not affected either.

\section{Case IIA}

In this case, we have $D=((1-\gamma) L+b) /(1-\delta)$ and

$$
\frac{L}{N} H^{\prime}(L)+H(L)+\frac{(1-\gamma) \delta\left(1+i^{R}\right)}{(1-\delta)(1+\mu)}=\frac{1-\gamma}{1-\delta}\left[r^{D}(D)+\frac{D}{N} r^{D^{\prime}}(D)\right]+\frac{\gamma}{\beta} .
$$

Increasing $b$ while holding $L$ constant will increase $D$, which means the right-hand side will be larger than the left-hand side. This means that $L$ must decrease for the equation to hold. Because $L$ will be lower, the right-hand side will be larger than the benchmark, which means $D$ will increase. Since $r^{B}$ is given by

$$
r^{B}=\frac{1}{1-\gamma}\left[\frac{L}{N} H^{\prime}(L)+H(L)\right]-\frac{\gamma}{(1-\gamma) \beta},
$$

it will increase after an increase in $b$.

Bank profit is given by

$$
-\frac{E}{N}+\beta\left[\frac{L}{N} r^{L}(L)\left[1-P\left(r^{L}(L)\right)\right]+\frac{z^{B}}{N} \frac{1+i^{R}}{1+\mu}+\frac{b}{N} r^{B}-\frac{D}{N} r^{D}(D)\right] .
$$

Since $r^{B}$ is higher, bank profit is higher even if bank's assets and liabilities remain the same. Hence, bank profit must be higher.

Finally, consider bank default probability $1-G(\hat{s})$. Note that $\hat{s}$ is given by

$$
D r^{D}(D)=\int_{\hat{s}}^{\bar{s}} L H(L, s) \mathrm{d} G(s)+G(\hat{s}) L H(L, \hat{s})+\frac{\left(1+i^{R}\right) \delta D}{1+\mu}+b r^{B} .
$$

Take the derivative w.r.t. $b$ to get

$$
\begin{aligned}
& {\left[D \hat{r}^{D^{\prime}}(D)+\hat{r}^{D}(D)-\frac{\left(1+i^{R}\right) \delta}{1+\mu}\right] \frac{\partial D}{\partial b}-r^{B}-\frac{b}{1-\gamma}\left[\frac{H^{\prime}(L)}{N}+\frac{L}{N} H^{\prime \prime}(L)+H^{\prime}(L)\right] \frac{\partial L}{\partial b}} \\
& =G(\hat{s}) L H_{s}(L, \hat{s}) \frac{\partial \hat{s}}{\partial b}+\left\{\int_{\hat{s}}^{\bar{s}}\left[L H_{L}(L, s)+H(L, s)\right] \mathrm{d} G(s)+G(\hat{s})\left[L H_{L}(L, \hat{s})+H(L, \hat{s})\right]\right\} \frac{\partial L}{\partial b} .
\end{aligned}
$$

Note that $\frac{\partial L}{\partial b}<0$ and $\frac{H^{\prime}(L)}{N}+\frac{L}{N} H^{\prime \prime}(L)+H^{\prime}(L)<0$. However, the overall effect is ambiguous because the terms $D \hat{r}^{D \prime}(D)+\hat{r}^{D}(D)-\frac{\left(1+i^{R}\right) \delta}{1+\mu}>0$ and $\int_{\hat{s}}^{\bar{s}}\left[L H_{L}(L, s)+H(L, s)\right] \mathrm{d} G(s)+G(\hat{s})\left[L H_{L}(L, \hat{s})+H(L, \hat{s})\right]$ may be positive or negative.

\section{Case IIB}

In this case, because the reserve requirement does not bind, a marginal increase in $b$ will simply lead banks to substitute bonds for reserves. Hence, it will have no effect on $L$ or $D$. Since $r^{B}=\frac{1+i^{R}}{1+\mu}$, it is unaffected by the increase in $b$. Similarly, bank profit and default probability are not affected either.

\section{Case IIIA}


In this case, we have $(1-\gamma) L=(1-\delta) D^{\prime}-b$, and

$$
D^{\prime}=\eta\left(u^{\prime}\right)^{-1}\left(\frac{1+\mu}{\beta}\right)(1+\mu) .
$$

Hence, $L$ will decrease while $D$ remain unchanged. Since $r^{B}$ is given by

$$
r^{B}=\frac{1}{1-\gamma}\left[\frac{L}{N} H^{\prime}(L)+H(L)\right]-\frac{\gamma}{(1-\gamma) \beta},
$$

it will increase after an increase in $b$.

Similar to Case IIA, bank profit must increase, because $r^{B}$ is higher so profit is higher even if bank's assets and liabilities remain the same. Finally, consider bank default probability $1-G(\hat{s})$. Note that $\hat{s}$ is given by

$$
D r^{D}(D)=\int_{\hat{s}}^{\bar{s}} L H(L, s) \mathrm{d} G(s)+G(\hat{s}) L H(L, \hat{s})+\frac{\left(1+i^{R}\right) \delta D}{1+\mu}+b r^{B} .
$$

Take the derivative w.r.t. $b$ to get

$$
\begin{aligned}
& -r^{B}-\frac{b}{1-\gamma}\left[\frac{H^{\prime}(L)}{N}+\frac{L}{N} H^{\prime \prime}(L)+H^{\prime}(L)\right] \frac{\partial L}{\partial b} \\
& =G(\hat{s}) L H_{s}(L, \hat{s}) \frac{\partial \hat{s}}{\partial b}+\left\{\int_{\hat{s}}^{\bar{s}}\left[L H_{L}(L, s)+H(L, s)\right] \mathrm{d} G(s)+G(\hat{s})\left[L H_{L}(L, \hat{s})+H(L, \hat{s})\right]\right\} \frac{\partial L}{\partial b} .
\end{aligned}
$$

Because $\frac{\partial L}{\partial b}<0$ and by Lemma B.1 we have

$\int_{\hat{s}}^{\bar{s}}\left[L H_{L}(L, s)+H(L, s)\right] \mathrm{d} G(s)+G(\hat{s})\left[L H_{L}(L, \hat{s})+H(L, \hat{s})\right]<\mathbb{E}\left[L H^{\prime}(L, s)+H(L, s)\right]=L H^{\prime}(L)+H(L)<0$, default probability will decrease.

\section{Case IIIB}

Similar to Case IIB, a marginal increase in $b$ will lead banks to substitute bonds for reserves. Hence, it will have no effect on $L$ or $D$. Since $r^{B}=\frac{1+i^{R}}{1+\mu}$, it is unaffected by the increase in $b$. Similarly, bank profit and default probability are not affected either.

Proof of Proposition 5.3: We consider the effects of a marginal increase in $i^{R}$ in all five cases.

\section{Case I}

In this case, the FOCs are

$$
\frac{L}{N} H^{\prime}(L)+H(L)=\frac{1}{\beta}
$$

and

$$
r^{D}(D)+\frac{D}{N} r^{D \prime}(D)=\frac{1-\delta}{\beta}+\frac{\delta\left(1+i^{R}\right)}{1+\mu} .
$$

Hence, $L$ will remain unchanged while $D$ will increase. Since $r^{B}=1 / \beta$, it is remains unchanged.

Bank profit is given by

$$
-\frac{E}{N}+\beta\left[\frac{L}{N} r^{L}(L)\left[1-P\left(r^{L}(L)\right)\right]+\frac{z^{B}}{N} \frac{1+i^{R}}{1+\mu}+\frac{b^{B}}{N} \frac{1}{\beta}-\frac{D}{N} r^{D}(D)\right] .
$$

Since $i^{R}$ is higher, bank profit is higher even if bank's assets and liabilities remain the same. Hence, bank profit must be higher.

\section{Case IIA}


In this case, we have $D=((1-\gamma) L+b) /(1-\delta)$ and

$$
\frac{L}{N} H^{\prime}(L)+H(L)+\frac{(1-\gamma) \delta\left(1+i^{R}\right)}{(1-\delta)(1+\mu)}=\frac{1-\gamma}{1-\delta}\left[r^{D}(D)+\frac{D}{N} r^{D^{\prime}}(D)\right]+\frac{\gamma}{\beta} .
$$

Hence, if $L$ is held constant, the left-hand side will increase. This means that $L$ must increase, which means $D$ will increase as well. Since $r^{B}$ is given by

$$
r^{B}=\frac{1}{1-\gamma}\left[\frac{L}{N} H^{\prime}(L)+H(L)\right]-\frac{\gamma}{(1-\gamma) \beta},
$$

it will decrease after an increase in $i^{R}$.

Bank profit is given by

$$
-\frac{E}{N}+\beta\left[\frac{L}{N} r^{L}(L)\left[1-P\left(r^{L}(L)\right)\right]+\frac{z^{B}}{N} \frac{1+i^{R}}{1+\mu}+\frac{b}{N} r^{B}-\frac{D}{N} r^{D}(D)\right] .
$$

Although $i^{R}$ is higher, $r^{B}$ is lower. Hence, the overall effect on bank profit is ambiguous.

Finally, consider bank default probability $1-G(\hat{s})$. Note that $\hat{s}$ is given by

$$
D r^{D}(D)=\int_{\hat{s}}^{\bar{s}} L H(L, s) \mathrm{d} G(s)+G(\hat{s}) L H(L, \hat{s})+\frac{\left(1+i^{R}\right) \delta D}{1+\mu}+b r^{B} .
$$

Take the derivative w.r.t. $i^{R}$ to get

$$
\begin{aligned}
& {\left[D \hat{r}^{D^{\prime}}(D)+\hat{r}^{D}(D)-\frac{\left(1+i^{R}\right) \delta}{1+\mu}\right]\left[\frac{1-\gamma}{1-\delta} \frac{\partial L}{\partial i^{R}}\right]-\frac{\delta D}{1+\mu}-\frac{b}{1-\gamma}\left[\frac{H^{\prime}(L)}{N}+\frac{L}{N} H^{\prime \prime}(L)+H^{\prime}(L)\right] \frac{\partial L}{\partial i^{R}}} \\
& =G(\hat{s}) L H_{s}(L, \hat{s}) \frac{\partial \hat{s}}{\partial i^{R}}+\left\{\int_{\hat{s}}^{\bar{s}}\left[L H_{L}(L, s)+H(L, s)\right] \mathrm{d} G(s)+G(\hat{s})\left[L H_{L}(L, \hat{s})+H(L, \hat{s})\right]\right\} \frac{\partial L}{\partial i^{R}} .
\end{aligned}
$$

Note that $\frac{\partial L}{\partial i^{R}}>0, \frac{H^{\prime}(L)}{N}+\frac{L}{N} H^{\prime \prime}(L)+H^{\prime}(L)<0$, and $\left[D \hat{r}^{D^{\prime}}(D)+\hat{r}^{D}(D)-\frac{\left(1+i^{R}\right) \delta}{1+\mu}\right]\left[\frac{1-\gamma}{1-\delta} \frac{\partial L}{\partial i^{R}}\right]>0$. Also, $\int_{\hat{s}}^{\bar{s}}\left[L H_{L}(L, s)+H(L, s)\right] \mathrm{d} G(s)+G(\hat{s})\left[L H_{L}(L, \hat{s})+H(L, \hat{s})\right]$ may be positive or negative. Hence, the overall effect is ambiguous.

\section{Case IIB}

In this case, the FOCs are

$$
r^{D}(D)+\frac{D}{N} r^{D \prime}(D)=\frac{1+i^{R}}{1+\mu}
$$

and

$$
\frac{1}{1-\gamma}\left[\frac{L}{N} H^{\prime}(L)+H(L)\right]=\frac{1+i^{R}}{1+\mu}+\frac{\gamma}{(1-\gamma) \beta} .
$$

Hence, $L$ will decrease while $D$ will increase. Since $r^{B}=\frac{1+i^{R}}{1+\mu}$, it will increase following an increase in $i^{R}$.

Bank profit is given by

$$
-\frac{E}{N+1}+\beta\left[\frac{L}{N+1} r^{L}(L)\left[1-P\left(r^{L}(L)\right)\right]+\frac{z^{B}}{N+1} \frac{1+i^{R}}{1+\mu}+\frac{b}{N+1} \frac{1+i^{R}}{1+\mu}-\frac{D}{N+1} r^{D}(D)\right] .
$$

Similar to Case I, since $i^{R}$ is higher, bank profit is higher even if bank's assets and liabilities remain the same. Hence, bank profit must be higher.

Finally, consider bank default probability $1-G(\hat{s})$. Note that $\hat{s}$ is given by

$$
D r^{D}(D)=\int_{\hat{s}}^{\bar{s}} L H(L, s) \mathrm{d} G(s)+G(\hat{s}) L H(L, \hat{s})+\frac{\left(1+i^{R}\right)(D-(1-\gamma) L)}{1+\mu} .
$$


Take the derivative w.r.t. $i^{R}$ to get

$$
\begin{aligned}
& {\left[D \hat{r}^{D^{\prime}}(D)+\hat{r}^{D}(D)-\frac{1+i^{R}}{1+\mu}\right] \frac{\partial D}{\partial i^{R}}-\frac{D-(1-\gamma) L}{1+\mu}+\frac{\left(1+i^{R}\right)(1-\gamma)}{1+\mu} \frac{\partial L}{\partial i^{R}}} \\
& =G(\hat{s}) L H_{s}(L, \hat{s}) \frac{\partial \hat{s}}{\partial i^{R}}+\left\{\int_{\hat{s}}^{\bar{s}}\left[L H_{L}(L, s)+H(L, s)\right] \mathrm{d} G(s)+G(\hat{s})\left[L H_{L}(L, \hat{s})+H(L, \hat{s})\right]\right\} \frac{\partial L}{\partial i^{R}} .
\end{aligned}
$$

Note that $\frac{\partial L}{\partial i^{R}}<0, \frac{\partial D}{\partial i^{R}}>0, \frac{H^{\prime}(L)}{N}+\frac{L}{N} H^{\prime \prime}(L)+H^{\prime}(L)<0$, and $\left[D \hat{r}^{D \prime}(D)+\hat{r}^{D}(D)-\frac{1+i^{R}}{1+\mu}\right] \frac{\partial D}{\partial i^{R}}>0$. Also, $\int_{\hat{s}}^{\bar{s}}\left[L H_{L}(L, s)+H(L, s)\right] \mathrm{d} G(s)+G(\hat{s})\left[L H_{L}(L, \hat{s})+H(L, \hat{s})\right]$ may be positive or negative. Hence, the overall effect is ambiguous.

\section{Case IIIA}

In this case, we have $(1-\gamma) L=(1-\delta) D^{\prime}-b$, and

$$
D^{\prime}=\eta\left(u^{\prime}\right)^{-1}\left(\frac{1+\mu}{\beta}\right)(1+\mu)
$$

Then a marginal increase in $i^{R}$ has no effect on $L$ or $D$. Since $r^{B}$ is given by

$$
r^{B}=\frac{1}{1-\gamma}\left[\frac{L}{N} H^{\prime}(L)+H(L)\right]-\frac{\gamma}{(1-\gamma) \beta},
$$

it will also remain unchanged. However, since $i^{R}$ is larger, profit will be higher. Finally, since $D$ and $L$ remain unchanged, a higher $i^{R}$ lowers the default probability.

\section{Case IIIB}

In this case, we have

$$
D^{\prime}=\eta\left(u^{\prime}\right)^{-1}\left(\frac{1+\mu}{\beta}\right)(1+\mu)
$$

and

$$
\frac{1}{1-\gamma}\left[\frac{L}{N} H^{\prime}(L)+H(L)\right]=\frac{1+i^{R}}{1+\mu}+\frac{\gamma}{(1-\gamma) \beta} .
$$

Hence, $L$ will decrease while $D$ remains unchanged. Since $r^{B}=\frac{1+i^{R}}{1+\mu}$, it will increase.

Similar to Case IIB, since $i^{R}$ is higher, bank profit is higher even if bank's assets and liabilities remain the same. Hence, bank profit must be higher.

Finally, consider bank default probability $1-G(\hat{s})$. Note that $\hat{s}$ is given by

$$
D r^{D}(D)=\int_{\hat{s}}^{\bar{s}} L H(L, s) \mathrm{d} G(s)+G(\hat{s}) L H(L, \hat{s})+\frac{\left(1+i^{R}\right)(D-(1-\gamma) L)}{1+\mu} .
$$

Take the derivative w.r.t. $i^{R}$ to get

$$
\begin{aligned}
& -\frac{D-(1-\gamma) L}{1+\mu}+\frac{\left(1+i^{R}\right)(1-\gamma)}{1+\mu} \frac{\partial L}{\partial i^{R}} \\
= & G(\hat{s}) L H_{s}(L, \hat{s}) \frac{\partial \hat{s}}{\partial i^{R}}+\left\{\int_{\hat{s}}^{\bar{s}}\left[L H_{L}(L, s)+H(L, s)\right] \mathrm{d} G(s)+G(\hat{s})\left[L H_{L}(L, \hat{s})+H(L, \hat{s})\right]\right\} \frac{\partial L}{\partial i^{R}} .
\end{aligned}
$$

Note that $\frac{\partial L}{\partial i^{R}}<0$. In addition, by Lemma B.1 we have

$\int_{\hat{s}}^{\bar{s}}\left[L H_{L}(L, s)+H(L, s)\right] \mathrm{d} G(s)+G(\hat{s})\left[L H_{L}(L, \hat{s})+H(L, \hat{s})\right]<\mathbb{E}\left[L H^{\prime}(L, s)+H(L, s)\right]=L H^{\prime}(L)+H(L)<0$, Hence, default probability will decrease.

Proof of Proposition 5.4: We consider the effects of a marginal increase in $\delta$ in all five cases. 


\section{Case I}

In this case, the FOCs are

$$
\frac{L}{N} H^{\prime}(L)+H(L)=\frac{1}{\beta}
$$

and

$$
r^{D}(D)+\frac{D}{N} r^{D^{\prime}}(D)=\frac{1-\delta}{\beta}+\frac{\delta\left(1+i^{R}\right)}{1+\mu}
$$

Hence, $L$ will remain unchanged while $D$ will decrease because $\frac{1+i^{R}}{1+\mu}<\frac{1}{\beta}$. Since $r^{B}=1 / \beta$, it is unaffected by the increase in $\delta$.

Bank profit is given by

$$
-\frac{E}{N}+\beta\left[\frac{L}{N} r^{L}(L)\left[1-P\left(r^{L}(L)\right)\right]+\frac{z^{B}}{N} \frac{1+i^{R}}{1+\mu}+\frac{b^{B}}{N} \frac{1}{\beta}-\frac{D}{N} r^{D}(D)\right] .
$$

Since banks could have chosen a higher reserve ratio if it was profit maximizing, bank profit must decrease.

\section{Case IIA}

In this case, we have $D=((1-\gamma) L+b) /(1-\delta)$ and

$$
\frac{L}{N} H^{\prime}(L)+H(L)+\frac{(1-\gamma) \delta\left(1+i^{R}\right)}{(1-\delta)(1+\mu)}=\frac{1-\gamma}{1-\delta}\left[r^{D}(D)+\frac{D}{N} r^{D^{\prime}}(D)\right]+\frac{\gamma}{\beta},
$$

which can be rewritten as

$$
(1-\gamma)\left[r^{D}(D)+\frac{D}{N} r^{D^{\prime}}(D)\right]=(1-\delta)\left[\frac{L}{N} H^{\prime}(L)+H(L)-\frac{\gamma}{\beta}\right]+\frac{(1-\gamma) \delta\left(1+i^{R}\right)}{1+\mu} .
$$

Note that in Case IIA,

$$
r^{B}=\frac{1}{1-\gamma}\left[\frac{L}{N} H^{\prime}(L)+H(L)\right]-\frac{\gamma}{(1-\gamma) \beta}>\frac{1+i^{R}}{1+\mu} .
$$

Hence, increasing $\delta$ will make the right-hand side of (B.62) smaller and the left-hand side larger. This means that $L$ must decrease. The effect on $D$, however, is ambiguous. Since $L$ will decrease, $r^{B}$ will increase.

Bank profit is given by

$$
-\frac{E}{N}+\beta\left[\frac{L}{N} r^{L}(L)\left[1-P\left(r^{L}(L)\right)\right]+\frac{z^{B}}{N} \frac{1+i^{R}}{1+\mu}+\frac{b}{N} r^{B}-\frac{D}{N} r^{D}(D)\right] .
$$

If $r^{B}$ remains unchanged, then a higher $\delta$ will lower bank profit because banks could have chosen a higher reserve ratio if it was profit maximizing. However, $r^{B}$ is also higher. Hence, the overall effect on bank profit is ambiguous.

Finally, consider bank default probability $1-G(\hat{s})$. Note that $\hat{s}$ is given by

$$
D r^{D}(D)=\int_{\hat{s}}^{\bar{s}} L H(L, s) \mathrm{d} G(s)+G(\hat{s}) L H(L, \hat{s})+\frac{\left(1+i^{R}\right) \delta D}{1+\mu}+b r^{B} .
$$

Take the derivative w.r.t. $\delta$ to get

$$
\begin{aligned}
& {\left[D \hat{r}^{D \prime}(D)+\hat{r}^{D}(D)-\frac{\left(1+i^{R}\right) \delta}{1+\mu}\right]\left[\frac{1-\gamma}{1-\delta} \frac{\partial L}{\partial \delta}+\frac{D}{1-\delta}\right]-\frac{\left(1+i^{R}\right) D}{1+\mu}-\frac{b}{1-\gamma}\left[\frac{H^{\prime}(L)}{N}+\frac{L}{N} H^{\prime \prime}(L)+H^{\prime}(L)\right] \frac{\partial L}{\partial \delta}} \\
& =G(\hat{s}) L H_{s}(L, \hat{s}) \frac{\partial \hat{s}}{\partial \delta}+\left\{\int_{\hat{s}}^{\bar{s}}\left[L H_{L}(L, s)+H(L, s)\right] \mathrm{d} G(s)+G(\hat{s})\left[L H_{L}(L, \hat{s})+H(L, \hat{s})\right]\right\} \frac{\partial L}{\partial \delta} .
\end{aligned}
$$

Note that $\frac{\partial L}{\partial \delta}<0, \frac{H^{\prime}(L)}{N}+\frac{L}{N} H^{\prime \prime}(L)+H^{\prime}(L)<0$, and $D \hat{r}^{D \prime}(D)+\hat{r}^{D}(D)-\frac{\left(1+i^{R}\right) \delta}{1+\mu}>0$. Also, $\int_{\hat{s}}^{\bar{s}}\left[L H_{L}(L, s)+\right.$ $H(L, s)] \mathrm{d} G(s)+G(\hat{s})\left[L H_{L}(L, \hat{s})+H(L, \hat{s})\right]$ may be positive or negative. Hence, the overall effect is ambiguous.

\section{Case IIB}


In this case, because reserve requirement does not bind, a marginal increase in $\delta$ has no effect on $L$ or $D$. Since $r^{B}=\frac{1+i^{R}}{1+\mu}$, it is unaffected by the increase in $\delta$. Similarly, bank profit and default probability are not affected either.

\section{Case IIIA}

In this case, we have $(1-\gamma) L=(1-\delta) D^{\prime}-b$, and

$$
D^{\prime}=\eta\left(u^{\prime}\right)^{-1}\left(\frac{1+\mu}{\beta}\right)(1+\mu) .
$$

Then increasing $\delta$ will decrease $L$ but have no effect on $D$. Since $L$ will decrease, $r^{B}$ will increase. Similar to Case IIA, the higher $r^{B}$ will increase bank profit while the higher $\delta$ will decrease bank profit. Hence, the overall effect is ambiguous.

Finally, consider bank default probability $1-G(\hat{s})$. Note that $\hat{s}$ is given by

$$
D r^{D}(D)=\int_{\hat{s}}^{\bar{s}} L H(L, s) \mathrm{d} G(s)+G(\hat{s}) L H(L, \hat{s})+\frac{\left(1+i^{R}\right) \delta D}{1+\mu}+b r^{B} .
$$

Take the derivative w.r.t. $\delta$ to get

$$
\begin{aligned}
& -\frac{\left(1+i^{R}\right) D}{1+\mu}-\frac{b}{1-\gamma}\left[\frac{H^{\prime}(L)}{N}+\frac{L}{N} H^{\prime \prime}(L)+H^{\prime}(L)\right] \frac{\partial L}{\partial \delta} \\
& =G(\hat{s}) L H_{s}(L, \hat{s}) \frac{\partial \hat{s}}{\partial \delta}+\left\{\int_{\hat{s}}^{\bar{s}}\left[L H_{L}(L, s)+H(L, s)\right] \mathrm{d} G(s)+G(\hat{s})\left[L H_{L}(L, \hat{s})+H(L, \hat{s})\right]\right\} \frac{\partial L}{\partial \delta} .
\end{aligned}
$$

Note that $\frac{\partial L}{\partial \delta}<0$. In addition, by Lemma B.1 we have

$\int_{\hat{s}}^{\bar{s}}\left[L H_{L}(L, s)+H(L, s)\right] \mathrm{d} G(s)+G(\hat{s})\left[L H_{L}(L, \hat{s})+H(L, \hat{s})\right]<\mathbb{E}\left[L H^{\prime}(L, s)+H(L, s)\right]=L H^{\prime}(L)+H(L)<0$,

Hence, default probability will decrease.

\section{Case IIIB}

Similar to Case IIB, because reserve requirement does not bind, a marginal increase in $\delta$ has no effect on $L$ or $D$. Since $r^{B}=\frac{1+i^{R}}{1+\mu}$, it is unaffected by the increase in $\delta$. Similarly, bank profit and default probability are not affected either.

Proof of Proposition 5.5: We consider the effects of a marginal increase in $\gamma$ in all five cases.

\section{Case I}

In this case, because capital requirement does not bind, a marginal increase in $\gamma$ has not effects on $L$ or $D$. Since $r^{B}=1 / \beta$, it is unaffected by the increase in $\gamma$. Similarly, bank profit is not affected either.

\section{Case IIA}

In this case, we have $D=((1-\gamma) L+b) /(1-\delta)$ and

$$
\frac{L}{N} H^{\prime}(L)+H(L)+\frac{(1-\gamma) \delta\left(1+i^{R}\right)}{(1-\delta)(1+\mu)}=\frac{1-\gamma}{1-\delta}\left[r^{D}(D)+\frac{D}{N} r^{D^{\prime}}(D)\right]+\frac{\gamma}{\beta},
$$

which can be rewritten as

$$
(1-\gamma)\left[r^{D}(D)+\frac{D}{N} r^{D^{\prime}}(D)\right]+\frac{\gamma(1-\delta)}{\beta}-\frac{\delta(1-\gamma)\left(1+i^{R}\right)}{1+\mu}=(1-\delta)\left[\frac{L}{N} H^{\prime}(L)+H(L)\right] .
$$

Then, we have

$$
\frac{\partial L}{\partial \gamma}=\frac{r^{D}(D)+\frac{D}{N} r^{D^{\prime}}(D)-\frac{1-\delta}{\beta}-\frac{\delta\left(1+i^{R}\right)}{1+\mu}+\frac{(1-\gamma) L}{1-\delta}\left[r^{D^{\prime}}(D)+\frac{1}{N} r^{D^{\prime}}(D)+\frac{D}{N} r^{D \prime \prime}(D)\right]}{(1-\gamma)^{2}\left[r^{D^{\prime}}(D)+\frac{1}{N} r^{D^{\prime}}(D)+\frac{D}{N} r^{D^{\prime \prime}}(D)\right]-\frac{(1-\delta)^{2}}{1-\gamma}\left[\frac{1}{N} H^{\prime}(L)+\frac{L}{N} H^{\prime \prime}(L)+H^{\prime}(L)\right]}
$$


and

$$
\frac{\partial D}{\partial \gamma}=\frac{r^{D}(D)+\frac{D}{N} r^{D^{\prime}}(D)-\frac{1-\delta}{\beta}-\frac{\delta\left(1+i^{R}\right)}{1+\mu}+\frac{(1-\delta)^{2} D}{(1-\gamma)^{2}}\left[\frac{1}{N} H^{\prime}(L)+\frac{L}{N} H^{\prime \prime}(L)+H^{\prime}(L)\right]}{(1-\gamma)\left[r^{D^{\prime}}(D)+\frac{1}{N} r^{D^{\prime}}(D)+\frac{D}{N} r^{D^{\prime \prime}}(D)\right]-(1-\delta)\left[\frac{1}{N} H^{\prime}(L)+\frac{L}{N} H^{\prime \prime}(L)+H^{\prime}(L)\right]}
$$

Note that $r^{D}(D)+\frac{D}{N} r^{D^{\prime}}(D)<\frac{1-\delta}{\beta}+\frac{\delta\left(1+i^{R}\right)}{1+\mu}$ in Case IIA. Hence, $\frac{\partial D}{\partial \gamma}<0$. As for $\frac{\partial L}{\partial \gamma}$, assume $u(q)=\frac{q^{1-\sigma}-1}{1-\sigma}$. Consider function $f(D)$.

$$
\begin{aligned}
f(D) & =r^{D}(D)+\frac{D}{N} r^{D^{\prime}}(D)+\frac{(1-\gamma) L}{1-\delta}\left[r^{D^{\prime}}(D)+\frac{1}{N} r^{D^{\prime}}(D)+\frac{D}{N} r^{D^{\prime \prime}}(D)\right] \\
& =\beta^{\frac{1}{\sigma-1}}\left(\frac{D}{\eta}\right)^{\frac{\sigma}{1-\sigma}} \frac{N-\sigma N+\sigma}{N-\sigma N} \frac{1+(\epsilon-1) \sigma}{1-\sigma},
\end{aligned}
$$

where $\epsilon=1-b /[(1-\delta) D]$. It is easy to see that $f^{\prime}(D)>0$. Note also that in Case IIA, $D>D^{\dagger}$ where $D^{\dagger}$ solves $r^{D}(D)=\frac{1}{1+\mu}$ Hence, $f(D) \geq f\left(D^{\dagger}\right)$, which is given by

$$
f\left(D^{\dagger}\right)=\frac{1}{1+\mu} \frac{N-\sigma N+\sigma}{N-\sigma N} \frac{1+(\epsilon-1) \sigma}{1-\sigma} .
$$

Then, $f(D)>1 / \beta$ as long as $\frac{1+(\epsilon-1) \sigma}{(1+\mu)(1-\sigma)}>\frac{1}{\beta}$. In such case, we have $\frac{\partial L}{\partial \gamma}>0$. Since $r^{B}$ is given by

$$
r^{B}=\frac{1}{1-\gamma}\left[\frac{L}{N} H^{\prime}(L)+H(L)\right]-\frac{\gamma}{(1-\gamma) \beta},
$$

$r^{B}$ will decrease.

Bank profit is given by

$$
-\frac{E}{N}+\beta\left[\frac{L}{N} r^{L}(L)\left[1-P\left(r^{L}(L)\right)\right]+\frac{z^{B}}{N} \frac{1+i^{R}}{1+\mu}+\frac{b}{N} r^{B}-\frac{D}{N} r^{D}(D)\right] .
$$

If $r^{B}$ remains unchanged, then a higher $\delta$ will lower bank profit because banks could have chosen a higher reserve ratio if it was profit maximizing. If $L$ increases, then $r^{B}$ will be lower. Hence, bank profit must decrease.

Finally, consider bank default probability $1-G(\hat{s})$. Note that $\hat{s}$ is given by

$$
D r^{D}(D)=\int_{\hat{s}}^{\bar{s}} L H(L, s) \mathrm{d} G(s)+G(\hat{s}) L H(L, \hat{s})+\frac{\left(1+i^{R}\right) \delta D}{1+\mu}+b r^{B} .
$$

Take the derivative w.r.t. $\gamma$ to get

$$
\begin{aligned}
& {\left[D \hat{r}^{D^{\prime}}(D)+\hat{r}^{D}(D)-\frac{\left(1+i^{R}\right) \delta}{1+\mu}\right] \frac{\partial D}{\partial \gamma}-\frac{b}{1-\gamma}\left[\frac{H^{\prime}(L)}{N}+\frac{L}{N} H^{\prime \prime}(L)+H^{\prime}(L)\right] \frac{\partial L}{\partial \gamma}} \\
& =G(\hat{s}) L H_{s}(L, \hat{s}) \frac{\partial \hat{s}}{\partial \gamma}+\left\{\int_{\hat{s}}^{\bar{s}}\left[L H_{L}(L, s)+H(L, s)\right] \mathrm{d} G(s)+G(\hat{s})\left[L H_{L}(L, \hat{s})+H(L, \hat{s})\right]\right\} \frac{\partial L}{\partial \gamma} .
\end{aligned}
$$

Note that $\frac{\partial L}{\partial \delta}>0, \frac{\partial D}{\partial \gamma}<0, \frac{H^{\prime}(L)}{N}+\frac{L}{N} H^{\prime \prime}(L)+H^{\prime}(L)<0$, and $D \hat{r}^{D \prime}(D)+\hat{r}^{D}(D)-\frac{\left(1+i^{R}\right) \delta}{1+\mu}>0$. However, $\int_{\hat{s}}^{\bar{s}}\left[L H_{L}(L, s)+H(L, s)\right] \mathrm{d} G(s)+G(\hat{s})\left[L H_{L}(L, \hat{s})+H(L, \hat{s})\right]$ may be positive or negative. Hence, the overall effect is ambiguous.

\section{Case IIB}

In this case, the FOCs are

$$
r^{D}(D)+\frac{D}{N} r^{D \prime}(D)=\frac{1+i^{R}}{1+\mu}
$$

and

$$
\frac{1}{1-\gamma}\left[\frac{L}{N} H^{\prime}(L)+H(L)\right]=\frac{1+i^{R}}{1+\mu}+\frac{\gamma}{(1-\gamma) \beta}
$$


Hence, $L$ will decrease while $D$ remains unchanged. Since $r^{B}=\frac{1+i^{R}}{1+\mu}$, it is unaffected by the increase in $\gamma$.

Bank profit is given by

$$
-\frac{E}{N+1}+\beta\left[\frac{L}{N+1} r^{L}(L)\left[1-P\left(r^{L}(L)\right)\right]+\frac{z^{B}}{N+1} \frac{1+i^{R}}{1+\mu}+\frac{b}{N+1} \frac{1+i^{R}}{1+\mu}-\frac{D}{N+1} r^{D}(D)\right] .
$$

Since banks could have raised more equity if it is profit maximizing, bank profit must decrease.

Finally, consider bank default probability $1-G(\hat{s})$. Note that $\hat{s}$ is given by

$$
D r^{D}(D)=\int_{\hat{s}}^{\bar{s}} L H(L, s) \mathrm{d} G(s)+G(\hat{s}) L H(L, \hat{s})+\frac{\left(1+i^{R}\right)(D-(1-\gamma) L)}{1+\mu} .
$$

Take the derivative w.r.t. $\gamma$ to get

$$
\begin{aligned}
& -\frac{\left(1+i^{R}\right) L}{1+\mu}+\frac{\left(1+i^{R}\right)(1-\gamma)}{1+\mu} \frac{\partial L}{\partial \gamma} \\
& =G(\hat{s}) L H_{s}(L, \hat{s}) \frac{\partial \hat{s}}{\partial \gamma}+\left\{\int_{\hat{s}}^{\bar{s}}\left[L H_{L}(L, s)+H(L, s)\right] \mathrm{d} G(s)+G(\hat{s})\left[L H_{L}(L, \hat{s})+H(L, \hat{s})\right]\right\} \frac{\partial L}{\partial \gamma} .
\end{aligned}
$$

Note that $\frac{\partial L}{\partial \delta}<0$. In addition, by Lemma B.1 we have

$\int_{\hat{s}}^{\bar{s}}\left[L H_{L}(L, s)+H(L, s)\right] \mathrm{d} G(s)+G(\hat{s})\left[L H_{L}(L, \hat{s})+H(L, \hat{s})\right]<\mathbb{E}\left[L H^{\prime}(L, s)+H(L, s)\right]=L H^{\prime}(L)+H(L)<0$, Hence, default probability will decrease.

\section{Case IIIA}

In this case, we have $(1-\gamma) L=(1-\delta) D^{\prime}-b$, and

$$
D^{\prime}=\eta\left(u^{\prime}\right)^{-1}\left(\frac{1+\mu}{\beta}\right)(1+\mu)
$$

Then $L$ will increase while $D$ remains unchanged. Banks raise equity and invest them in loans. Since $r^{B}$ is given by

$$
r^{B}=\frac{1}{1-\gamma}\left[\frac{L}{N} H^{\prime}(L)+H(L)\right]-\frac{\gamma}{(1-\gamma) \beta},
$$

it is decreasing in both $L$ and $\gamma$. Hence, $r^{B}$ will decrease following an increase in $\gamma$. Hence, bank profit will also decrease.

Finally, consider bank default probability $1-G(\hat{s})$. Note that $\hat{s}$ is given by

$$
D r^{D}(D)=\int_{\hat{s}}^{\bar{s}} L H(L, s) \mathrm{d} G(s)+G(\hat{s}) L H(L, \hat{s})+\frac{\left(1+i^{R}\right) \delta D}{1+\mu}+b r^{B} .
$$

Take the derivative w.r.t. $\gamma$ to get

$$
\begin{aligned}
& -\frac{b}{1-\gamma}\left[\frac{H^{\prime}(L)}{N}+\frac{L}{N} H^{\prime \prime}(L)+H^{\prime}(L)\right] \frac{\partial L}{\partial \gamma} \\
& =G(\hat{s}) L H_{s}(L, \hat{s}) \frac{\partial \hat{s}}{\partial \gamma}+\left\{\int_{\hat{s}}^{\bar{s}}\left[L H_{L}(L, s)+H(L, s)\right] \mathrm{d} G(s)+G(\hat{s})\left[L H_{L}(L, \hat{s})+H(L, \hat{s})\right]\right\} \frac{\partial L}{\partial \gamma} .
\end{aligned}
$$

Note that $\frac{\partial L}{\partial \delta}>0$ and $\frac{H^{\prime}(L)}{N}+\frac{L}{N} H^{\prime \prime}(L)+H^{\prime}(L)<0$. In addition, by Lemma B.1 we have $\int_{\hat{s}}^{\bar{s}}\left[L H_{L}(L, s)+H(L, s)\right] \mathrm{d} G(s)+G(\hat{s})\left[L H_{L}(L, \hat{s})+H(L, \hat{s})\right]<\mathbb{E}\left[L H^{\prime}(L, s)+H(L, s)\right]=L H^{\prime}(L)+H(L)<0$, Hence, default probability will increase.

\section{Case IIIB}


In this case, the FOCs are

$$
D^{\prime}=\eta\left(u^{\prime}\right)^{-1}\left(\frac{1+\mu}{\beta}\right)(1+\mu)
$$

and

$$
\frac{1}{1-\gamma}\left[\frac{L}{N} H^{\prime}(L)+H(L)\right]=\frac{1+i^{R}}{1+\mu}+\frac{\gamma}{(1-\gamma) \beta} .
$$

Hence, $L$ will decrease while $D$ remains unchanged. Since $r^{B}=\frac{1+i^{R}}{1+\mu}$, it is unaffected by the increase in $\gamma$.

Similar to Case IIB, because banks could have raised more equity if it is profit maximizing, bank profit must decrease.

Finally, consider bank default probability $1-G(\hat{s})$. Note that $\hat{s}$ is given by

$$
D r^{D}(D)=\int_{\hat{s}}^{\bar{s}} L H(L, s) \mathrm{d} G(s)+G(\hat{s}) L H(L, \hat{s})+\frac{\left(1+i^{R}\right)(D-(1-\gamma) L)}{1+\mu} .
$$

Take the derivative w.r.t. $\gamma$ to get

$$
\begin{aligned}
& -\frac{\left(1+i^{R}\right) L}{1+\mu}+\frac{\left(1+i^{R}\right)(1-\gamma)}{1+\mu} \frac{\partial L}{\partial \gamma} \\
& =G(\hat{s}) L H_{s}(L, \hat{s}) \frac{\partial \hat{s}}{\partial \gamma}+\left\{\int_{\hat{s}}^{\bar{s}}\left[L H_{L}(L, s)+H(L, s)\right] \mathrm{d} G(s)+G(\hat{s})\left[L H_{L}(L, \hat{s})+H(L, \hat{s})\right]\right\} \frac{\partial L}{\partial \gamma} .
\end{aligned}
$$

Note that $\frac{\partial L}{\partial \delta}<0$. In addition, by Lemma B.1 we have $\int_{\hat{s}}^{\bar{s}}\left[L H_{L}(L, s)+H(L, s)\right] \mathrm{d} G(s)+G(\hat{s})\left[L H_{L}(L, \hat{s})+H(L, \hat{s})\right]<\mathbb{E}\left[L H^{\prime}(L, s)+H(L, s)\right]=L H^{\prime}(L)+H(L)<0$, Hence, default probability will decrease. 